\title{
Mechanisms of synaptic plasticity mediated by Clathrin Adaptor-protein complexes 1 and 2 in mice
}

\author{
Dissertation
}

for the award of the degree "Doctor rerum naturalium" at the Georg-August-University Göttingen

within the doctoral program "Molecular Biology of Cells" of the Georg-August University School of Science (GAUSS)

Submitted by

\section{Ratnakar Mishra}

Born in Birpur, Bihar, India

Göttingen, Germany 2019 


\section{Members of the Thesis Committee}

Prof. Dr. Peter Schu

(Supervisor and first referee)

Dr. Hans Dieter Schmitt

(Second referee)

Prof. Dr. med. Thomas A. Bayer
Institute for Cellular Biochemistry, University Medical Center

Göttingen, Germany

Neurobiology, Max Planck Institute for Biophysical Chemistry, Göttingen, Germany

Division of Molecular Psychiatry, University Medical Center, Göttingen, Germany

\section{Additional Members of the Examination Board}

Prof. Dr. Silvio O. Rizzoli

Dr. Roland Dosch

Prof. Dr. med. Martin Oppermann
Department of Neuro-and Sensory Physiology, University Medical Center Göttingen, Germany

Institute of Developmental Biochemistry, University Medical Center Göttingen, Germany

Institute of Cellular and Molecular Immunology, University Medical Center, Göttingen, Germany

Date of oral examination: $14^{\text {th }}$ may 2019 


\section{Table of Contents}

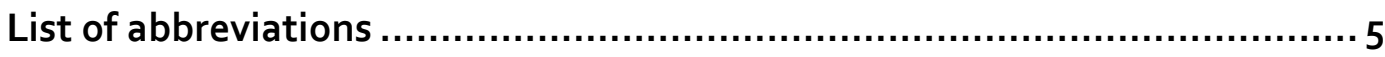

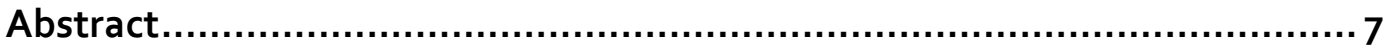

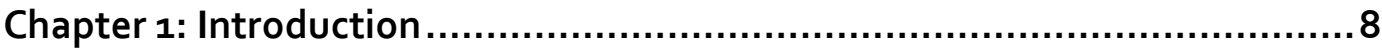

1.1 Intracellular protein transport ............................................................. 8

1.1.1 COP coated vesicles in early secretory pathway .....................................11

1.1.1.1 COPII mediated anterograde protein transport ................................. 11

1.1.1.2 COPI mediated retrograde protein transport: ................................... 13

1.1.2 Clathrin-coated vesicles in late secretory and endocytic pathways:...........14

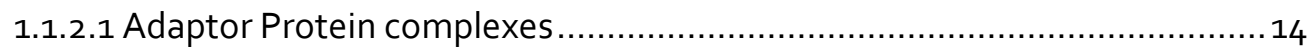

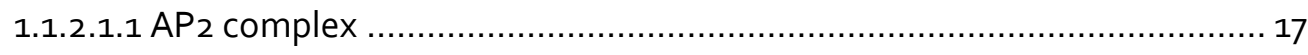

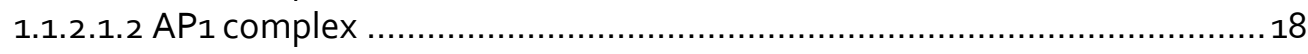

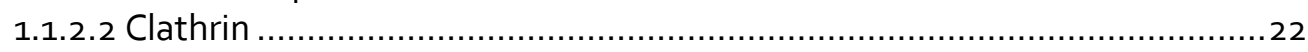

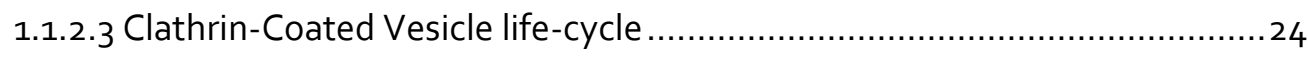

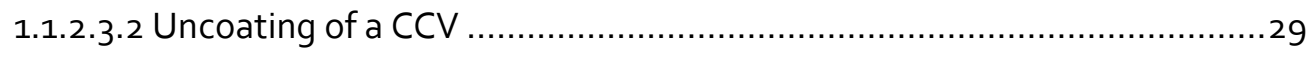

1.1.2.3.2.1 Hsc70 mediated CCV uncoating .................................................29

1.1.2.3.2.2 PI-4, $5-\mathrm{P}_{2}$ dephosphorylation in CCV uncoating ................................. 31

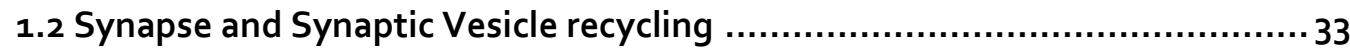

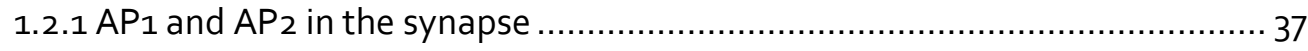

1.2.2. $A P_{1} / \sigma_{1} B$ functions in synaptic vesicle recycling ......................................... 39

1.2.3. Synaptic Plasticity and AP 2 functions in the Synapse ...............................42

1.2.4. Maturation of early endosomes is regulated by $A P_{1} / \sigma_{1} A$ and $A P_{1} / \sigma_{1} B \ldots \ldots .44$

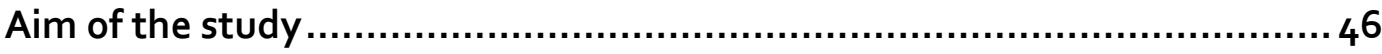

Chapter 2: Material and Methods.................................................... 47

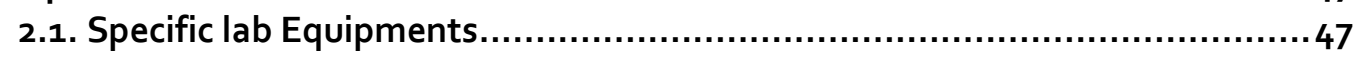

2.2. Chemical, buffers and solutions:.................................................... 47

2.2.1. Clathrin Coated Vesicle (CCV) Isolation Buffer:..................................48

2.2.2. SDS Poly-Acrylamide Gel Electrophoresis (PAGE): ............................48

2.2.2.1. Stacking gel Buffer: ..................................................................... 48

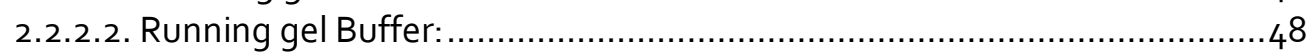

2.2.2.3. Rotiphorese ${ }^{\circledR}$-Gel30: Acrylamide-/Bisacrylamide .................................48

2.2.2.4. APS: $10 \%$ (w/v) Ammonium peroxodisulfate .......................................48

2.2.2.5. TEMED: $\mathrm{N}, \mathrm{N}, \mathrm{N}^{\prime} \quad \mathrm{N}^{\prime} \quad$ Tetramethyl ethylenediamine ............................49

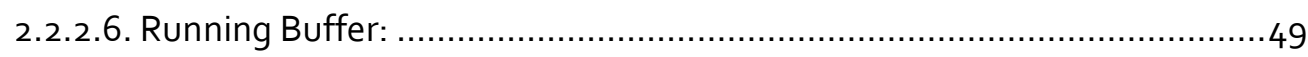

2.2.2.7. 6x reducing sample buffer:............................................................ 49

2.2.2.8. Protein molecular weight marker: ....................................................... 49

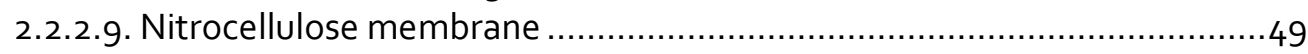

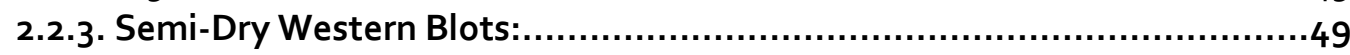

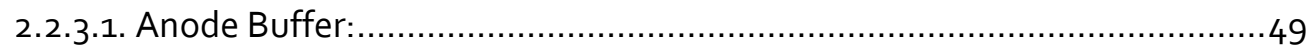

2.2.3.2. Cathode Buffer: ......................................................................... 50

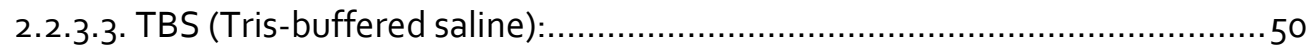

2.2.3.4. TBST (Tris buffered saline with Tween 20) ........................................... 50

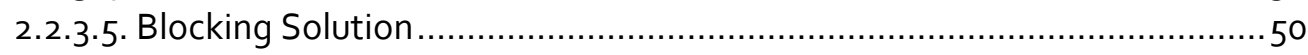

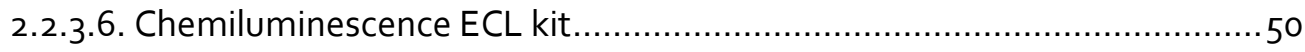

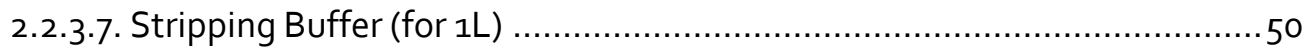

2.2.4. MEF Cell Culture Media and Solutions: ........................................ 51

2.2.4.1. PBS (Phosphate-buffered saline): ...................................................... 51 


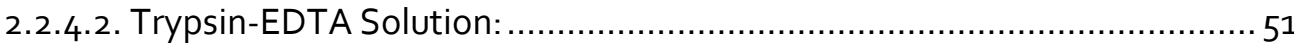

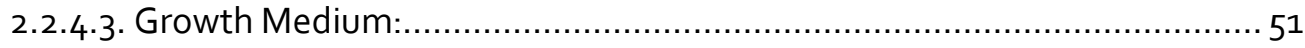

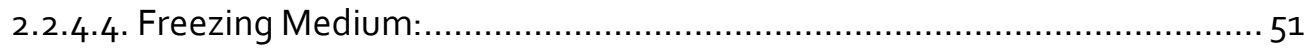

2.3. Protein extract preparations ...................................................... 53

2.3.1. Preparation of protein extracts from murine brain cortices .....................53

2. 3.2. Isolation of synaptosomes from brain cortex extracts .......................... 53

2.3.3. Isolation of synaptic Clathrin-coated vesicles ...................................5 54

2.3.4. Immunoisolation of a sub-fraction of synaptic Clathrin Coated Vesicles .....54

2.3.5 Isolation of proteins from adipose tissue ............................................ 56

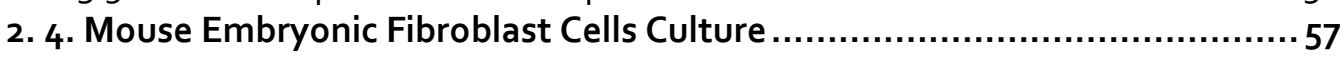

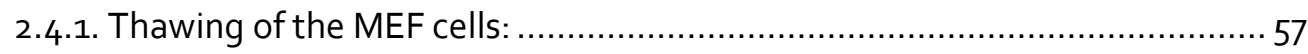

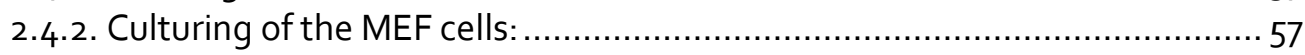

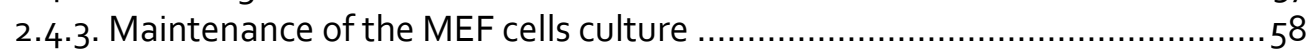

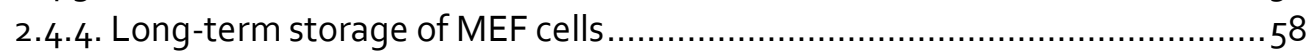

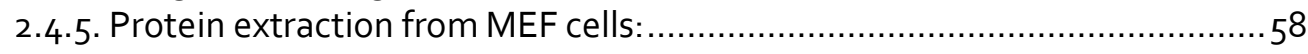

2.5. Biochemical analysis of protein extracts: .....................................6o

2.5.1. Protein concentration determination by Bradford Assay: .......................6o

2.5.2. Semi-quantitative western blot analysis: ......................................6o

Chapter $3:$ Results ............................................................................65

3.1 Altered $A P_{1}$ and $A P_{2}$ mediated protein transport in $\sigma_{1} B-/-$ synapses ..........65

3.1.1 AP 2 CCV accumulation in the $A P_{1} / \sigma_{1} B-/-$ synapses ............................66

3.1.2. $A P_{2} C C V$ accumulation is synapse specific in $A P_{1} / \sigma_{1} B-/-$ mice .................67

3.2. Existence of stabilized $A P_{2}$ CCV in $\sigma_{1} B-/$ - synapses ............................ 68

3.2.1 Upregulated CME in the stabilized $A P_{2} C C V$ of $A P_{1} / \sigma_{1} B-/-$ synapses :.........70

3.3 Molecular mechanisms for the formation of stabilized AP2 CCV: .............. 73

3.3.1 Reduced recruitment of Hsp110 to the stabilized AP 2 CCV: .................... 73

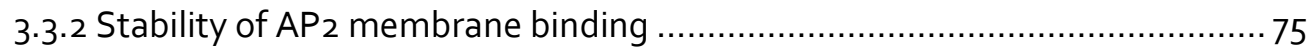

3.3.2.1. Reduced Synaptojanin-1 in stabilized AP 2 CCV : ............................ 75

3.3.2.2 Synaptojanin-1 recruiting proteins EndophilinA 1 and Amphiphysin ..........78

3.3.2.3 Reduction of Intersectin-1 in stabilized AP 2 CCV ............................... 79

3.3.2.4 Increased level of SGIP1 in the stabilized AP 2 CCV ............................... 81

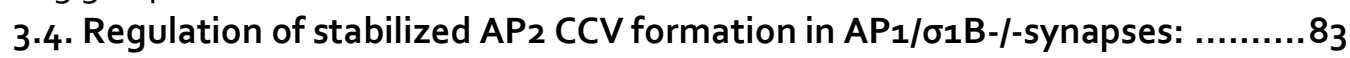

3.4.1. Increased LRRK2 in the stabilized $A P_{2} C C V$ of $A P_{1} / \sigma_{1} B-/-$ synapses.......... 83

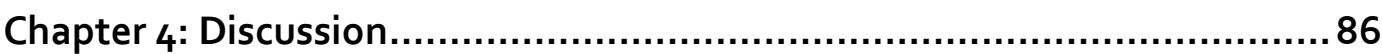

4.1 Brain-specific $A P_{2} C C$ accumulation in the $A P_{1} / \sigma_{1} B-/$ - synapses..................87

4.2. Existence of a sub-pool of stabilized AP2 CCV:................................... 89

4.2.1 Altered active zone dynamics in $A P_{1} / \sigma_{1} B-/-$ synapses............................90

4.2.2. Molecular mechanisms for the formation of stabilized $A_{2}$ CCV .............. 91

4.2.3 Analysis of Synaptojanin-1 recruiting proteins ............................... 93

4.3 Regulation of stabilized AP 2 CCV formation in AP1/ $\sigma_{1} B-/-$ synapses: .........95

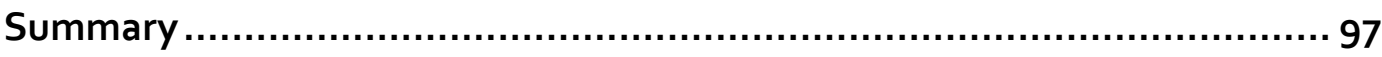

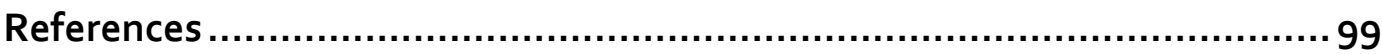

Acknowledgements ...............................................................111 


\section{List of abbreviations}

AP

AP1

AP2

ATP

$\mathrm{CCP}$

$\mathrm{CCV}$

$\mathrm{CHC}$

CLASP

CLC

CME

COP

DMEM

DMSO

DNA

DTT

E.coli

EDTA

EM

ENTH

ER

$\mathrm{kb}$

ko

MEF

MPR

MVB

OD

PBS

PCR

PI -4,5-P

PI-4-P

PMSF
Adaptor Protein

Adaptor protein complex-1

Adaptor protein complex-2

Adenosine triphosphate

Clathrin-coated-pits

Clathrin-coated-vesicles

Clathrin-Heavy-Chain

Clathrin associated protein

Clathrin-Light-Chain

Clathrin-mediated-endocytosis

Coat protein complex

Dulbecco's modified Eagle medium

Dimethylsulfoxide

Desoxyribonucleic acid

Dithiothreitol

Escherichia coli

Ethylene dinitrilotetraacetic acid

Electron microscopy

Epsin N-terminal homology

Endoplasmic reticulum

kilobasepairs

knock-out

Mouse embryonic fibroblasts

Mannose 6-phosphate receptor

Multivesicular bodies

Optical density

Phosphate-buffered saline

Polymerase chain reaction

Phosphatidylinositol 4,5-biphosphate

Phosphatidylinositol-4-phosphate

Phenylmethylsulfonylfluoride 
RNA

RNAi

rpm

RT-PCR

SDS

SH3

SNARE

TBS

TD

TEMED

TGN

wt
Ribonucleic acid

RNA interference

rotations per minute

real-time PCR

Sodium dodecylsulfate

SRC homology 3

Soluble NSF attachment protein

receptor

Tris buffered saline

Terminal domain

$\mathrm{N}, \mathrm{N}, \mathrm{N}^{\prime}, \mathrm{N}^{\prime}$-tetramethyl-ethylene

diamine

Trans-Golgi network

wild-type 


\section{Abstract}

Clathrin adaptor protein complexes 1 and 2 (AP1 and AP2) have essential functions in synaptic vesicle (SV) recycling. In all cell types and tissues, AP1 mediates TGN/endosome protein sorting via clathrin-coated-vesicles (CCV), whereas AP2 transports proteins by clathrin-mediated endocytosis (CME). Both AP complexes are heterotetrameric, made of four adaptins. Neurons express the ubiquitous $\mathrm{AP} 1 / \sigma 1 \mathrm{~A}$ complex and in addition, the tissue-specific AP1/ $1 \mathrm{~B}$ complex. In our lab, we have generated $\sigma 1 \mathrm{~B}-/-$ mice. The deficiency of $\sigma 1 \mathrm{~B}$ adaptin leads to severe learning, memory and motor coordination deficits in the knockout mice. $\sigma 1 \mathrm{~B}$ knockout mice are also a model for a severe X-linked mental retardation disease in humans, where the $\sigma 1 \mathrm{~B}$ gene has a premature STOP codon. Synapses lacking the AP1/ 1 1B complex, display two major phenotypes. Firstly, synaptic vesicle (SV) recycling is impaired, and early endosomes accumulate. The ubiquitous AP1/ $1 \mathrm{~A}$ complex binds to these endosomes and stimulates their maturation into late, multivesicular-body endosomes, up regulating endolysosomal protein transport. Secondly, the endocytic AP2 CCV accumulate, a surprise given the reduction in the major vesicular transport route, SV recycling. This indicated that CME is a major mechanism of synaptic plasticity. AP2 CCV accumulation could be caused by upregulation of $\mathrm{CME}$ or by the stabilization of AP2 CCV extending their half-life. In this project, I have biochemically characterized these AP2 CCV and demonstrated that two populations of AP2 CCV exist in synapses. One formed by canonical clathrin-mediated-endocytosis (CME) and the other one formed by a specialized pathway, which is characterized by a stabilized CCV coat. Both CME routes are upregulated two-fold in AP1/ $\sigma 1 \mathrm{~B}$ deficient synapses. In addition, the longer-lived AP2 CCV of the AP1/ $1 \mathrm{~B}-/$ - synapses are stabilized by three distinct molecular mechanisms compared to the respective AP2 CCV from wt synapses.

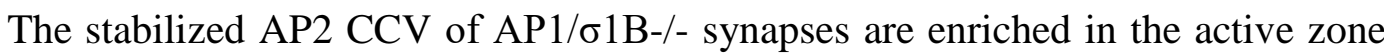
proteins, Stonin 2 and Git1. The AP1/ $\sigma 1 B$ deficient synapses contain more Git1 than wild-type synapses, indicating alterations in the dynamics of the active zone in these synapses. Thus, two CME routes characterized by specific lifetimes and specific cargo proteins contribute to synaptic plasticity. 


\section{Chapter 1: Introduction}

\subsection{Intracellular protein transport}

In all eukaryotic cells, there is an intricate network for protein transport, as majority of the proteins are synthesized in the endoplasmic reticulum (ER) and are then transported to different cell organelles of the secretory pathway. The Secretory pathway is composed of several organelles and membrane-bound transport intermediates, which transport proteins between them. The secretory pathway starts at the site of protein synthesis, the ER and proceeds through ER exit site (ERES), ER-to-Golgi intermediate compartment (ERGIC) and the Golgi-apparatus (Figure.1.1) (Szul \& Sztul, 2011). The transport of proteins takes place in specialized membrane-bound vesicles, which are formed at the donor compartment and fuse with the membrane of the corresponding acceptor compartment, thereby delivering the proteins to the acceptor organelles. There are three different classes of vesicles depending upon their coat compositions, which mediate protein transport into different cellular routes: (1) Coatomer or COP vesicle, (2) Clathrin associated transport vesicle (3) non-clathrin associated vesicle. COP vesicles mediate ER to Golgi trafficking, while Clathrin-coated vesicle (CCV) mediate protein transport between TGN and endosomes and between the plasma membrane and endosomes. All newly synthesized membrane proteins are translated at the rough endoplasmic reticulum (RER) and are then exported from specialized ER exit sites (ERES)(Figure 1.1). With the advent of the latest microscopy techniques and new organelle markers, it has been established now that proteins are exported from RER, only from specialized ERES. ERES is defined as the smooth projections of ER from which COPII vesicles are generated and cargoes are exported. In mammalian cells, ERES are formed by fusion and fission of existing ER sites as well as by de novo formation of new sites (Stephens, 2003). In mammalian cells, 50-70 ERES of approximate $50 \mu \mathrm{m}$ diameter, are randomly scattered and are relatively stable with a life span of >10min (Hammond \& Glick, 2000; Stephens, 2003) from which COPII vesicles are generated to transport cargo proteins from ERES to ERGIC. 


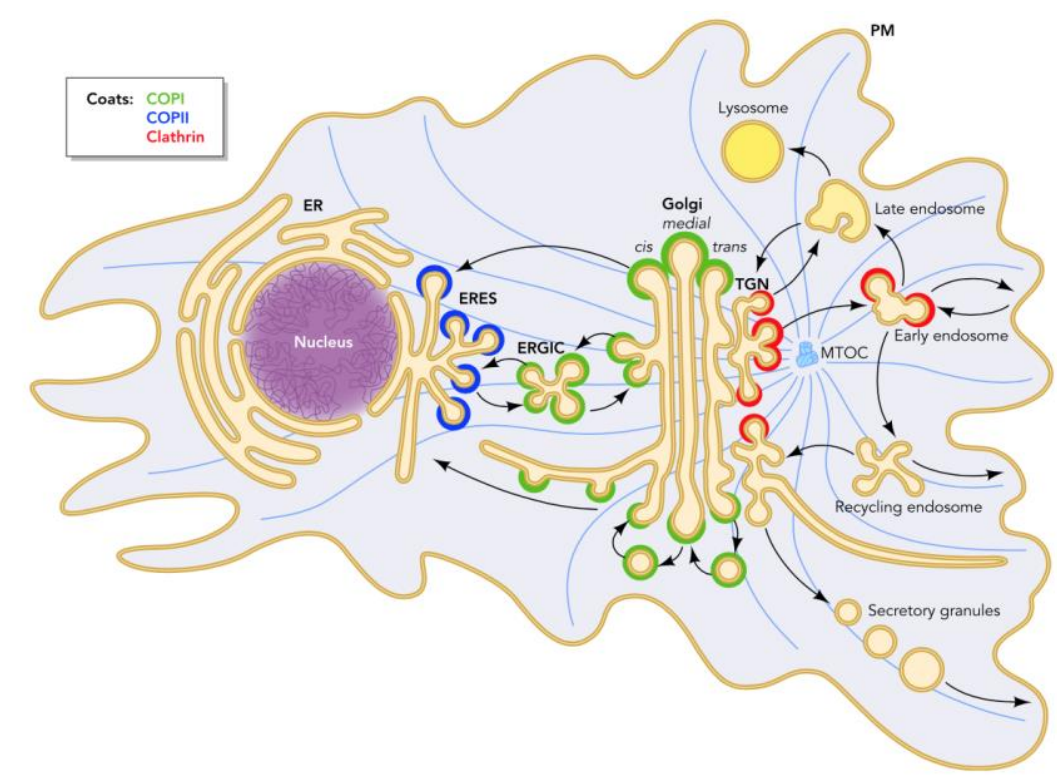

Figure 1.1 Intracellular Protein transport network: of secretory and endosomal pathways. Proteins are synthesized in the ER, transported from ERES to ERGIC in COPII vesicles. Cargos are than sorted from ERGIC and move to Golgi, for posttranslational modifications. The modified proteins then move through Golgi, and are sorted at TGN for delivery to plasma membrane, early and late endosomes and to secretory granules. A retrograde pathway mediated by COPI vesicles retrieves proteins from Golgi and returns back to ER. Figure adapted from (Szul \& Sztul, 2011)

ERGIC, also known as pre-Golgi intermediates, is a collection of vesiculo-tubular compartments that are adjacent to ERES. With the help of live microscopy and ERGIC markers like ERGIC-53, it has been shown that ERGIC is a stationary sorting station, which sorts cargo into the anterograde direction to the Golgi apparatus (Ben-Tekaya et al, 2005). In addition to sorting of proteins in the anterograde direction to Golgi, ERGIC also sorts cargo in the retrograde direction to the ER. The ER and ERGIC resident proteins are sent back to ER from the Golgi apparatus or are retained in ERGIC, respectively. The transport of cargos in retrograde direction is mediated by COPI coated vesicles formed at the ERGIC.

In different cell types, the Golgi complex has a different morphological characteristic. In mammalian cells, the Golgi complex is organized in the form of a single ribbon of staked cisterna. In C.elegans, D. melanogaster and plant A.thaliana, the Golgi complex exists as discrete stacked elements distributed throughout the cell, whereas in yeast S.cerevisiae, it exists as discrete tubules scattered throughout the cells (Faso et al, 2009). Despite the different morphological characteristics of the Golgi complex in different eukaryotic cells, all 
those Golgi complexes are composed of closely packed membrane cisternae with cis Golgi facing towards ER, followed by the medial-Golgi and finally the transGolgi. Several biochemical and microscopic analysis in the past have clearly reflected the polarity of the Golgi complex by the localization of certain glycosyltransferases as markers. Cis-and-medial Golgi are enriched in early acting enzymes of the biosynthetic pathway such as mannosidase I and mannosidase II respectively, whereas the trans side has late acting galactosyl-transferase (Velasco et al, 1993; Szul \& Sztul, 2011). Both cis and trans side have a network of tubules called a cisGolgi network (CGN) and trans-Golgi network (TGN) respectively. The CGN contains protein transport intermediates, COPII and COPI vesicles, transporting proteins between ER and Golgi. The TGN is enriched in clathrin-coated vesicles, transporting proteins to endosomes or to the secretory granules (Szul \& Sztul, 2011). 


\subsubsection{COP coated vesicles in early secretory pathway}

ER-Golgi transport is mediated by COP (coat protein complex) vesicles formed by COPI or COPII protein complexes. COPII vesicles transport proteins from ER in the anterograde direction towards Golgi complex, whereas COPI vesicles functions in the retrograde direction back to ER. The formation of these vesicles is conserved from yeast to mammals and involves coat proteins, Sar1/Arf GTPases and their GEFs and GAPs.

\subsubsection{COPII mediated anterograde protein transport}

COPII vesicles mediate anterograde protein transport. In eukaryotes, a COPII protein vesicle is formed by COPII coat proteins: Sar1, Sec23/24, and Sec13/31, which polymerize to form a coat and further sort cargo proteins in the coated vesicles (Matsuoka et al, 1998; Jackson, 2014). Sar1 is a GTPase present on the membrane of ER, which is activated by its GEF (Guanine nucleotide exchange factor), Sec12 (Weissman et al, 2001) (Figure.1.2). The activated Sar1 then binds directly to Sec23/24 complex of COPII coat and Sec 23/24 in-turn recruits the heterotetrameric subcomplex of Sec13/31 to its core and further sort cargo proteins for transport in COPII vesicles (Weissman et al, 2001). The sorting of cargo into the COPII nascent vesicles is mediated by the sec24 subunit of the COPII and by different cargo-specific isoforms of Sec24. Sec24 binds to the cytoplasmic tail of the transmembrane cargo proteins. There are four isoforms of sec24: sec24a-d, which bind to specific motifs on the cargo proteins and sort them into vesicle for transport. Sec24a and Sec24b both bind to DXE and LXXL/ME sorting motifs on the cargo protein, while Sec24c and Sec24d bind to the IXM sorting motifs on the transmembrane cargo proteins (X refers to any amino acid) (Szul \& Sztul, 2011). The binding of Sar1 to sec13/31 also ensures, that the vesicle coat is polymerized only when the cargo proteins are sorted into the nascent vesicle. After packaging of cargo proteins into the nascent vesicle, the vesicle coat polymerizes, which deforms the donor membrane, eventually leading to the scission of the vesicle. Detailed molecular mechanism for the scission of COPII vesicle remains elusive. However, the membrane deformation and scission of the COPII vesicle is most likely to be mediated by Sar1 and Sec23/24 complex. Sar1 has been shown to deform the donor 
membrane in-vitro (Lee et al, 2005) and has been suggested to function in an analogous manner to that of dynamin (Pucadyil \& Schmid, 2008), which is required for the scission of Clathrin-coated vesicles from the donor membrane. Sar1 uses its GTP regulated amphipathic N-terminal helix to bind to the donor membrane, constricts and deforms it to release the COPII vesicles (Bielli et al, 2005). Inhibition of GTP hydrolysis resulted in the formation of COPII vesicles, but these vesicles fail to detach from the membrane (Bielli et al, 2005).

After scission from the donor membrane, the COPII vesicle moves toward the acceptor membrane to deliver cargo proteins. When the vesicle comes in close approximation to the acceptor membrane, the COPII coat is removed from the vesicles and eventually the vesicle tethers to the membrane via SNARE-dependent mechanisms. Barlowe and colleagues have studied the tethering of COPII vesicles in yeast and have shown that yeast protein Uso1p and a small GTPase, Ypt1p, helps in tethering of COPII vesicles to the yeast Golgi (Cao, 1998), (Cao \& Barlowe, 2000). The Uso1p links the COPII vesicles to the Golgi membrane by binding to the Golgi proteins, however, the exact binding protein is not certain. The mammalian homolog of Uso1p is p115, which binds SNAREs. Thus it could be that Uso1p also binds to the known ER-Golgi SNAREs like Bet1, Bos1, Sec22, and Ykt6 (Cao, 1998).

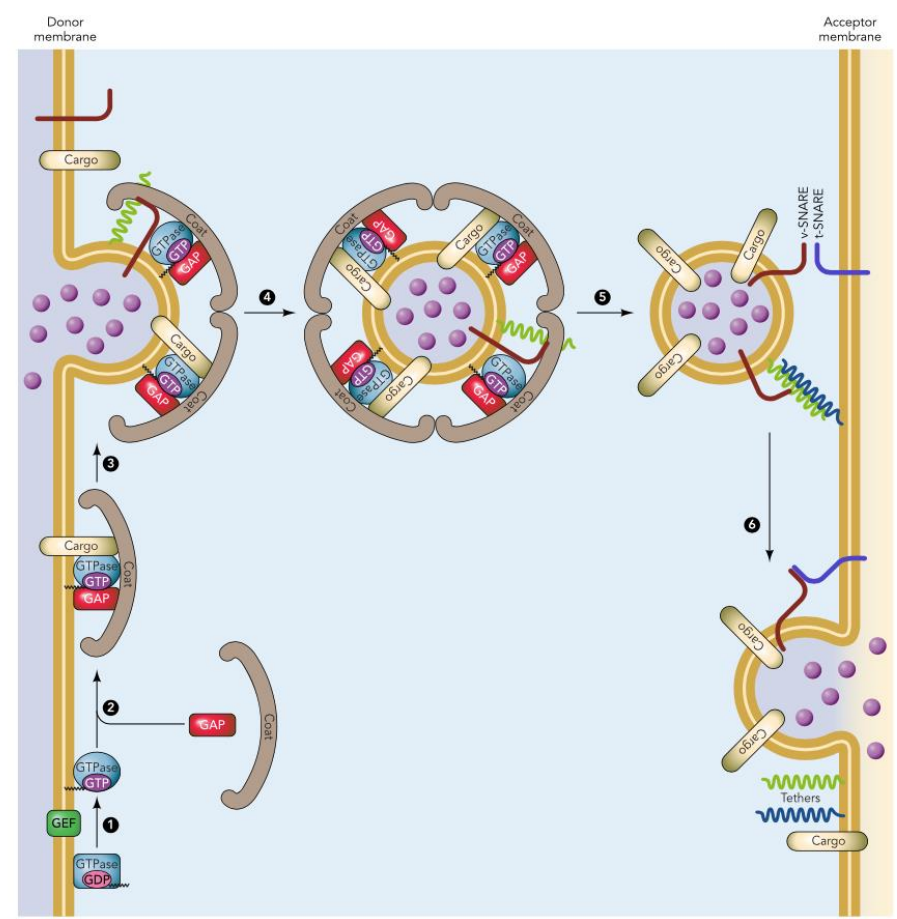


Figure. 1. 2. Mechanisms of vesicular transport Proteins are transported in the vesicles, which bud from the donor membrane, move to the target organelle and fuse with the acceptor membrane to deliver the cargo proteins. The initial steps involve the activation of GTPase on the membrane of the ER (Sar1) by its GEF Sec21 (step 1). The activated Sar1 recruits the coat proteins (step 2), cargo proteins are sorted into the transport vesicle (step 3), and vesicle is scissed from the donor membrane following the polymerization of the vesicle coat (step 4). The coated vesicle moves towards the target organelle, un-coats (step 5) and tethers to the acceptor membrane via SNARE proteins mediated fusion mechanism to the deliver the cargo proteins (step 6). Figure adapted from (Szul \& Sztul, 2011).

There are other proteins as well, which participate in tethering of COPII vesicles. Studies in the past have shown that the yeast protein Grh1p, which is closely related to GRASP65, is associated with tethering of COPII vesicles by binding to the Sec23/Sec24 complex of COPII vesicle coat (Behnia et al, 2007). Grh1p bind with coiled-coil protein Bug1p (Bug1p is homologous to mammalian GM130 protein, a known interactor of GRASP65) and could possibly be involved in the tethering of COPII vesicles. In-vitro studies have shown that Bug1p is required in tethering of COPII vesicles (Behnia et al, 2007), however, the exact molecular mechanism is not clearly understood.

\subsubsection{COPI mediated retrograde protein transport:}

The retrograde protein transport from Golgi to ER and ERGIC is mediated by COPI vesicles. The coat of COPI vesicles is formed by heptameric complexes called coatomers. The coatomers are composed of two sub-complexes: a trimeric complex composed of $\alpha, \beta^{\prime}$ and $\varepsilon$ subunits, and a tetrameric complex made of $\gamma, \beta, \delta$ and $\zeta$ subunits (Eugster et al, 2000). The X-ray crystallographic structure of COPI coat suggests that the trimeric COP complex has structural similarity to the $\sec 13 / \sec 31$ complex of COPII coat (Lee \& Goldberg, 2010); $\gamma$ COP subunit has structural similarity to $\alpha$ and $\beta$ subunit of adaptor protein complex 2 which forms the inner core of Clathrin-coated vesicles (Hoffman et al, 2003). Thus, it is proposed that the trimeric COP complex $\left(\alpha, \beta^{\prime}\right.$ and $\left.\varepsilon\right)$ forms the outer coat and that the tetrameric complex $(\gamma, \beta, \delta$, and $\zeta)$ forms the inner core of the COPI vesicles. 


\subsubsection{Clathrin-coated vesicles in late secretory and endocytic pathways:}

Clathrin-coated vesicles (CCVs) mediate protein transport in the late secretory pathway, between the trans-Golgi network and the early endosomes and between the plasma membrane and the early endosomes. Clathrin is a trimeric protein, which polymerizes into hexagonal and pentagonal lattices and forms the outer basket of the CCV. CCVs are formed at the TGN membrane and at the plasma membrane and involve the cumulative interaction of a number of other proteins apart from Clathrin. Clathrin does not directly bind to the membrane or to the cargo proteins to be transported. At the TGN, the adaptor protein complex 1 (AP1) and at the plasma membrane, adaptor protein complex 2 (AP2) binds to the membrane and recruits clathrin to the site of vesicle formation and they bind the cargo proteins to be transported.

\subsubsection{Adaptor Protein complexes}

In vertebrates, there are five members in the family of adaptor protein (AP) complexes, AP1 to AP5. All the adaptor protein complexes are heterotetrameric complexes made up of four subunits/adaptins: two large subunits of $\approx 100 \mathrm{kDa}$ each, one medium subunit of $\approx 50 \mathrm{kDa}$ and one smaller subunit of $\approx 20 \mathrm{kDa}$ (Figure 1.3). All the four subunits are closely associated with each other and detergents are required to dissociate them. One of the larger subunits is $\gamma / \alpha / \delta / \varepsilon / \zeta$ in AP1-AP5 complexes respectively, which shows limited sequence homology among each other. $\gamma$ subunit of AP1 and $\alpha$ subunit of AP2 show 25\% sequence identity (Robinson, 1990). The second large subunit is $\beta 1-5$, in AP1-AP5 complexes respectively, which have the highest sequence conservation. $\beta 1$ and $\beta 2$ have $84 \%$ sequence identity (Kirchhausen et al, 1989). The medium subunits are $\mu 1-\mu 5$ and the smaller subunits are $\sigma 1-\sigma 5$ in AP1-AP5 complexes respectively, which share 40\% amino acid identity with each other (Thurieau et al, 1988; Nakayama et al, 1991). In mammalian cells, there are several isoforms of some of these adaptins, and some of them have tissue-specific functions. AP1 complex has two $\gamma$ isoforms, $\gamma 1$ and $\gamma 2$, two $\mu$ isoforms, $\mu 1 \mathrm{~A}$ and $\mu 1 \mathrm{~B}$ and three $\sigma 1$ isoforms, $\sigma 1 \mathrm{~A}, \sigma 1 \mathrm{~B}$ and $\sigma 1 \mathrm{C}$. AP2 complex has two $\alpha$ isoforms, $\alpha \mathrm{A}$ and $\alpha \mathrm{C}$, which are $\sim 80 \%$ identical and both are 
localized on the plasma membrane. AP3 complex has two $\beta$ isoforms, $\beta 3 \mathrm{~A}$ and $\beta 3 \mathrm{~B}$, two $\mu$ isoforms, $\mu 3 \mathrm{~A}$ and $\mu 3 \mathrm{~B}$ and two $\sigma$ isoforms, $\sigma 3 \mathrm{~A}$, and $\sigma 3 \mathrm{~B}$ (Park \& Guo, 2014).

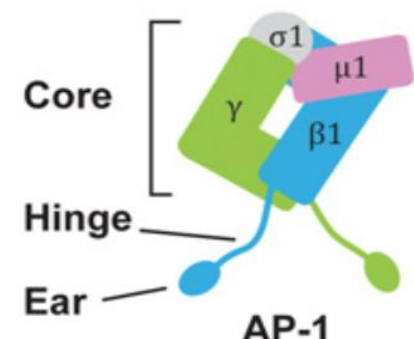

AP-1

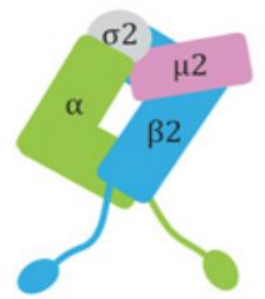

AP-2

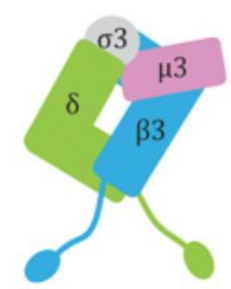

AP-3

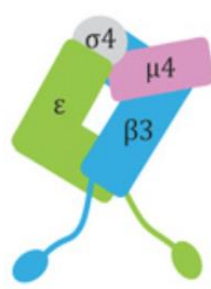

AP-4

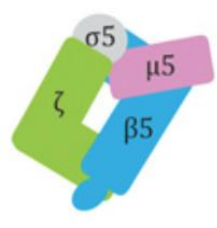

AP-5

Figure 1.3. Diagrammatic representation of Adaptor Protein (AP) complexes: all large adaptins have a core domain, hinge and an ear domain except AP5, which lacks a hinge domain. Core adaptins bind with cargo proteins and membrane, while hinge and ear domains are required for the interaction with coat proteins and accessory proteins. Figure adapted from (Park and Guo, 2014)

The AP complexes are localized at different organelles and transport proteins in different cellular routes (Figure 1.4). Only AP1 and AP2 complexes recruit clathrin and forms clathrin-coated vesicles (CCV) for intracellular protein transport. AP1 is localized on TGN and endosomes and mediates protein transport between TGN and endosome, particularly in basolateral sorting at epithelial cells (Meyer et al, 2000; Yáñez-Mó et al, 2015). AP1 is also necessary for maturation of endocrine, exocrine and neuroendocrine secretory granules in Drosophila (Burgess et al, 2011). AP2 complex is found exclusively on the plasma membrane and transports a wide range of proteins including receptors and adhesion molecules via Clathrin-Mediated Endocytosis (CME) from the plasma membrane to early endosomes. AP3 is localized on tubular endosomes and shuttles cargo from tubular endosomes to late endosomes and is essential for the biogenesis of lysosome-related organelles (LRO). AP3 also functions with AP1 in sorting of tyrosinase from endosomes to melanosomes (Theos et al, 2005), and is also required in the lysosomal sorting of 
cargo proteins during the formation of large dense core vesicles (Grabner et al, 2006). AP4 localizes to TGN and transport cargo between TGN and endosomes and to the basolateral plasma membrane. AP5 localizes to the late endosomes and transport proteins from late endosome to lysosomes. Dysfunction in any of the AP complexes leads to the defect in its respective protein transport routes and are associated with a variety of disorders. In our lab, we are interested to study the late secretory and endocytic protein transport mediated by AP1 and AP2 complex. Therefore, I will focus more on the intracellular transport mechanism mediated by AP1 and AP2 complexes.

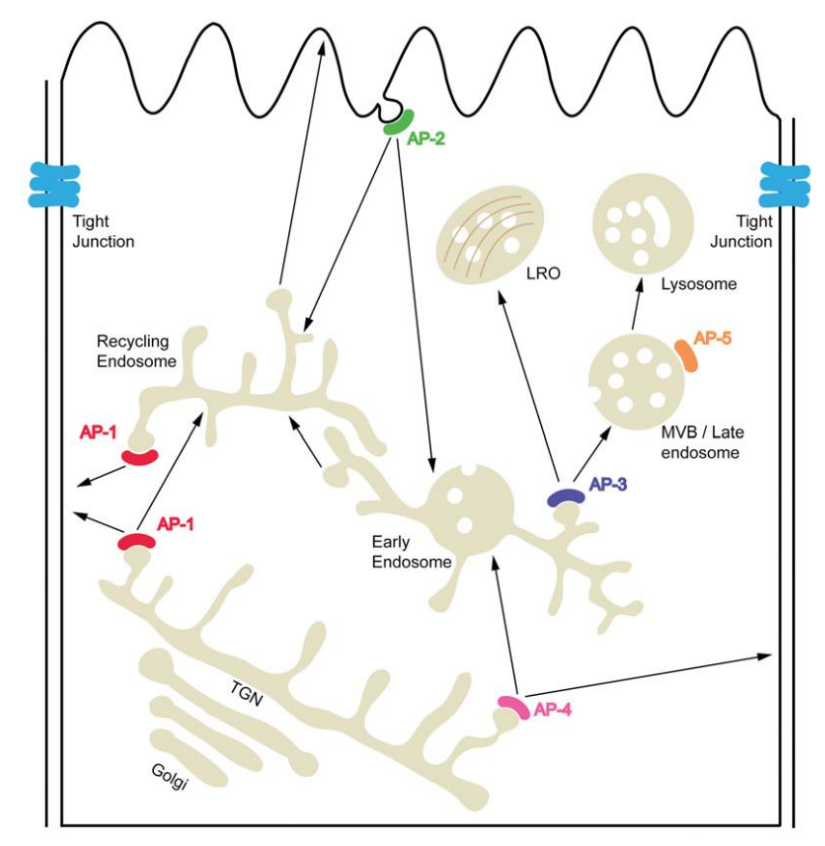

Figure. 1. 4 Scheme showing localization and protein transport routes of different adaptor protein complexes. Figure adapted from (Park and Guo, 2014). 


\subsection{AP2 complex}

The adaptor protein complex 2 (AP2) is the most studied adaptor protein complex. AP2 mediates endocytosis of proteins and receptors at the plasma membrane viaclathrin-coated-vesicles (CCV) called Clathrin-mediated endocytosis (CME) (see section 1.1.2.3 for CME and CCV formation). The AP2 structure consists of two brick-like 'head' region flanked by two symmetrically placed appendages or ear domains (Figure 1.5). The ear domains are the globular $\mathrm{C}$ terminal domain, which are separated by a $\sim 6 \mathrm{~nm}$ flexible proline-rich, stalk (Figure 1.5) (Damke et al, 1994; Owen et al, 2004). The flexible ear domains bind to co-adaptor proteins complexes, while clathrin is bound by the core of $\alpha$ and the ear of $\beta 2$ adaptin (Owen et al, 2004). The different subunits of AP2 complex have different essential functions in general, and some isoforms of the subunits have tissue-specific functions. $\alpha$ and the $\beta_{2}$ subunit of AP2 bind to the phosphatidylinositol-4,5bisphosphate $\left(\mathrm{PIP}_{2}\right)$ on the plasma membrane and $\beta 2$ also bind to the clathrin (Owen et al, 2004). $\mu 2$ subunit also binds to the $\mathrm{PIP}_{2}$ and to cargo proteins, with tyrosinebased sorting motifs. $\sigma_{2}$ binds only to cargo proteins with di-leucine-based sorting motifs (Owen et al, 2004). The binding of $\alpha$ and $\beta 2$ to the membrane is weak and the high-affinity membrane binding of AP2 require it's binding to the cargos proteins as well. The firm binding of AP2 to the membrane is achieved and regulated by the conformational change of $\mathrm{AP} 2$, which releases a steric hindrance of cargo-binding to $\mu 2$ and $\sigma_{2}$ adaptins It also brings the $\mathrm{PIP}_{2}$ binding motif of $\mu 2$ closer to the membrane. This conformational change of AP2 is favored by the phosphorylation of $\mu 2-\mathrm{Thr}^{156}$ by AAK1 kinase ( $\alpha$ adaptin associated kinase) (Ricotta et al, 2002; Conner et al, 2003). AAK1 is not the only kinase responsible for the phosphorylation of $\mu 2$, but the others are not known yet. 

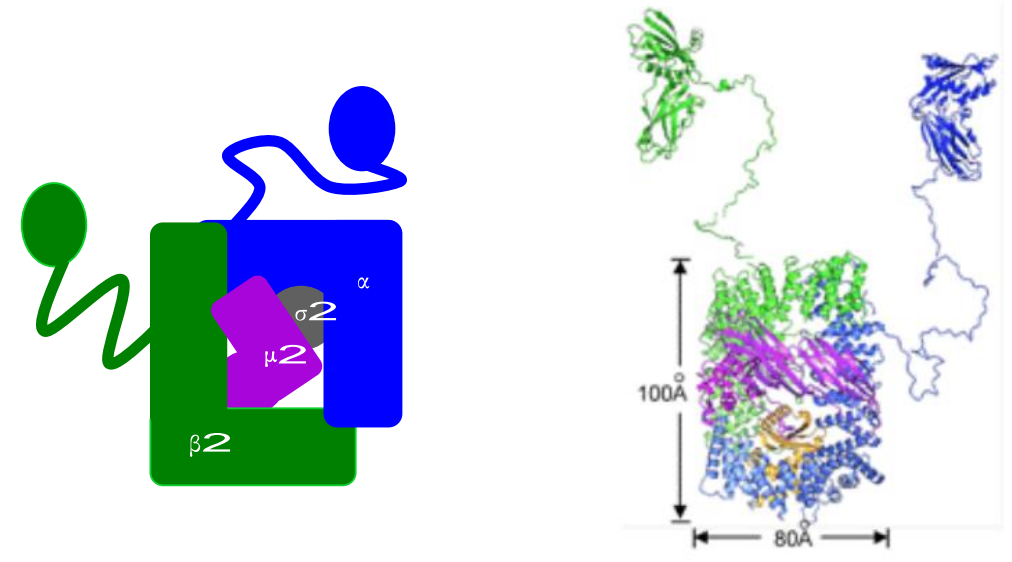

Figure 1.5 Structure of AP2 Complex: (left-right) Cartoon illustration of the structure of AP2 complex and the structural model of AP2 complex ( $\alpha$ blue, $\sigma 2$ gray, $\beta 2$ green, and $\mu 2$ purple). This structural model is reconstructed from the crystal structure of the core heterotetrameric complex $(\alpha$, $\beta 2, \sigma 2$ and $\mu 2$ ) (Collins $\boldsymbol{e t} \boldsymbol{a l , ~ 2 0 0 2 )}$ ) and the appendage structure (Owen et al, 1999; Owen, 2000). The linkers connecting them to the core subunits were drawn to scale. Figure adapted from (Owen et al, 2004)

\subsection{AP1 complex}

The AP1 complexes is expressed ubiquitously like AP2, and mediates protein sorting between trans-Golgi network (TGN) and endosomes, which is essential for the development of vertebrates (Meyer et al, 2000). There are different types of AP1 complexes based on the tissue-specific expression of different subunits of AP1. Mammals express 5 different types of AP1/ $\gamma 1$ complexes (Figure 1.6) with tissue-specific functions (Glyvuk et al, 2010; Boehm \& Bonifacino, 2001) . There are AP1/ $\gamma 2$ isoforms as well (Zizioli et al, 2017), but in this thesis, I will focus only on different types of AP1/ $\gamma 1$ complexes. The AP1A complex is ubiquitously expressed and is formed by the two large adaptin subunits $\gamma 1$ and $\beta 1$ (also known as $\mathrm{AP} 1 \mathrm{G} 1$ and $\mathrm{AP} 1 \mathrm{~B} 1$, respectively), one medium subunit $\mu 1 \mathrm{~A}$ and one small subunit $\sigma 1 \mathrm{~A}$ (also known as AP1M1 and AP1S1, respectively). AP1 with $\mu 1 \mathrm{~B}$, instead of $\mu 1 \mathrm{~A}$, is expressed only in polarized epithelial cells (Ohno et al, 1999), $\mathrm{AP} 1 / \mu 1 \mathrm{~B}$ with either $\sigma 1 \mathrm{~B}$ or $\sigma 1 \mathrm{C}$ isoform instead of $\sigma 1 \mathrm{~A}$ is expressed in the polarized epithelial cell, as all the tissue expresses $\sigma 1 \mathrm{~A}$ along with $\sigma 1 \mathrm{~B}$ or $\sigma 1 \mathrm{C}$ isoform (Glyvuk et al, 2010; Ohno et al, 1999). AP1 with $\sigma 1 \mathrm{~B}$ and $\sigma 1 \mathrm{C}$ isoforms instead of $\sigma 1 \mathrm{~A}$ (also known as AP1S2 and AP1S3, respectively) shows complementary tissue-specific expression, with most of the tissue expressing 
ubiquitous AP1/ $\sigma 1 \mathrm{~A}$ along with either of the other two $\sigma 1$ isoform complexes,

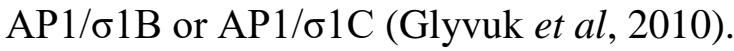

In our lab, we are interested in studying the molecular functions of different subunits of AP1 in the protein sorting and vesicular protein transport network in the cell. The knockout mice of AP1/ $\gamma 1$ are embryonic lethal and die at the age of 3.5 day post-coitus(p.c), demonstrating the essential role of $\gamma 1$-adaptin for the viability of the mice (Zizioli et al, 1999). The AP $1 / \gamma 1$ deficient mice grew only to the blastocyst stage and thus, AP1/ $\gamma 2$ does not compensate for the $\gamma 1$ deficiency during development. There are two- $\mu 1$ isoforms of AP1 in mammals, $\mu 1 \mathrm{~A}$ and $\mu 1 \mathrm{~B}$ (Ohno et al, 1999), and additional $\mu 1 \mathrm{C}$ in zebrafish (Gariano et al, 2013). $\mu 1 \mathrm{~A}$ is ubiquitously expressed, whereas the $\mu 1 \mathrm{~B}$ expression is restricted to the cells of polarized epithelial cells (Ohno et al, 1999) and $\mu 1 \mathrm{C}$ is expressed only in zebrafish (Gariano et al, 2013). The knockout of $\mu 1 \mathrm{~A}$ gene in mice develops primitive organs but dies at the age of 13.5 days (p.c.) (Meyer et al, 2000), demonstrating the essential function of $\mu 1 \mathrm{~A}$ in the viability of the mice. The reason that $\mu 1 \mathrm{~A}-/-$ mice develop primitive organs is most likely due to the homologous isoform $\mu 1 \mathrm{~B}$ (Ohno et al, 1999), and this also indicates that the embryonic survival and organ development requires the AP1 complex (Meyer et al, 2000). In the $\mu 1 \mathrm{~A}$ deficient cells, AP1 adaptins are not able to bind to the TGN and clathrin coats are not assembled at the TGN (Meyer et al, 2000). However, the AP1 and clathrin binding were restored after the re-expression of $\mu 1 \mathrm{~A}$, illustrating the critical role of $\mu 1 \mathrm{~A}$ in the binding of AP1 to the TGN (Meyer et al, 2000). In addition, the $\mu 1 \mathrm{~A}$ deficient cells have defects in the distribution of mannose-6-phosphate receptors, MPR46 and MPR300. Mannose-6-phosphate receptors (MPR) are the cargo molecules, which exit the TGN in AP1 CCV. Due to the deficiency of $\mu 1 \mathrm{~A}$, the distribution of MPR46 and MPR300 was shifted to the early endosomes and both fail to recycle back from early endosome to the TGN (Meyer et al, 2000). This defect in MPR recycling demonstrate that $\mathrm{AP} 1 / \mu 1 \mathrm{~A}$ is required for retrograde transport of receptors from early endosomes to the TGN (Meyer et al, 2000).

As described earlier in this section, three- $\sigma 1$ isoforms exist: $\sigma 1 \mathrm{~A}, \sigma 1 \mathrm{~B}$ and $\sigma 1 \mathrm{C}$. $\sigma 1 \mathrm{~A}$ is ubiquitously expressed in all the tissues along with either $\sigma 1 \mathrm{~B}$ or $\sigma 1 \mathrm{C}$. Mutations in the $\sigma 1 \mathrm{~A}$ gene cause autosomal recessive perinatal lethal MEDNIK 
syndrome, characterized by mental retardation, enteropathy, deafness, neuropathy, ichthyosis and keratodermia (Montpetit et al, 2008), suggesting the critical role of $\sigma 1 \mathrm{~A}$ in the development of the skin and spinal cord. The brain is the tissue with the highest expression of $\sigma 1 \mathrm{~B}$ along with $\sigma 1 \mathrm{~A}$ (Figure 1.6) (Glyvuk et al, 2010). The knockout mice of $\sigma 1 \mathrm{~B}$ are viable and fertile, but they are hypoactive, have impaired motor coordination and have impaired learning and memory (Glyvuk et al, 2010). Premature STOP codons in the $\sigma 1 \mathrm{~B}$ gene in humans causes a X-linked mental retardation disease, also known as Fried or Pettigrew syndrome (Tarpey et al, 2006), also characterized by the hypoactivity and uncoordinated motor functions in the patients. The MRI or autopsy studies in few patients with Pettigrew syndrome suggest the deposition of iron in the basal ganglia (Cacciagli et al, 2014). Thus, the neurological features associated with the deficiencies of $\sigma 1 \mathrm{~A}$ and $\sigma 1 \mathrm{~B}$ could probably be due to mislocalization of neuronal AP1 cargos, that specifically requires sorting by $\sigma 1 \mathrm{~A}$ and $\sigma 1 \mathrm{~B}$, respectively. The $\sigma 1 \mathrm{C}$ isoform is expressed in the skin and the mutations in the $\sigma 1 \mathrm{C}$ gene are associated with severe autoinflammatory skin disorder known as Pustular psoriasis, characterized by the disruption of endosomal translocation of innate pattern-recognition receptor TLR-3 (Toll-like receptor 3) (Setta-Kaffetzi et al, 2014). Thus, the findings associated with the Pustular psoriasis, demonstrate the role of $\mathrm{AP} 1 / \sigma 1 \mathrm{C}$ in Toll-like receptor homeostasis. 
A

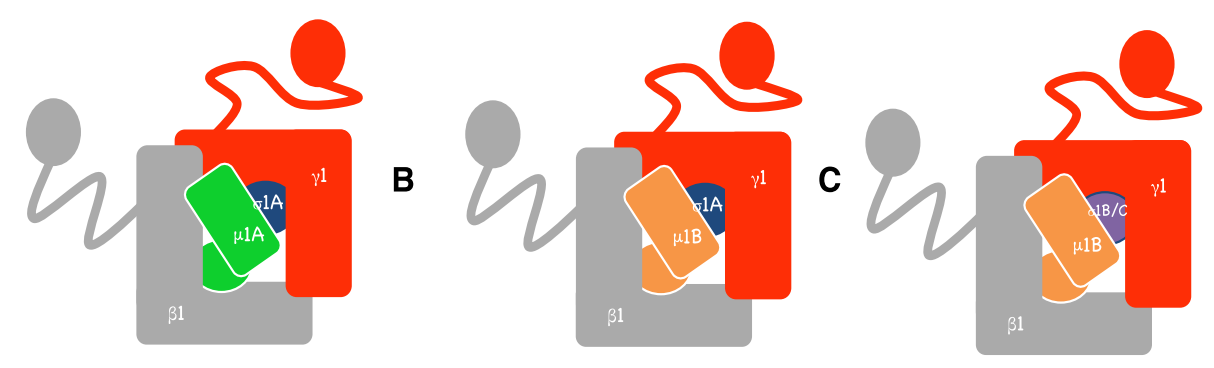

D

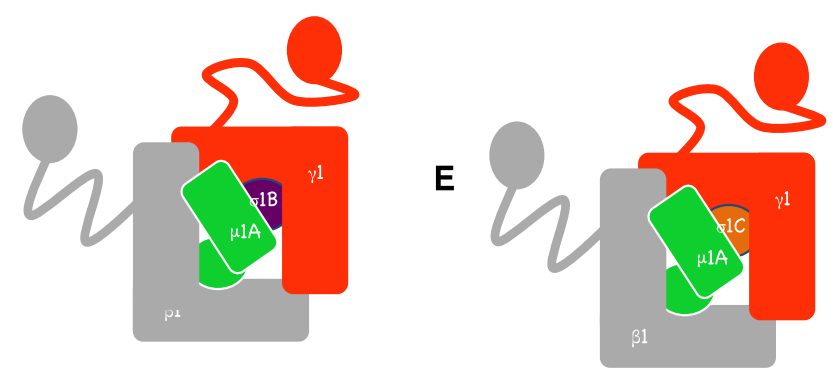

Figure 1.6 Cartoon representation of the different types of AP $1 / \gamma 1$ complexes expressed in mammals (A) AP1A (ubiquitously expressed) formed by the two large adaptin subunits $\gamma 1$ and $\beta 1$, one medium subunit $\mu 1 \mathrm{~A}$ and one small subunit $\sigma 1 \mathrm{~A}$, (B) AP1A with $\mu 1 \mathrm{~B}$, insteadof $\mu 1 \mathrm{~A}$, expressed only in polarized epithelial cell (Ohno et al, 1999) (C) AP1A/ $\mu 1 \mathrm{~B}$, with either $\sigma 1 \mathrm{~B}$ or $\sigma 1 \mathrm{C}$ expressed in polarized epithelial cell (D) AP1A with $\sigma 1 \mathrm{~B}$ isoform (E) AP1A with $\sigma 1 \mathrm{C}$ isoforms. $\mathrm{AP} 1 / \sigma 1 \mathrm{~B}$ and AP1/ $\sigma 1 \mathrm{C}$ shows complementary tissue-specific expression, with most of the tissue expressing ubiquitous AP1/ $\sigma 1 \mathrm{~A}$ along with either of the other two $\sigma 1$ isoforms, AP $1 / \sigma 1 \mathrm{~B}$ or AP $1 / \sigma 1 \mathrm{C}$ (Glyvuk et al, 2010). Figure adapted and modified from (Zizioli $\boldsymbol{e t}$ al, 2017) 


\subsubsection{Clathrin}

The term clathrin usually refers to the clathrin-heavy-chain $(\mathrm{CHC})$ protein. The $\mathrm{CHC}$ is a $180 \mathrm{kDa}$ protein: an amino-terminal, $\beta$-propeller domain, followed by a polypeptide chain of 30 amino acid residue, $\alpha$ helix and C-terminal with 45 residues (Fotin et al, 2004) (Figure 1.7). Three CHC molecules are connected at aminotermini, forming the clathrin triskelion (Fotin et al, 2004; Brodsky, 2012). A second clathrin protein is the clathrin-light-chain (CLC) of $20 \mathrm{kDa}$. The CLC has two isoforms in mammalian cells, CLCa and CLCb which, bind with the CHC at the vertex of proximal segment and stabilizes the clathrin triskelion basket (Kirchhausen et al, 1987; Fotin et al, 2004; Wilbur et al, 2008; Brodsky, 2012). Several clathrin triskelia polymerize to form a hexagonal and pentagonal coat structures known a 'clathrin cages'. A clathrin cage appears to be a sturdy coat, but actually, it's not. The biochemically isolated CCV easily dissociate at physiological $\mathrm{pH}$ and could reassemble at $\mathrm{pH}<6.5$, into empty cages even without the interaction of adaptor protein complexes (Smith et al, 1998; Fotin et al, 2004). However, in the presence of AP complexes, the cage formation is enhanced and allows in-vitro assembly at neutral pH (Smith et al, 1998; Fotin et al, 2004). Therefore, CCV isolation at slightly acidic pH 6.4 is essential for the clathrin cages to stay intact (Figure 1.7) (Brodsky, 2012).

$\mathrm{CHC}$ and CLC are both required for the formation of stable clathrin triskelia, however, CHC and CLC is not present in a 1:1 ratio and is less than 1 in all tissues, with the exception of the brain. In the brain, CHC: CLC ratio is 1.5 and thus, most of the clathrin-coated vesicles have not all their CHC binding sites occupied by CLC (Kratzke et al, 2014). This altered expression ratio also indicates important functions for the interaction of CLC with the actin cytoskeleton. One of the biochemical link to explain the interaction of clathrin and actin is the recruitment of huntingtin-interacting protein-1 related protein (HIP1R) (Bennett et al, 2001). A coiled-coil domain in the center of HIP1R protein binds to the amino terminal of CLC, and the carboxy-terminal of HIP1R binds to the F-actin. An amino-terminal ANTH domain binds to the membrane (Bennett et al, 2001) and helps in the recruitment of HIP1R . 
Besides basket stabilization, CLC binds additional proteins, like the already mentioned actin and thus has an additional function besides the regulation of clathrin basket stability. CLC knockdown cells suggest mislocalization and accumulation of HIP1R proteins in patches near the MPR clusters at TGN and also over-assembly of actin filaments (Poupon et al, 2008). Thus, suggesting the additional function of CLC in protein sorting, apart from stabilizing the clathrin basket. In another study, Ferreira, and colleagues (Ferreira et al, 2012) have demonstrated the role of CLC in the endocytosis of a G-protein coupled receptor kinase 2 (GRK2). Thus, the functions of CLC are highly dynamic and tissuespecific.
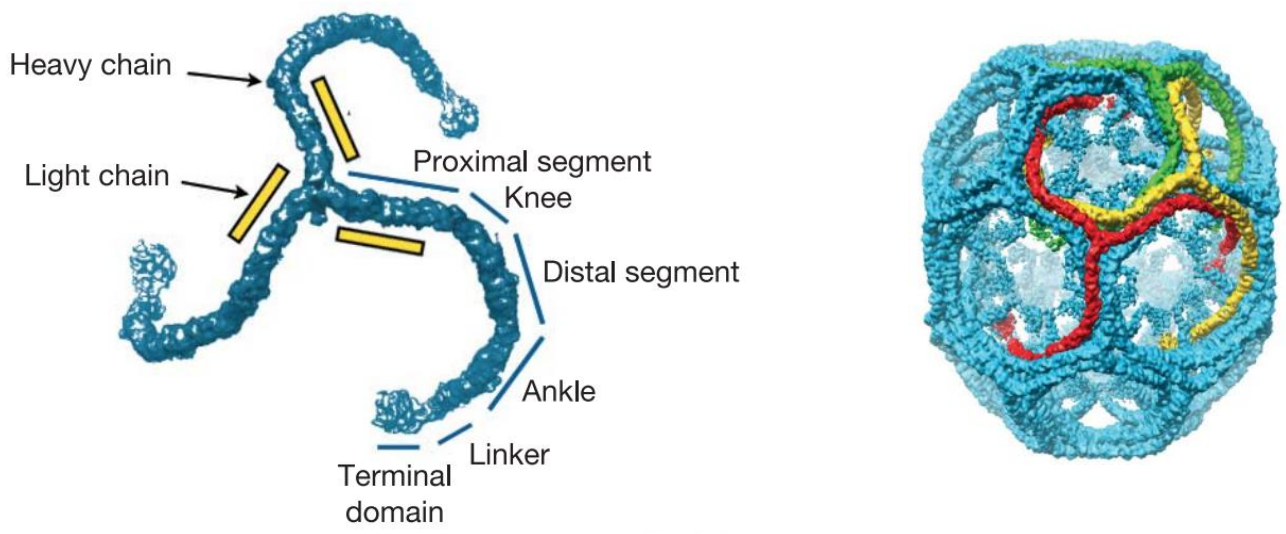

Figure. 1.7 (left-Right) Clathrin triskelion and Clathrin hexagonal coat (only CHCs are depicted for simplicity). Figures adapted from (Fotin et al, 2004). 


\subsubsection{Clathrin-Coated Vesicle life-cycle}

Clathrin-mediated-endocytosis (CME) is the major pathway for the uptake of receptors (cargo proteins) from the surface of the plasma membrane, and thus is the best model to study the formation of clathrin-coated-vesicle (CCV) life-cycle. CME plays an essential role in cell-cell, cell-substrate interactions, intracellular signaling and in maintaining cellular homeostasis. CME is the best understood endocytotic pathway due to the ease of visualization by TIRF microscopy and live imaging techniques. Its concentrative properties and multiple interactions with number of proteins have been characterized biochemically and signaling pathways have been dissected to understand its relevance in human health and disease (Mettlen et al, 2018). CME occurs through the formation of clathrin-coated pits (CCPs), by the assembly of major clathrin coat proteins comprising of clathrin-heavy-chain (CHC), tightly associated clathrin-light-chains (CLCs) and adaptor protein complex 2 (AP2) (Mettlen et al, 2018). The CME is dissected into four stages: initiations, stabilization, maturation and membrane fission (Figure1.8). In the following steps, a $\mathrm{CCP}$ matures into a $\mathrm{CCV}$ and is released from the donor membrane. Fission of the CCV is mediated by the GTPase dynamin (Antonny et al, 2016), which is recruited at low levels to nascent $\mathrm{CCP}$ and presumably taking part in the regulation of CCP initiation and maturation step. Fission is achieved by assembling dynamin into short helical rings around the neck of the CCP (Mettlen et al, 2018; Antonny et al, 2016).

CME is a very tightly regulated endocytotic pathway and in addition to the major coat proteins, a numerous endocytic accessory proteins (EAPs) (see Table 1) which functions as scaffolds, cargo recruiters, membrane curvature sensor and generators, regulates the CME (Mettlen et al, 2018). Table 1 summarizes the EAPs involved in $\mathrm{CME}$ and their effects for the formation of $\mathrm{CCV}$. 


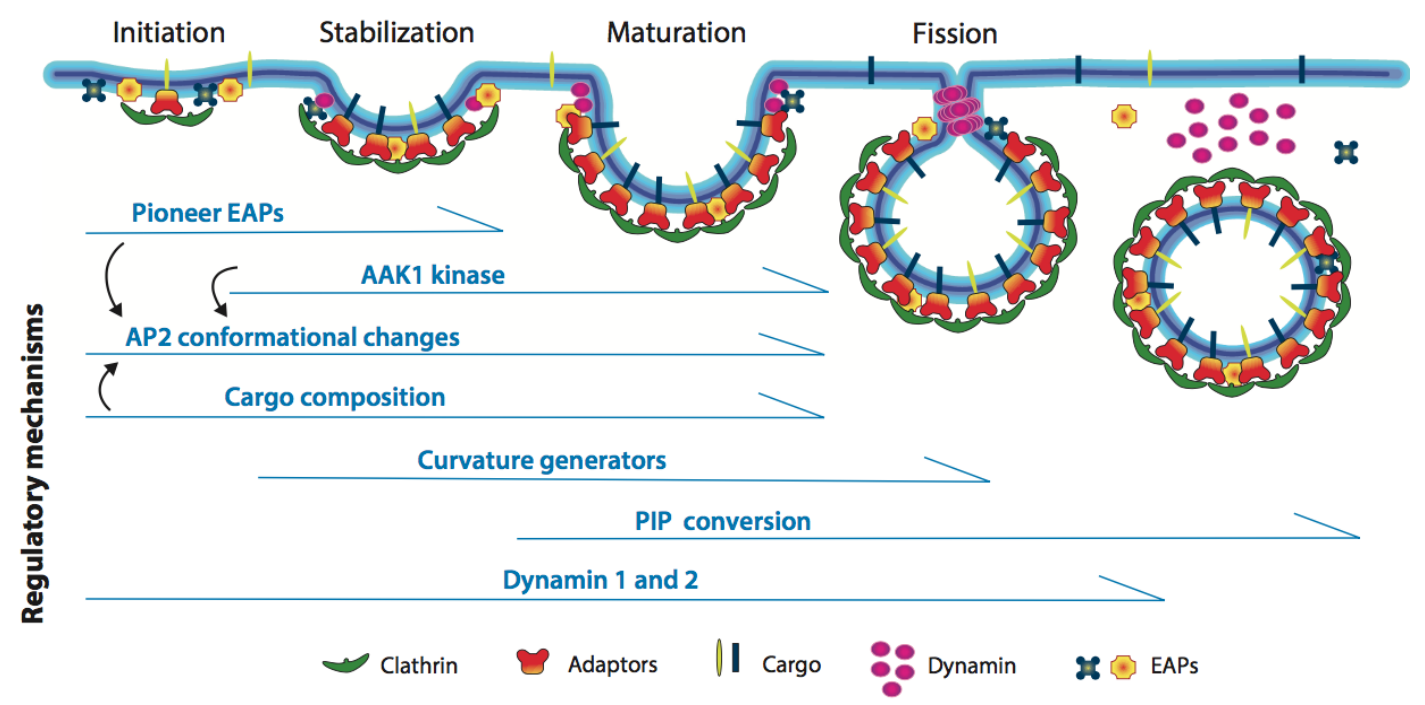

Figure 1.8 Mechanism and regulation of Clathrin-mediated-endocytosis and clathrin coated vesicle formation, Figure adapted from (Mettlen et al, 2018)

CME is mediated exclusively by AP2 CCVs, which are formed by Adaptor Protein complex 2 (AP2) (Figure 1.8). The following model about the molecular mechanism regulating CME has been developed over the last two decades. The livemicroscopy analysis in the non-neuronal cells have demonstrated that, not all the CCP matures and buds off from the membrane, and those $\mathrm{CCP}$ which matures and buds from the membrane has a life time of 20-120s (Mettlen et al, 2018). However, at the active zone in the synapses, the rate of endocytosis is much faster than CME, the ultrafast endocytosis occurs at the speed of 50-100ms (Watanabe et al, 2013). The first step of an AP2 CCV formation is the Initiation stage, where certain EAPs like, FCH domain only 1/2 (FCHo1/2) protein, EGFR pathway substrate 15 (EPS15) and Intersectins, NECAP, CALM and Epsin (Mettlen et al, 2018; Stimpson et al, 2009; Henne et al, 2010; Reider et al, 2009) are recruited on the plasma membrane. They define the specific sites on the membrane for presence of membrane-specific lipids phosphatidylinositol-4,5-bisphosphate (PI-4,5- $\left.\mathrm{P}_{2}\right)$ on the plasma membrane (Stimpson et al, 2009; Henne et al, 2010; Reider et al, 2009). The F-BAR domains of the FCHo proteins have membrane bending activity and act like a curvature sensor, required for the progression of CCP (Henne et al, 2010). The depletion in any one of these proteins shows defects in the stability of the forming clathrin coat. AP2 is recruited to the membrane where AP2 recruits clathrin 
for the formation of CCP (Stimpson et al, 2009; Henne et al, 2010; Reider et al, 2009).

In the stabilization stage, the binding of AP2 to the membrane phospholipid $\mathrm{PIP}_{2}$ and to cargo proteins is enhanced by its conformational change from a closed to an open conformation, in which the C-terminal domain of AP2/ $\mu 2$ comes in close contact to the membrane and binds firmly to $\mathrm{PIP}_{2}$ and the cargo proteins on the plasma membrane. This conformational change is favored by the phosphorylation of $\mu 2-\mathrm{Thr}^{156}$ by the AP2 associated kinase, AAK1 (Ricotta et al, 2002; Conner et $a l, 2003)$. The activity of AAK1 kinase increases at the stabilization stage, ensuring the firm binding of AP2 to the membrane (Figure 1.8).

The third stage is the Maturation stage, during which the CCP grows to its final size. Most of the clathrin is recruited from the cytosol by the core adaptor protein, AP2 complex. The membrane domains can be coated with AP2 and clathrin and only upon trapping of the cargo proteins, the vesicle budding process is initiated. Alternatively, high protein concentration of the cargo proteins induce the recruitment of AP2 and the formation of CCV (Haucke \& De Camilli, 1999). Post recruitment of clathrin, clathrin polymerizes into cages at the membrane, and mediates membrane bending as the coated pit invaginates (Hinrichsen et al, 2006). Following maturation, fission takes place, where CCV buds off from the membrane. The budding of CCV from the membrane is mediated by the action of a mechanochemical enzyme, dynamin (Kosaka \& Ikeda, 1983). Dynamin is recruited by the BAR domain proteins like endophilin, amphiphysin and sorting nexin 9 (SNX9), to the neck of the vesicle bud. All of these BAR-domain proteins have a SRC homology 3 (SH3) domain that binds to the proline-rich domain of Dynamin (Wigge et al, 1997; Ferguson et al, 2009; Sundborger et al, 2011). According to several studies done in the past, it is suggested that the dynamin polymerization around the neck of the vesicle favors GTP hydrolysis (Sweitzer \& Hinshaw, 1998), leading to conformational changes (Stowell et al, 1999), mediating vesicle scission (Roux, A. et al., 2006), (Bashkirov, P. V. et al., 2008). The electron microscopy studies of dynamin mediated vesicle fission suggest, that in GTP bound state dynamin ring appears to be closely packed, but after GTP hydrolysis, the spacing between the dynamin ring increase lengthwise like a 'spring' (Stowell et $a l, 1999)$. This conformational change in dynamin helix might participate in the fission of vesicles from the membrane. Mutation or inhibition in dynamin 
recruitment arrests the formation of the $\mathrm{CCV}$ at the vesicle scission stage, demonstrating that the activity of dynamin is essential for the scission of the vesicle from the membrane (van der Bliek et al, 1993; Macia et al, 2006).

Once the vesicle buds off from its parent membrane, it moves towards its target organelle to deliver the protein cargo. Before its fusion with the target membrane, the vesicle has to un-coat, so that the membranes come in contact. The uncoating stage, of a CCV cycle is demonstrated by two key mechanisms: disassembly of the clathrin basket by Heat-shock-cognate 70 (Hsc70), and the dephosphorylation of PI-4,5-P $\mathrm{P}_{2}$ by the action of phosphatase, Synaptojanin-1 (see section 1.1.2.3.2, for the detail mechanism of uncoating of a CCV). The later facilitates the release of the AP2 and other co-adaptor proteins, which also bind PIP $_{2}$. 


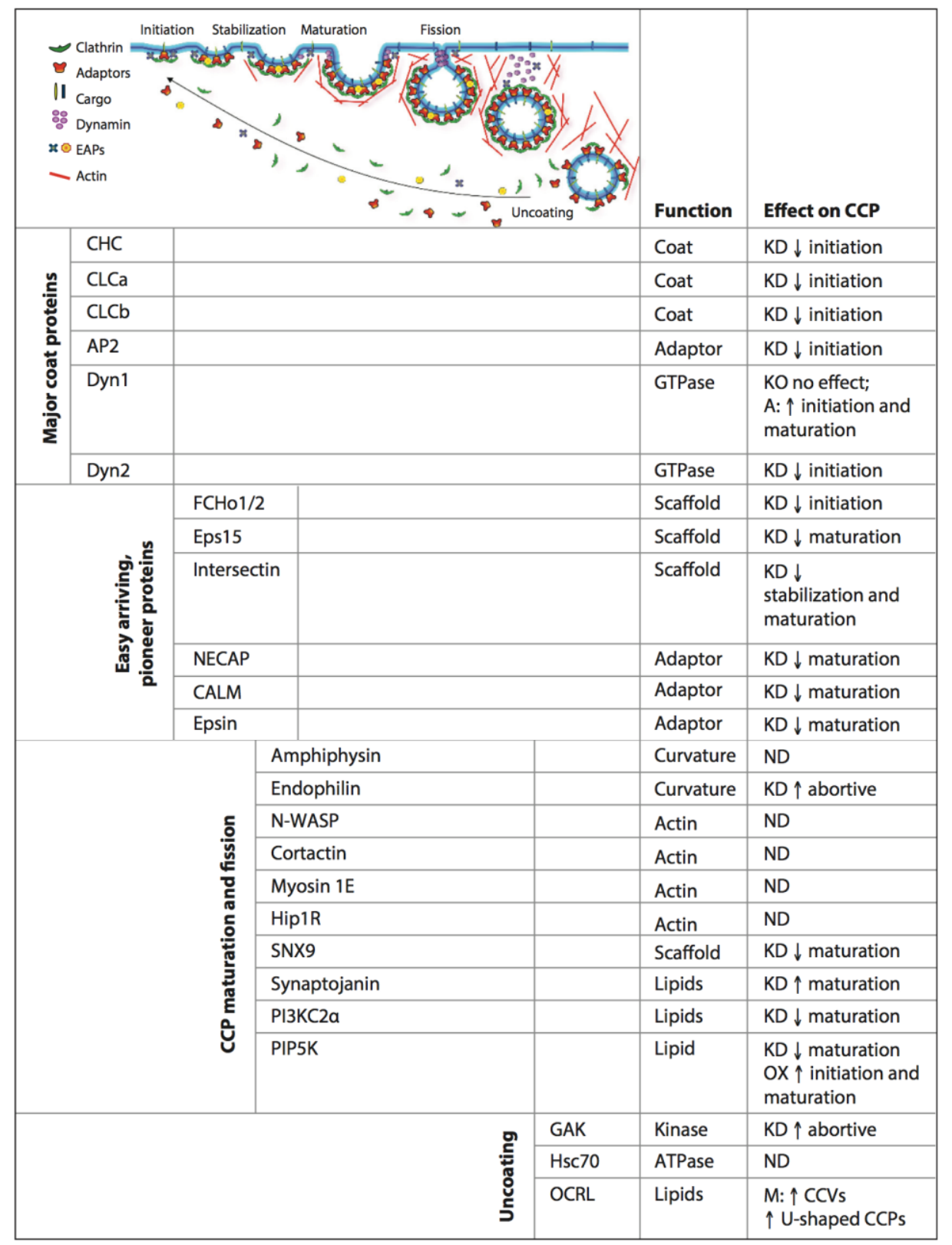

Table 1: List of proteins involved in CME and their effects on CCP and CCV formation. Table adapted from (Mettlen et al, 2018). Abbreviations used : A, activation; AP2, adaptor protein-2; CALM, clathrin assembly lymphoid myeloid leukemia; CCP, clathrin-coated pit; CHC, clathrin heavy chain; CLC, clathrin light chain; Dyn, dynamin; EAPs, endocytic accessory proteins; Eps15, EGF-receptor phosphorylation substrate; FCHo1/2, Fer/Cip4 homology domain-only proteins 1/2; GAK, cyclin G associated kinase; Hip1R, Huntingtin interacting protein-1 related; Hsc70, heat shock protein 70 kD; KD, knockdown; KO, knockout; M, mutation; ND, not determined; NECAP, adaptin-ear-binding coat-associated protein; N-WASP, neural Wiskott-Aldrich syndrome protein; OCRL, oculocerebrorenal Lowe syndrome protein; OX, overexpression; PI3KC2 $\alpha$, phosphatidylinositol 3-kinase C2 $\alpha$; PIP, phosphatidylinositol phosphate; SNX9, sorting nexin 9. 


\subsection{Uncoating of a CCV}

While many studies have investigated the CCV budding process using Total internal reflection fluorescent (TIRF) microscopy, not much is known about the regulation of the lifetime of a $\mathrm{CCV}$. CCVs are transported from the plasma membrane into the interior of the cell and thus, they move out of the field observed by TIRF microscopy. However, proteins taking part in the disassembly the CCV are known and their molecular mechanisms have been studied. There are two key mechanisms responsible for the uncoating of a CCV: dephosphorylation of PI-4,5$\mathrm{P}_{2}$ by $\mathrm{PIP}_{2}$ phosphatase, Synaptojanin-1, and the disassembly of clathrin basket by Hsc70 and its J-domain cochaperones, Auxilin1/2 (Kaksonen \& Roux, 2018).

\subsection{Hsc70 mediated CCV uncoating}

Hsc70 is an ATPase protein, which is involved in the uncoating mechanisms of a CCV. Rothman lab in 1984 (Braell, 1984; Schlossman, 1984) first reported that $\mathrm{Hsc70}$, an abundantly expressed protein is required to disassemble the CCV coat before its fusion to the target organelles. Hsc70 is recruited to the CCV by its cochaperones, Auxilin1/2. Auxilins have a clathrin basket binding domain and a J domain with which it binds to the carboxy-terminal of the clathrin-heavy-chain and to the Hsc70: ATP, respectively (Scheele et al, 2003). Auxilin 1, also binds to dynamin (Newmyer et al, 2003; Scheele et al, 2003) and thus, mostly recruited to the $\mathrm{CCV}$ at the time of scission, may contribute to the sequence of fission of vesicle followed by uncoating. There are two models proposed to explain the uncoating of CCV by Hsc70: Brownian/steric wedge model (Xing et al, 2009) and the wrecking ball model (Sousa et al, 2016)

The "Brownian/Steric Wedge" mechanism (Xing et al, 2009) (Figure 1.9), suggests that even in the absence of bound Hsc70 to the clathrin basket, the clathrin coat experiences constant fluctuations between the triskelia, but these fluctuations are never sufficient to lead to the disassembly of the clathrin basket. However, when Hsc70:ATP bind to the C-terminal tails of each CHC vertex, Hsc70 dissociates ATP and clamps firmly on $\mathrm{CHC}$, thus sterically blocking the reversal of these 
fluctuations in the clathrin basket. The blockade is increased with the increase in the accumulation of Hsc70, finally to the point where it results in the disassembly of the clathrin basket (Xing et al, 2009).

The "wrecking ball" model suggests that Hsc70 does not act as a passive, steric wedge that causes the disassembly of the clathrin basket. Hsc70 are bound to each vortex by the association of the flexible polypeptide tethers and such flexible tethers allow Hsc70 to generate a disassembling force through its collision to the walls of the clathrin coat (Sousa et al, 2016), thus disassembling the clathrin basket from inside. The wrecking ball model is the latest model.

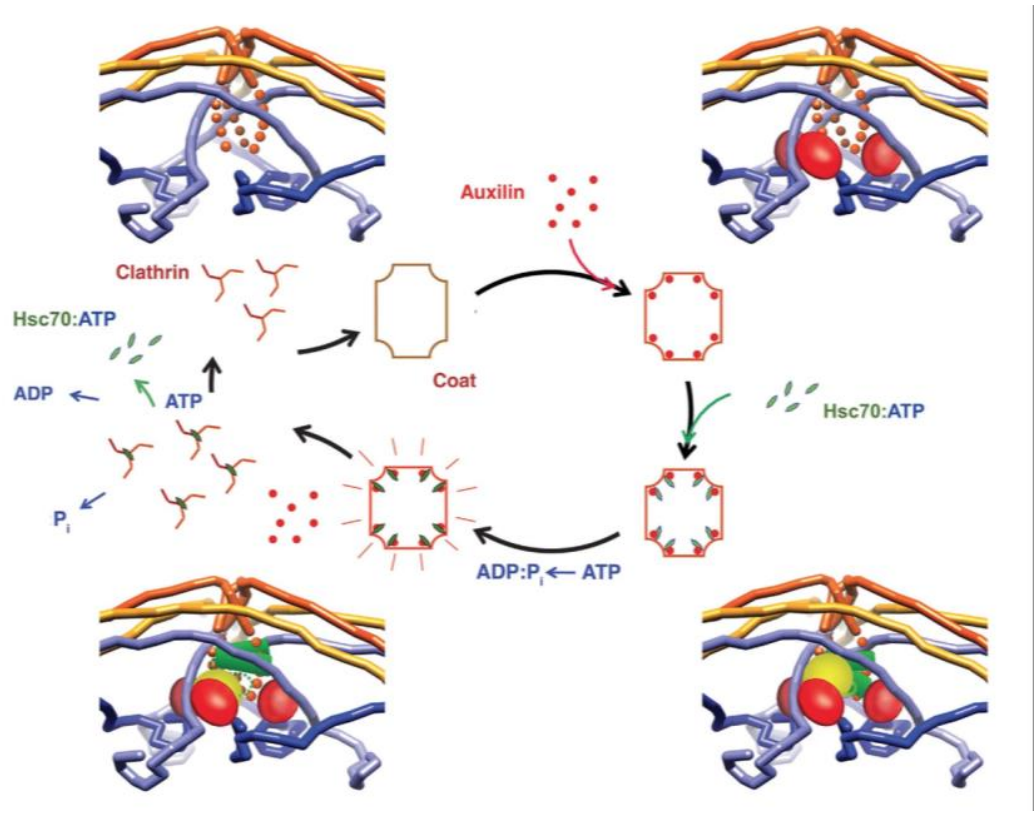

Figure. 1.9 Schematic representation for the uncoating mechanism mediated by Hsc70. Clockwise from upper left side representing the binding of Auxilin to the clathrin coat (red); Auxilin recruits Hsc70: ATP( ATPase domain: yellow, substrate binding domain: green); Hsc70 cleaves ATP and the substrate binding domain of Hsc70 clamps firmly onto a specific segment of C-terminal of clathrin heavy chain which further strains the clathrin lattice; enough number of Hsc70 bound with the vertices of clathrin basket generates enough pressure to dissociate the clathrin coat. Adapted from (Xing et al, 2009) 
Once the clathrin coat is disassembled, Hsc70 still remains associated with the clathrin triskelia and inhibits the polymerization of the clathrin, required for subsequent rounds of CCV formation (Schuermann et al, 2008). Thus, Hsc70 not only disassembles the clathrin coat, but it also chaperones the triskelia. Mutations in Hsc70 impair the clathrin polymerization and lead to defects in endocytosis (Newmyer \& Schmid, 2001). Therefore, the chaperoning activity of Hsc70 must be regulated, in order to release the Hsc70 from Hsc70:ADP: clathrin, for its requirement in endocytosis. Hsc70 nucleotide exchange factors (NEFs) are the class of proteins, which regulate the dissociation of Hsc70 from their protein substrates, by stimulating the release of ADP from Hsc70:ADP:substrate complex (Packschies et al, 1997). The release of ADP allows ATP to bind, which further stimulates the release of substrate from the otherwise stable substrate complex. HSP110 is the NEF critical for Hsc70 in the clathrin cycle (Sousa \& Lafer, 2015). Hsp110 is known to be phosphorylated at the serine residue by casein kinase II (CKII) or a kinase that has CKII-like specificity (Ishihara et al, 2000). Thus, the activity of CKII also plays a role in regulating the CCV uncoating mechanism mediated by Hsc70.

\subsection{PI-4,5-P2 dephosphorylation in CCV uncoating}

The AP2 requires PI-4,5- $\mathrm{P}_{2}$ on the membrane for its high-affinity binding. Thus, dephosphorylation of $\mathrm{PIP}_{2}$ helps in detachment of AP2 from the membrane and thus, it is an essential step in uncoating of a CCV (Perera et al, 2006). Dephosphorylation of PI-4,5-P $\mathrm{P}_{2}$ to PI-4-P and to PI is mediated by PI-4,5-P2 phosphatase Synaptojanin-1 (McPherson et al, 1996). Synaptojanin-1 has two isoforms, which differ in their C terminal domain: ubiquitous Synaptojanin-1 and brain-specific Synaptojanin 1 (Perera et al, 2006). Both Synaptojanins are rapidly recruited before the detachment of AP2 $\mathrm{CCV}$ from the membrane (Perera et al, 2006). The knock-out of the brain-specific Synaptojanin-1 encoding gene, Synj1 in mice, leads to the accumulation of coated synaptic vesicles as well as of PI-4,5-P2 in the neurons, suggesting that the role of Synaptojanin-1 is essential in uncoating of vesicles (Cremona et al, 1999). The role of Synaptojanin-1 in fibroblast cells also suggests that it plays an important role in clathrin-coated vesicle cycle, as the 
depletion of Synaptojanin-1 from the plasma membrane in the fibroblast cells depletes the available clathrin pool and completely stops the formation of clathrincoated pits (Zoncu et al, 2007). Furthermore, the disruption of PI-4,5-P 2 synthesis impairs the formation and trafficking of synaptic vesicles in the nerve terminals of mice (Paolo et al, 2004), suggesting the role of PI-4,5- $\mathrm{P}_{2}$ synthesis in the regulation of the synaptic vesicle cycle.

Apart from Synaptojanin, another PI-4,5- $\mathrm{P}_{2}$ phosphatase, inositol polyphosphate 5phosphatase OCRL1 (encoded by OCRL), was identified to be directly involved in clathrin-mediated endocytosis (CME) (Erdmann et al, 2007) and regulates protein trafficking between early endosomes and TGN (Choudhury et al, 2005). OCRL1 interacts directly with clathrin and AP2 and is assumed to act after dynaminmediated scission and participate in dephosphorylation of PI-4,5- $\mathrm{P}_{2}$ (Choudhury et al, 2005; Ungewickell et al, 2004). 


\subsection{Synapse and Synaptic Vesicle recycling}

Chemical synapses, the site of neuron-to-neuron signal transmission is formed between a 'pre-synapse', which releases the neurotransmitters, and the receiving target synapse is the 'post-synapse'. There is a gap between pre-and post-synapse called a 'synaptic cleft', into which the neurotransmitter molecules are released. The efficacy, with which the neurotransmitter molecules are transmitted between pre-post-synapse, is crucial for the function of the nervous system.

The neurotransmitters are packed in small $(\sim 50 \mathrm{~nm})$ round, seemingly identical organelles called as 'Synaptic Vesicles' (SV) (Mundigl \& De Camilli, 1994; Rizzoli, 2014). SV are specialized secretory organelles, which mediate fast and local signaling in the nerve cells. Neurotransmitters such as glutamate, $\gamma$ aminobutyric acid (GABA) and acetylcholine are filled in the SV (Mundigl \& De Camilli, 1994). At the pre-synaptic plasma membrane, the synaptic vesicles fuse at the specialized area called 'active zone' upon the stimulus received by the influx of $\mathrm{Ca}^{+2}$ ions, they release the neurotransmitter molecules (exocytosis) (Rizzoli, 2014). The synaptic vesicle protein Synaptotagmin1 (syt1), a well-known calcium sensor, binds incoming $\mathrm{Ca}^{+2}$ and release the block of the vesicle fusion (Hui et al, 2009). The released neurotransmitter molecules diffuse across the synaptic cleft and bind to the receptor of the post-synaptic membrane leading to the activation or inhibition of post-synaptic signaling events. Following exocytosis, the SV components are immediately retrieved from the plasma membrane to enable the reformation of SV for the subsequent round of exocytosis. In 1973, Heuser and Reese have suggested the term 'synaptic vesicle recycling' for this process of exocytosis and endocytosis, required for the release of neurotransmitter. Synaptic vesicle recycling mechanisms has been extensively studied since then and is one of the best-studied cellular pathways. Many of the proteins involved in synaptic vesicle recycling have been identified and their functions becoming clear over time. However, the complete understanding of the synaptic vesicle-recycling pathway as a whole is still difficult and is on the progressive side with the advancement of the latest research techniques.

The complete synaptic vesicle cycle is a complex process and involves the interaction of a number of proteins. The studies of the synaptic vesicle have 
revealed that one synaptic vesicle, contains about 1500-2000 neurotransmitter molecules and most of the SV proteins are present in multiple copy numbers per vesicle \{Takamori: 2006jz\}. Only few proteins, like synaptic vesicle 2-related protein (SV2) and the V-ATPase are present in only one or two copies in a single vesicle (Takamori et al, 2006). This study demonstrates the diversity of proteins contained in one single synaptic vesicle. The synaptic vesicle displays functional specializations, which demonstrates the existence of more than one type of synaptic vesicle pool in the pre-synaptic terminal. The ultrastructure studies of pre-and postsynaptic membranes have revealed the presence of clusters of synaptic vesicles in the pre-synaptic nerve terminal, which participate in the exo-and endocytosis cycle (Rizzoli, 2014; Truckenbrodt \& Rizzoli, 2014). The classical three-pool model, suggest that there are three different pools of SV: the readily releasable pool (1-2\% of all vesicles) which, provides fast initial neurotransmitter release, the recycling pool (10-20\%) that, maintains the neurotransmitter release during physiological levels of stimulations, and the reserve pool ( $>80 \%)$, which is inert in terms of neurotransmitter release under physiological stimulation protocols (Truckenbrodt \& Rizzoli, 2014; Rizzoli, 2014). The extent to which, the reserve pool participate in the neurotransmitter release during the sustained period of high-level activity is not clearly understood. However, the mobilization of the reserved pool could be controlled by the cell division protein kinase 5 (CDK5), in the mammalian cells (Kim \& Ryan, 2010). CDK5 is a kinase known for its function in the nervous system and is involved in post-synaptic signaling mechanism (Kim \& Ryan, 2010). The SV numbers and pool sizes are not dependent on the number of active zones and are almost similar in different glutamatergic synapses, like with 2 active zones in hippocampal synapse or 500-600 active zones in the calyx of Held (a large glutamatergic nerve terminal in the auditory pathway) (Neher, 2010). This demonstrates that the vesicle supply is not the limiting factor in the release of neurotransmitter, rather the availability of release site, is the limiting factor during sustained synaptic activity (Neher, 2010).

During the synaptic vesicle cycle (Figure. 1.10), the neurotransmitter-filled synaptic vesicles are docked and primed at the active zone (AZ). The binding of SV and AZ SNARE proteins, facilitates the priming of the synaptic vesicle. Before the fusion of synaptic vesicle, there is a coupling between Synaptobrevin (a synaptic 
vesicle transmembrane protein) and the plasma membrane SNARE protein, synaptosome-associated protein, SNAP25 (Haucke et al, 2011). The SNARE Syntaxin is also a part of the fusion controlling SNARE complex. The activity of the SNAREs is tightly regulated by the activity of two key proteins, Munc13 and Munc18, which are also involved in the priming of the SV. The neurotransmitter release is triggered by the influx of $\mathrm{Ca}^{+2}$, through the calcium channels located at the AZ.

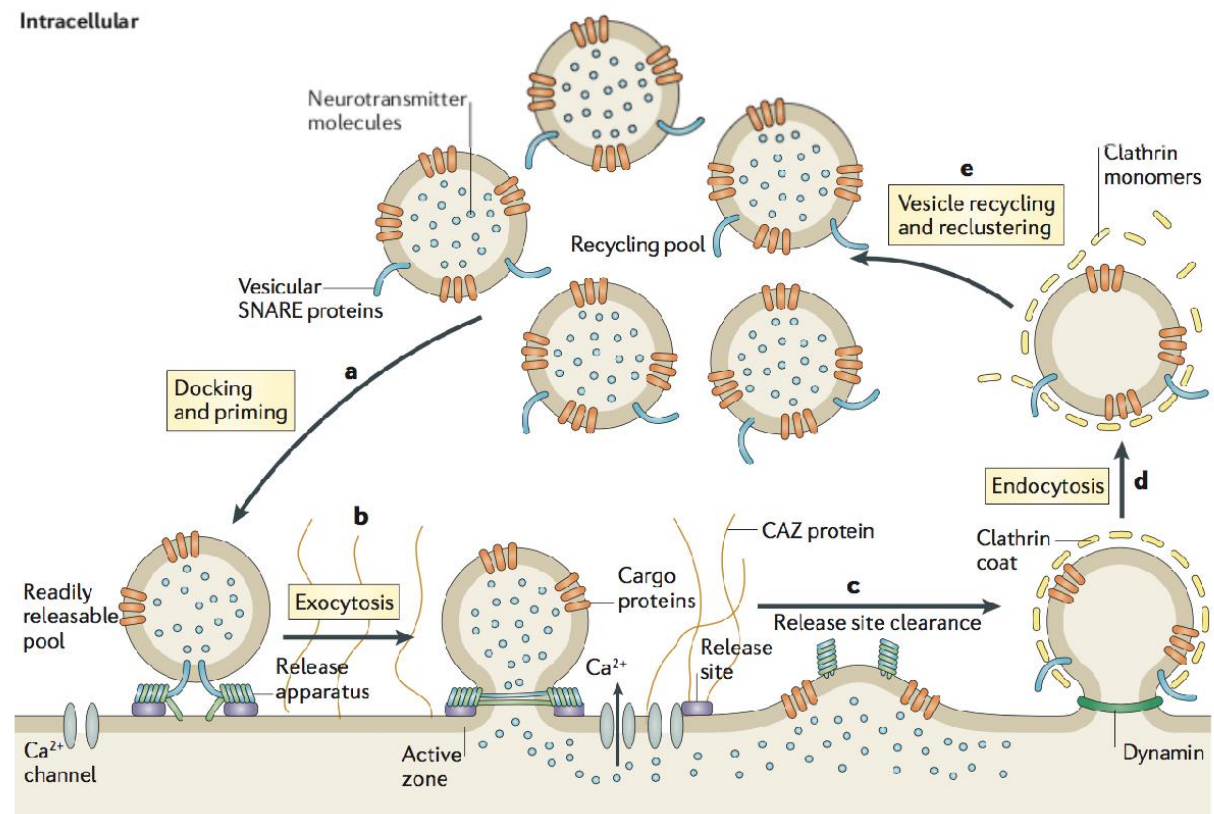

Figure 1.10 Illustration of synaptic vesicle cycle: a.) Synaptic vesicles (SV) from the readily accessible pool is docked and primed near the active zone, b.) Following $\mathrm{Ca}^{+2}$ influx, the SV undergo exocytosis and release the neurotransmitters. The exocytosis preferable occurs at the specialized area on the pre-synaptic membrane, known as 'active zone', characterized by the presence of $\mathrm{Ca}^{+2}$ channels and scaffolding proteins of the cytoplasmic matrix of active zone (CAZ), c.) After exocytosis, the SV proteins, as well as SV membranes, are endocytosed preferentially within the periactive zone that surrounds the active zone, $\mathbf{d}$.) Clathrin-mediated endocytosis by Adaptor Protein complex 2 and dynamin-dependent pathways predominantly mediate SV endocytosis, e.) Following clathrin uncoating and neurotransmitter uptake, the SV returns to the recycling pool for next round of exocytosis. Figure adapted from (Haucke et al, 2011).

The fusion of synaptic vesicles is induced by the steep rise in the levels of $\mathrm{Ca}^{+2}$, 
leading to the exocytosis of neurotransmitters. The vesicle protein, Synaptotagmin1 (syt1), senses the $\mathrm{Ca}^{+2}$ and bends the membrane during fusion of the vesicles (Hui et al, 2009). Many other important proteins regulate the fusion of the vesicles including the Rabs and complexins. Complexins are high affinity SNAREsbinding, synaptic proteins, which regulates the post-priming events during neurotransmitter release (Xue et al, 2007). A study done in the past suggests that Complexin I (CplxI) binding to the SNARE complex via its central $\alpha$ helix is necessary, but not sufficient alone for its function in the release of neurotransmitter (Xue et al, 2007). There is an accessory $\alpha$ helix, on the $\mathrm{N}$ terminal side of the SNARE complex-binding region of CplxI, which, has an inhibitory effect in the fast synaptic exocytosis. However, the sequences adjacent to this helix facilitate Calcium-dependent exocytosis, even in the absence of synaptotagmin-1. Thus, the distinct functional domains of Complexin I, regulate the synaptic exocytosis and play a key role in fine-tuning of the events during the fast release of neurotransmitters (Xue et al, 2007).

After the fusion of the membrane, the assembled SNARE complexes are disassembled and their components are resorted as per their destinations, in order to maintain the subsequent rounds of vesicle release. For example, Synaptobrevin is separated from its SNARE complex, sorted, translocated and then endocytosed. The disassembly of the SNARE complex is an energy-dependent procedure and requires the involvement of the specialized ATPase NSF and its adaptor protein, the $\alpha$-soluble NSF attachment protein ( $\alpha$-SNAP) (Galli \& Haucke, 2004; Südhof \& Rothman, 2009). Thus, these steps constitute the kinetic bottleneck and are the ratelimiting step for the efficiency of endo-exocytosis coupling in the synapse. Following the exocytosis of synaptic vesicle and the release of neurotransmitters, the SV proteins are endocytosed and are recycled for the next round of synaptic vesicle release (Südhof, 2004). 


\subsubsection{AP1 and AP2 in the synapse}

AP1 and AP2 functions are indispensable for the survival and embryonic development of mammals. Of all the AP1 knockout mice generated in our lab, only AP1/ $1 \mathrm{~B}$ mice were viable and fertile, but have severe defects pertaining to nervous system development and brain functions (see section 1.1.2.1.2 on AP1 complex) (Meyer et al., 2000; Glyvuk et al., 2010; Zizioli et al., 1999). This suggests the essential role of AP1 in embryonic survival as well as in brain development. In addition, the conditional AP2 knockouts demonstrate the indispensable functions of AP2 in neurons (Saheki \& De Camilli, 2012; Kononenko et al, 2014) (see section 1.1.2.1.1 on AP2 complex for details)

Vesicular protein transport is most active in synapses, the site of neuron-to-neuron signal transmission (see section 1.2 on synapse and synaptic vesicle recycling for details). While the 'post-synapse', a specialization of the dendrite of the neuron, is most active in signal transduction pathways, the pre-synapse is the site of highly active vesicular membrane trafficking. Pre-synapse is filled with the SV, which fuse upon neuron stimulation with the plasma membrane at the specialized, active zones, releasing neurotransmitters into the synaptic cleft, where they bind to their receptors on the post-synaptic membrane (see section 1.2 for the detailed steps of neurotransmitter release)

The synaptic vesicle has to be endocytosed to be reformed and refilled with the neurotransmitters to enable the synapse for multiple rounds of signal transmission. The AP2 functions in this pathway of synaptic vesicle endocytosis. Due to the high turnover of synaptic vesicles in the neurons, the nerve terminals have developed an efficient endocytic mechanism to recapture and reuse the SV. AP2 mediated CME plays a major role in the internalization of synaptic vesicle proteins and it has been suggested that SV could be derived directly from the uncoating of AP2 CCV (Saheki \& De Camilli, 2012; Kononenko et al, 2014). Kononenko, and colleagues (Kononenko et al, 2014) have demonstrated that AP2/clathrin, in addition to their role at the plasma membrane are also operational at the internal endosome like vacuoles, to regenerate synaptic vesicles but are not the only mechanism for membrane retrieval. 
They have demonstrated this by conditional knockouts of $\mu 2$ adaptin of AP2 complex.

In another study done in our lab, Kratzke and colleagues (Kratzke et al, 2014) have demonstrated evidence for SV recycling via AP2 CCV and via early endosomes. They have studied this mechanism in the of AP1/ $1 \mathrm{~B}-/$ - knockout mice, which have reduced synaptic vesicle recycling and increased endosome accumulation in the hippocampal synapses (Glyvuk et al, 2010; Kratzke et al, 2014). The accumulated endosomes were isolated by M. Kratzke and biochemically characterized. They were identified as phosphatidylinositol-3-phosphate (PI-3-P) positive classic early endosomes. The $\sigma 1 \mathrm{~B}$-deficiency induces alterations in synaptic vesicle protein numbers and their sorting into the endolysosomal pathway (Kratzke et al, 2014). There are certain proteins like tetraspanins, which are selectively enriched in $\sigma 1 \mathrm{~B}$ /- synaptosomes, but not in their endosome and or CCVs, suggesting AP1/ $/ \mathrm{B}-/-$

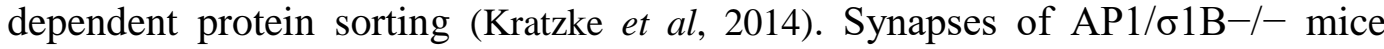
contain twice as much AP2 CCV compared to the wild-type, which is surprising as they contain less synaptic vesicles due to inefficient synaptic vesicle recycling. These AP2 CCV were also biochemically characterized and have a different coat composition suggesting altered CME (Kratzke et al, 2014). These data demonstrate a direct connection between AP2 mediated endocytosis and AP1/ $/ \mathrm{B}$-mediated SV reformation (Kratzke et al, 2014). 


\subsubsection{AP1/ $/ \mathrm{B}$ functions in synaptic vesicle recycling}

The $\sigma 1 \mathrm{~B}$ adaptin is encoded by $\sigma 1 \mathrm{~B}$ gene present on the $\mathrm{X}$-chromosome in mice and in humans. In order to study the specific function of $\sigma 1 \mathrm{~B}$ in the vesicular transport network, AP1/ $\sigma 1 \mathrm{~B}$ knockout mice were generated in the lab by a targeted mutation in the $\sigma 1 \mathrm{~B}$ locus. A genomic fragment of the X-chromosomal $\sigma 1 \mathrm{~B}$ locus was isolated, mutated, and introduced into the $129 \mathrm{SV} / \mathrm{J}$ mouse line and crossed with C57/B16 animals to generate the o1B-/- mouse model (Glyvuk et al, 2010).

Unlike the knockouts of other subunits of AP1, $\sigma 1 \mathrm{~B}$ knockout mice were viable and fertile, but the behavioral studies revealed that the knockout mice were hypoactive, have impaired motor coordination and learning and spatial memory is also perturbed (Glyvuk et al, 2010). Human studies have also revealed that patients suffering from severe X-linked mental retardation disease, have a premature stop codon in the $\sigma 1 \mathrm{~B}$ gene (Tarpey et al, 2006). The patients are hypoactive, have impaired motor coordination, learning and memory. They learn to walk at the age of 4-6 years and are not able to develop any intelligible language capabilities and require lifelong comprehensive care (Tarpey et al, 2006). Thus, $\sigma 1 \mathrm{~B}$ knockout mice are also the animal model to study X-linked mental retardation disorder.

Our mouse phenotypes suggest the involvement of $\sigma 1 \mathrm{~B}$ in the vesicular transport of synaptic proteins, which are responsible for brain function. Hippocampal synapses were studied in detail, because hippocampus is the site of memory formation and is associated with motor learning and coordination. The analysis of the hippocampal synapses revealed a slower and incomplete SV recycling rate and the accumulation of endocytic membranes (Figure 1.10) (Glyvuk et al, 2010). In the hippocampal synapse, SV recycling was measured after stimulation by 600 AP/10 $\mathrm{Hz}$ (AP: action potential; Hz: Hertz). Within the first 10s after stimulation, only $45 \%$ of the exocytosed material was retrieved in knockout synapses compared to 90\% in wild-type controls (Figure 1.10), demonstrating slower synaptic vesicle recycling (Glyvuk et al, 2010). In addition, SV recycling was incomplete, because only $70 \%$ of the SV were reformed by this altered recycling pathway (Glyvuk et al, 2010). 


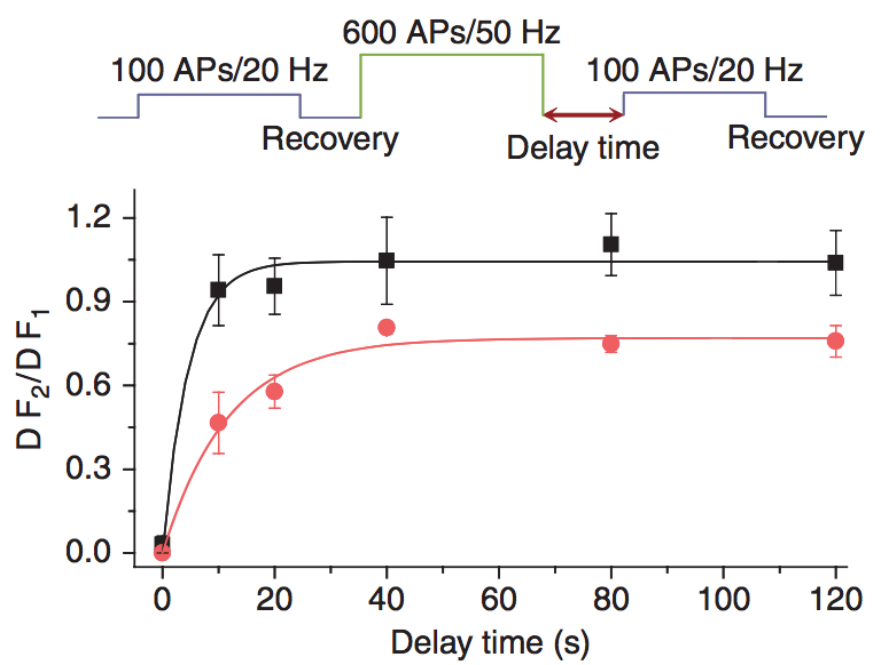

Fig. 1.10. Delayed SV re-priming after full depletion of the total recycling SV pool by $600 \mathrm{AP} / 50$ $\mathrm{Hz}$ stimulation. Within the first $10 \mathrm{~s}$ after stimulation, only $45 \%$ of the exocytosed material was retrieved compared with $90 \%$ in wild-type controls and only $70 \%$ SV were reformed (Adapted from (Glyvuk et al, 2010).

The morphological characterization of the hippocampal synapses by electron microscopy (Figure 1.11) revealed a decrease in the number of synaptic vesicles in the knockout synapse compared to the wild-type, in line with reduced synaptic vesicle recycling rate (Glyvuk et al, 2010). Surprisingly, there were accumulations of large endosomes and CCVs in the knockout synapse, despite of fewer synaptic vesicles and slower synaptic vesicle-recycling rate (Figure 1.11). 


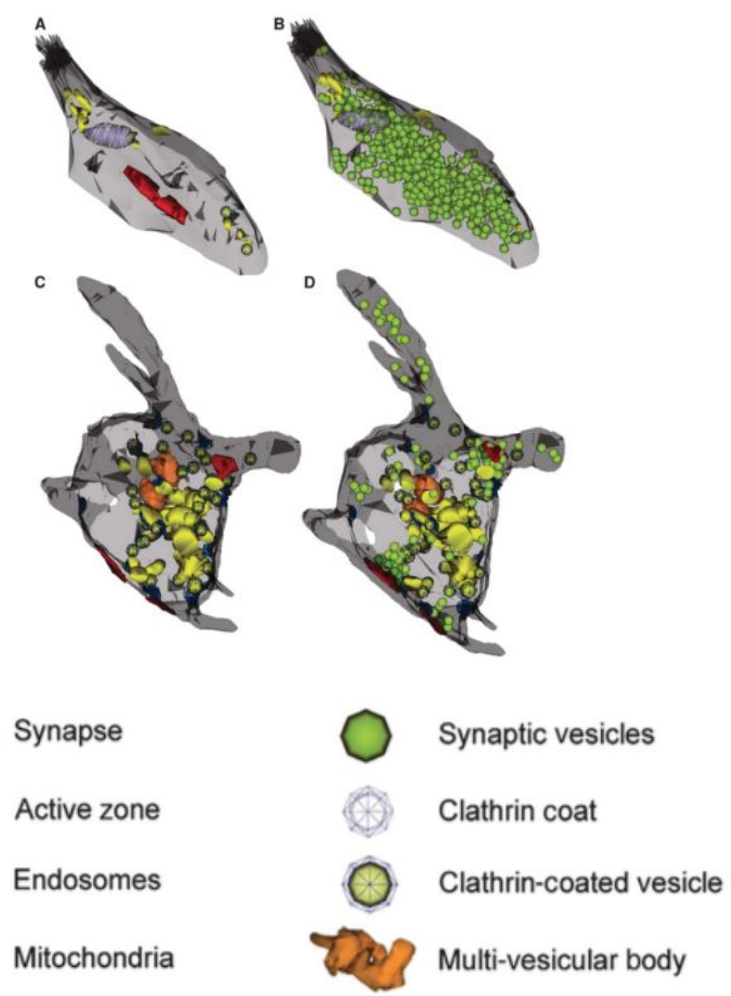

Figure.1.11 3D-reconstruction of electron microscopy images of synapses: $(\mathbf{A}, \mathbf{B})$ wild-type and $(\mathbf{C}$, D) AP1/ $\sigma 1 B$-deficient synapses. In (A) and (C) synaptic vesicles are excluded for clear visualization. Figure adapted from (Glyvuk et al, 2010) 


\subsubsection{Synaptic Plasticity and AP2 functions in the Synapse}

As discussed in section 1.2.2, the $\sigma 1 \mathrm{~B}$ knockout synapses have fewer synaptic vesicles and slower synaptic vesicle-recycling rate, however, they have an accumulation of large endosomes and AP2 CCV. The study done by Kratzke and colleagues in our lab, (Kratzke et al, 2014) developed a protocol to separate these accumulated endosomes from the majority of neuronal endosomes. The biochemical characterization of these accumulated endosomes revealed that they were actually classic early endosomes with an increase in phosphatidylinositol 3phosphate (PI-3-P), to which proteins bind, which mediate protein sorting out of

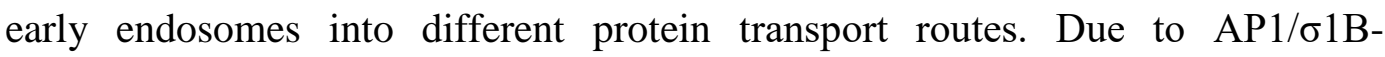
deficiency, there was an alteration in the endosomal protein-sorting pathway. About two-thirds of the synaptic vesicle proteins were reduced in the $\sigma 1 \mathrm{~B}-/$-synapse and the Multivesicular-body (MVB) pathway for degradation of proteins was upregulated, indicating that the majority of SV proteins are indeed degraded via this endolysosomal pathway.

Endosomal recycling pathways were not up-regulated, but specific SV proteins like tetraspanins were misrouted and accumulated in $\sigma 1 \mathrm{~B}$ knockout synaptosomes, but not in their endosomes or CCVs, indicating AP1/ $\sigma 1 \mathrm{~B}$ dependent protein sorting (Kratzke et al, 2014). The accumulated CCVs in the $\sigma 1 \mathrm{~B}$ knockout synapses were also biochemically characterized. These accumulated CCV were not nonfunctional/crippled AP1 CCV, as one would expect because of the missing $\sigma 1 \mathrm{~B}$ subunit of AP1, rather they were AP2 CCV (Kratzke et al, 2014). The increase in $\mathrm{AP} 2 \mathrm{CCV}$ in the AP1/ $\sigma 1 \mathrm{~B}-/-$ synapses is a secondary phenotype of $\sigma 1 \mathrm{~B}$ deficiency, suggesting a link between AP1 regulated protein sorting and exocytosis with AP2 regulated endocytosis. Thus, the characterization of hippocampal synapses not only revealed the function of $\mathrm{AP} 1 / \sigma 1 \mathrm{~B}$ in $\mathrm{SV}$ protein sorting in the synapse, but also in AP2 dependent CME. The accumulation of early endosomes and endocytotic AP2 $\mathrm{CCV}$ indicates the regulation of SV recycling via early endosomes and as well as by interdependent regulation of AP2 mediated endocytosis and AP1/ $\sigma 1 \mathrm{~B}$ mediated SV reformation. 


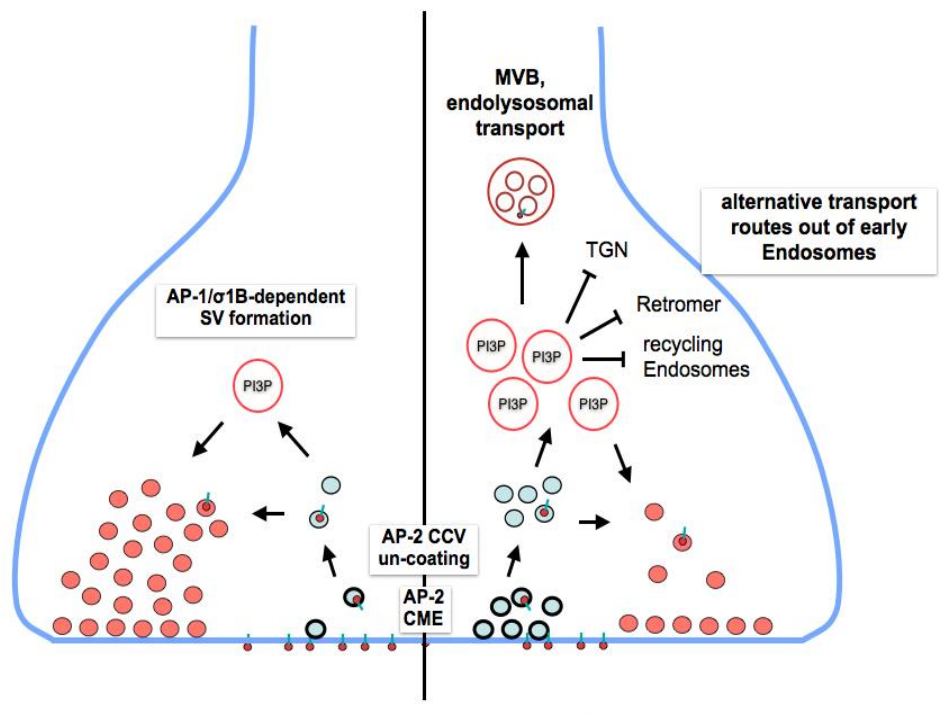

wt

AP-1/\%1B -/-

Figure 1.12. Scheme summarizing the alterations in SV protein trafficking in AP $1 / \sigma 1 B$ knockout synapses: The knockout synapses have fever SV, but shows an increase in endocytic AP2 CCV, and early endosome accumulation. Their maturation of early endosomes into late multi-vesicular-body endosomes is up-regulated, but other protein export routes out of early endosomes are not upregulated, suggesting that the degradation of the one-third of the synaptic vesicle proteins are mediated via endolysosomal pathway. Scheme adapted from (Kratzke et al, 2014). 


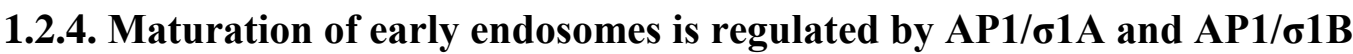

There are two isoforms of $\sigma 1$ adaptin and thus AP1 complexes expressed in the brain: $\mathrm{AP} 1 / \sigma 1 \mathrm{~A}$ and $\mathrm{AP} 1 / \sigma 1 \mathrm{~B}$, having $87 \%$ sequence homology. Both of the isoforms bind cargo proteins with di-leucine-based sorting motifs but sortilin is exclusively bound by o1B (Baltes et al, 2014; Poirier et al, 2013; Glyvuk et al, 2010). $\mathrm{AP} 1 / \sigma 1 \mathrm{~A}$ is essential in the development of brain, whereas $\sigma 1 \mathrm{~B}$ plays an important role in synaptic vesicle recycling (Glyvuk et al, 2010; Meyer et al, 2000; Kelly et al, 2008). Mutations in $\sigma 1 \mathrm{~A}$ in humans, cause defects in the development of skin and spinal cord and the patients die post-natally (Montpetit et al, 2008). $\sigma 1 \mathrm{~A}$ knock-out mice die in-utero and the few born, die perinatally (Schu, unpublished). Thus, $\mathrm{AP} 1 / \sigma 1 \mathrm{~A}$ and $\mathrm{AP} 1 / \sigma 1 \mathrm{~B}$ are required for the neuronal development and function.

In the $\sigma 1 \mathrm{~B}$ knockout synapses, there was an accumulation of early endosomes and of AP2 CCV (as discussed in section 1.2.3). The study done in our lab by Candiello

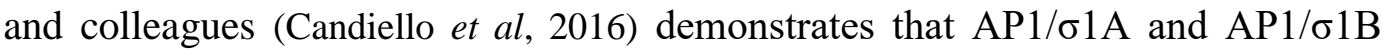
regulate the maturation of the accumulated early endosomes into multivesicular body (MVB) late endosomes, thereby controlling synaptic vesicle protein transport into a degradative pathway (Figure 1.13). The maturation of MVB is regulated by the formation of a tripartite complex made of AP1/ 1 A-ArfGAP1-Rabex5. ArfGAP1 is the GTPase, which activates Arf1GTP. There are two isoforms of ArfGAP 1 expressed in the brain: ubiquitous ArfGAP1 and brain-specific ArfGAP1. The tripartite complex formation is most efficient with brain-specific ArfGAP1. Rabex5 is a Rab5 GDP-GTP exchange factor. Rab5 activates Vps34, a PI 3-kinase (PI3KC3) (Stack et al, 1993) whose activity is essential for the formation of multivesicular body endosomes (Kratzke et al, 2014; Backer, 2008). Upon binding of $\sigma 1 \mathrm{~A}$, ArfGAP1 binds Rabex5 and form a stable AP1/o1A-ArfGAP1-Rabex5 complex, leading to more endosomal Rabex5. This enhances the Rab5GTPstimulated Vps34 PI3-kinase activity, which is essential for multivesicular body endosome formation. $\sigma 1 \mathrm{~B}$ binds Rabex 5 and inhibits AP1/ $\sigma 1 \mathrm{~A}-\mathrm{ArfGAP} 1-\mathrm{Rabex} 5$ complex formation thus, limiting the stable recruitment of Rabex5, further hindering the formation of MVB endosomes. Thus, AP1/ $\sigma 1 \mathrm{~A}$ and AP $1 / \sigma 1 \mathrm{~B}$ adaptor proteins differentially regulate the neuronal early endosome maturation into the multivesicular body via the Rab5/Vps34 pathway (Candiello et al, 2016). Also, in the 
Alzheimer's and Parkinson's diseases, the sorting of endosomal proteins are disturbed and thus the novel function of AP1 could be important for the understanding of the molecular mechanism of these diseases as well.

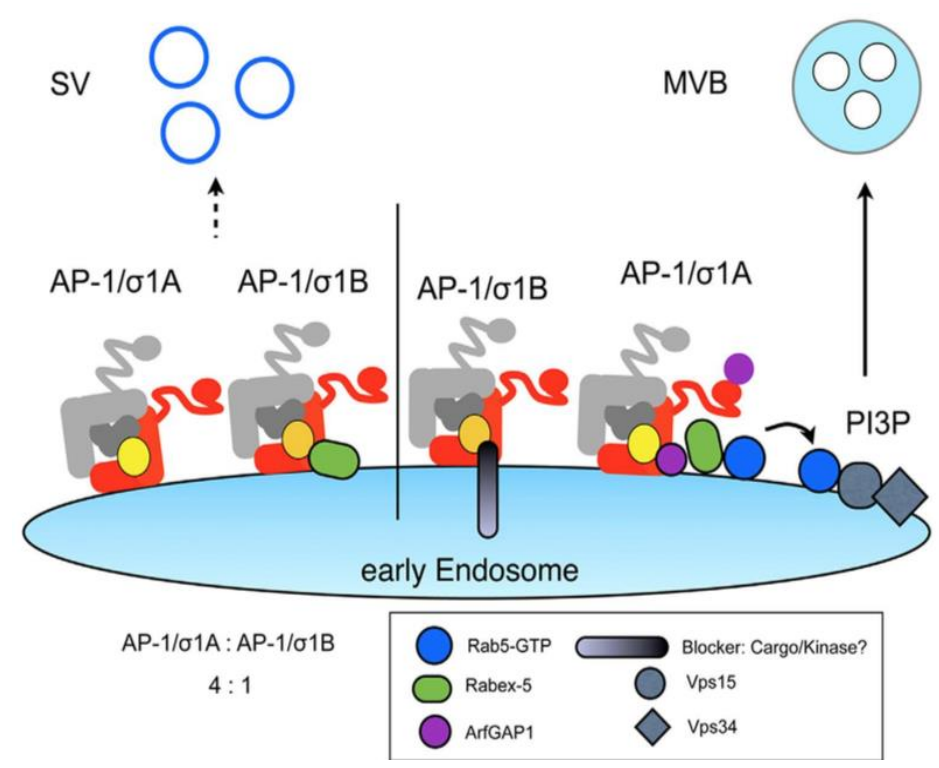

Figure 1.13. Model for $\mathrm{AP} 1 / \sigma 1 \mathrm{~A}$ and $\mathrm{AP} 1 / \sigma 1 \mathrm{~B}$ mediated regulation of $\mathrm{SV}$ protein degradation via the multivesicular body late endosome (MVB) pathway. The MVB maturation is upregulated by the

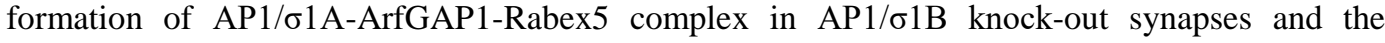
subsequent stimulation of the stable Rab5/Vps34 . Model adapted from (Candiello et al, 2016). 


\section{Aim of the study}

The aim of this study was to answer the questions stipulated by the phenotypes of

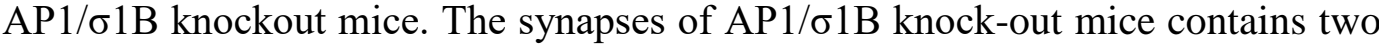
times more AP2 and endocytosis mediating AP2 CCV than wild-type synapses, despite of a slower synaptic vesicle recycling rate and fewer synaptic vesicles. In addition, it was not known whether these phenotypes are synapses specific, or whether they are a more general phenomenon of $\sigma 1 \mathrm{~B}$ deficiency.

The specific molecular mechanism for the accumulation of AP2 CCV has to be understood. The increase in AP2 CCV could be due to an increase in clathrinmediated endocytosis, or it could be due to the extended lifetime of the AP2 CCV, thus leading to an accumulation of AP2 CCVs. However, these mechanisms are not exclusive of each other and could operate at the same time. The aim of this project, was to identify a molecular mechanism responsible for the accumulation of AP2 CCVs and also of their functions in the AP1/ $1 \mathrm{~B}$-/- synapses. 


\section{Chapter 2: Material and Methods}

\subsection{Specific lab Equipments}

\begin{tabular}{|l|l|}
\hline Equipment & Manufacturer \\
\hline Sonicator 220F & Heat System ultrasonic, QC Canada \\
\hline Intelligent Dark Box II, LAS 100 & Fujifilm, Japan \\
\hline Gradient Station IP & Biocomp, Canada \\
\hline Confocal Scanning Microscope SP2 & Leica Bensheim, Germany \\
\hline UV-Visible Spectrometer (Varian Cary & Conquer Scientific, USA \\
\hline Western Blot unit & Bio-Rad, Germany \\
\hline SDS page Unit & Bio-Rad, Germany \\
\hline Standard Power Pack P25 & Biometra, Germany \\
\hline Cell homogenizer & Isobiotech, Germany \\
\hline Glass porter homogenizer & Wheaton, USA \\
\hline
\end{tabular}

\subsection{Chemical, buffers and solutions:}

All the buffers and solutions were prepared in Ultra-pure deionised water (Gen

Pure Recovered, TKM, Germany). 


\begin{tabular}{|c|c|}
\hline Solutions & Source \\
\hline $\begin{array}{l}\text { 2.2.1. Clathrin Coated Vesicle (CCV) Isolation } \\
\text { Buffer: }\end{array}$ & \\
\hline 10mM MES & AppliChem, Germany \\
\hline $0.5 \mathrm{mM}$ EGTA & Sigma, Germany \\
\hline $0.5 \mathrm{mM} \mathrm{MgCl} 2$ & Merck, Germany \\
\hline $320 \mathrm{mM}$ Sucrose & $\begin{array}{l}\text { Carl Roth GmbH, } \\
\text { Germany }\end{array}$ \\
\hline $1 \mathrm{mM} \mathrm{Na}_{3} \mathrm{VO}_{4}$ & Sigma, St. Louis, USA \\
\hline $10 \mathrm{mM} \mathrm{NaF}$ & Sigma, St. Louis, USA \\
\hline 10nM Calyculin A & Abcam, Cambridge, UK \\
\hline Protease Inhibitor Cocktail & Sigma, St. Louis, USA \\
\hline \multicolumn{2}{|l|}{ pH 6.4} \\
\hline $\begin{array}{l}\text { 2.2.2. SDS Poly-Acrylamide Gel Electrophoresis } \\
\text { (PAGE): }\end{array}$ & \\
\hline \multicolumn{2}{|l|}{ 2.2.2.1. Stacking gel Buffer: } \\
\hline $0.5 \mathrm{M}$ Tris/HCl & $\begin{array}{l}\text { Carl Roth GmbH, } \\
\text { Germany }\end{array}$ \\
\hline $0.4 \%(w / v)$ Sodium dodecyl sulfate (SDS) & $\begin{array}{l}\text { SERVA GmbH, } \\
\text { Germany }\end{array}$ \\
\hline \multicolumn{2}{|l|}{ pH 6.8} \\
\hline \multicolumn{2}{|l|}{ 2.2.2.2. Running gel Buffer: } \\
\hline $1.5 \mathrm{M}$ Tris/HCl & $\begin{array}{l}\text { Carl Roth GmbH, } \\
\text { Germany }\end{array}$ \\
\hline $0.4 \%$ (w/v) Sodium dodecyl sulfate (SDS) & $\begin{array}{l}\text { SERVA GmbH, } \\
\text { Germany }\end{array}$ \\
\hline \multicolumn{2}{|l|}{$\mathrm{pH} 8.8$} \\
\hline $\begin{array}{l}\text { 2.2.2.3. Rotiphorese®-Gel30: Acrylamide- } \\
\text { /Bisacrylamide }\end{array}$ & $\begin{array}{l}\text { Carl Roth GmbH, } \\
\text { Germany }\end{array}$ \\
\hline 2.2.2.4. APS: $10 \%(\mathrm{w} / \mathrm{v})$ Ammonium peroxodisulfate & Merck, Germany \\
\hline
\end{tabular}




\begin{tabular}{|c|c|}
\hline $\begin{array}{l}\text { 2.2.2.5. TEMED: } \mathrm{N}, \mathrm{N}, \mathrm{N}^{\prime}, \mathrm{N}^{\prime} \text { Tetramethyl } \\
\text { ethylenediamine }\end{array}$ & $\begin{array}{l}\text { SERVA GmbH, } \\
\text { Germany }\end{array}$ \\
\hline \multicolumn{2}{|l|}{ 2.2.2.6. Running Buffer: } \\
\hline 50mM Tris & $\begin{array}{l}\text { Carl Roth GmbH, } \\
\text { Germany }\end{array}$ \\
\hline 400mM Glycine & $\begin{array}{l}\text { Carl Roth GmbH, } \\
\text { Germany }\end{array}$ \\
\hline $0.1 \%(w / v)$ Sodium Dodecyl Sulfate & $\begin{array}{l}\text { SERVA GmbH, } \\
\text { Germany }\end{array}$ \\
\hline \multicolumn{2}{|l|}{ pH 8.6} \\
\hline \multicolumn{2}{|l|}{ 2.2.2.7. 6x reducing sample buffer: } \\
\hline 750mM Tris/HCl & $\begin{array}{l}\text { Carl Roth GmbH, } \\
\text { Germany }\end{array}$ \\
\hline $9 \%(w / v)$ Sodium Dodecyl Sulfate & $\begin{array}{l}\text { SERVA GmbH, } \\
\text { Germany }\end{array}$ \\
\hline 1\% (v/v) Bromophenol blue & Merck, Germany \\
\hline $60 \%(\mathrm{v} / \mathrm{v})$ Glycerol & Sigma-Aldrich, Germany \\
\hline $50 \mathrm{mM}$ DTT & AppliChem, Germany \\
\hline \multicolumn{2}{|l|}{ pH 6.8} \\
\hline \multicolumn{2}{|l|}{ 2.2.2.8. Protein molecular weight marker: } \\
\hline $\begin{array}{l}\text { Precision Plus Protein Standard All Blue (250kDa- } \\
\text { 10kDa), catalog\#1610372 }\end{array}$ & Bio-Rad, Germany \\
\hline 2.2.2.9. Nitrocellulose membrane & $\begin{array}{l}\text { GE healthcare, } \\
\text { Netherland }\end{array}$ \\
\hline \multicolumn{2}{|l|}{ 2.2.3. Semi-Dry Western Blots: } \\
\hline \multicolumn{2}{|l|}{ 2.2.3.1. Anode Buffer: } \\
\hline $75 \mathrm{mM}$ Tris/HCl & $\begin{array}{l}\text { Carl Roth GmbH, } \\
\text { Germany }\end{array}$ \\
\hline $20 \%$ Methanol & AppliChem, Germany \\
\hline pH 7.4 & \\
\hline
\end{tabular}




\begin{tabular}{|c|c|}
\hline 2.2.3.2. Cathode Buffer: & \\
\hline 40mM Aminocaproic Acid & $\begin{array}{l}\text { Carl Roth GmbH, } \\
\text { Germany }\end{array}$ \\
\hline 20mM Tris/HCl & $\begin{array}{l}\text { Carl Roth GmbH, } \\
\text { Germany }\end{array}$ \\
\hline $20 \%$ Methanol & AppliChem, Germany \\
\hline \multicolumn{2}{|l|}{ pH 9.0} \\
\hline \multicolumn{2}{|l|}{ 2.2.3.3. TBS (Tris-buffered saline): } \\
\hline $100 \mathrm{mM}$ Tris/HCl & $\begin{array}{l}\text { Carl Roth GmbH, } \\
\text { Germany }\end{array}$ \\
\hline $100 \mathrm{mM} \mathrm{NaCl}$ & AppliChem, Germany \\
\hline \multicolumn{2}{|l|}{ pH 7.5} \\
\hline \multicolumn{2}{|l|}{ 2.2.3.4. TBST (Tris buffered saline with Tween 20) } \\
\hline 100mM Tris/HCl & $\begin{array}{l}\text { Carl Roth GmbH, } \\
\text { Germany }\end{array}$ \\
\hline $100 \mathrm{mM} \mathrm{NaCl}$ & AppliChem, Germany \\
\hline $0.05 \%$ Tween 20 & AppliChem, Germany \\
\hline \multicolumn{2}{|l|}{ pH 7.5} \\
\hline \multicolumn{2}{|l|}{ 2.2.3.5. Blocking Solution } \\
\hline $5 \%$ Skimmed milk powder in TBST & $\begin{array}{l}\text { Ferma Reform, GmbH, } \\
\text { Germany }\end{array}$ \\
\hline \multicolumn{2}{|l|}{ 2.2.3.6. Chemiluminescence ECL kit } \\
\hline SuperSignal West Pico Plus chemiluminescent Substrate & Thermo Scientific, USA \\
\hline $\begin{array}{l}\text { SuperSignal West Femto Plus chemiluminescent } \\
\text { Substrate }\end{array}$ & Thermo Scientific, USA \\
\hline SuperSignal West Dura Plus chemiluminescent Substrate & Thermo Scientific, USA \\
\hline \multicolumn{2}{|l|}{ 2.2.3.7. Stripping Buffer (for 1L) } \\
\hline $15 \%$ Glycine & $\begin{array}{l}\text { Carl Roth GmbH, } \\
\text { Germany }\end{array}$ \\
\hline $1 \% \mathrm{SDS}$ & $\begin{array}{l}\text { SERVA GmbH, } \\
\text { Germany }\end{array}$ \\
\hline $0.1 \%$ Tween 20 & AppliChem, Germany \\
\hline
\end{tabular}




\begin{tabular}{|c|c|}
\hline pH 2.2 & \\
\hline 2.2.4. MEF Cell Culture Media and Solutions: & \\
\hline 2.2.4.1. PBS (Phosphate-buffered saline): & \\
\hline $140 \mathrm{mM} \mathrm{NaCl}$ & AppliChem, Germany \\
\hline $2.5 \mathrm{mM} \mathrm{KCl}$ & $\begin{array}{l}\text { Carl Roth GmbH, } \\
\text { Germany }\end{array}$ \\
\hline $6.5 \mathrm{mM} \mathrm{Na}_{2} \mathrm{HPO}_{4}$ & $\begin{array}{l}\text { Carl Roth GmbH, } \\
\text { Germany }\end{array}$ \\
\hline $1.5 \mathrm{mM} \mathrm{KH}_{2} \mathrm{PO}_{4}$ & $\begin{array}{l}\text { Carl Roth GmbH, } \\
\text { Germany }\end{array}$ \\
\hline pH 7.4 & \\
\hline 2.2.4.2. Trypsin-EDTA Solution: & \\
\hline $0.5 \mathrm{~g} / \mathrm{L}$ Trypsin & $\begin{array}{l}\text { Gibco Invitrogen, } \\
\text { Germany }\end{array}$ \\
\hline $0.2 \mathrm{~g} / \mathrm{L}$ EDTA & $\begin{array}{l}\text { Gibco Invitrogen, } \\
\text { Germany }\end{array}$ \\
\hline 2.2.4.3. Growth Medium: & \\
\hline 4.5 g/L Dulbecco’s Modified Eagle Medium (DMEM) & $\begin{array}{l}\text { Gibco Invitrogen, } \\
\text { Germany }\end{array}$ \\
\hline 10\%(v/v) Fetal Calf Serum (FCS) & PAN, Germany \\
\hline 1\%(v/v) Penicillin/Streptomycin (100x Stock solution) & $\begin{array}{l}\text { Gibco Invitrogen, } \\
\text { Germany }\end{array}$ \\
\hline $1 \%(\mathrm{v} / \mathrm{v})$ Glutamine (200mM, 100x Stock solution) & $\begin{array}{l}\text { Gibco Invitrogen, } \\
\text { Germany }\end{array}$ \\
\hline 2.2.4.4. Freezing Medium: & \\
\hline 4.5 g/L Dulbecco’s Modified Eagle Medium (DMEM) & $\begin{array}{l}\text { Gibco Invitrogen, } \\
\text { Germany }\end{array}$ \\
\hline 10\%(v/v) Fetal Calf Serum (FCS) & PAN, Germany \\
\hline 5\%(v/v) Dimethyl sulfoxide & Fluka, Germany \\
\hline 1\%(v/v) Penicillin/Streptomycin (100x Stock solution) & $\begin{array}{l}\text { Gibco Invitrogen, } \\
\text { Germany }\end{array}$ \\
\hline
\end{tabular}




\subsection{Protein extract preparations}

\subsubsection{Preparation of protein extracts from murine brain cortices}

The wild-type and knockout murine brains were excised and flash froze in liquid Nitrogen $\left(-196^{\circ} \mathrm{C}\right)$ and stored at $-80^{\circ} \mathrm{C}$ until the experiment. The knockout and wild-type cortices preparations were always done in parallel on the same day to take into account any differences based on sample preparation. On the day of the experiment, one brain at a time was thawed on ice, cerebellum with brain stem was removed and cerebral cortex was sliced with a scalpel in $1.5 \mathrm{ml}$ of CCV buffer (see section 2.2.1). The sliced cortex was transferred to a glass porter and was homogenized with "Loose Piston" until no visible pieces of tissue sample were observed, followed by "tight Piston" until reduced resistance was felt. The homogenized cortices were centrifuged at 1000x g for 10 minutes; supernatant (S1) was separated and stored in an Eppendorf and pellet (P1) was resuspended in $1 \mathrm{ml}$ of CCV buffer and centrifuged again at 1000x g for 10 minutes. The supernatant (S2) was isolated and combined with S1; pellet (P2) was discarded. The combined supernatant (S1+ S2) contains proteins from brain cortex. The protein concentrations of the extracts prepared was determined by Bradford Assay (see section 2.5.1) and were biochemically characterized by semi-quantitative western blot analysis (see section 2.5.2).

\section{3.2. Isolation of synaptosomes from brain cortex extracts}

The brain cortex extracts were prepared as described in section 2.3.1 and the synaptosomes were separated from the whole brain cortex by differential centrifugation. The cortex extract $(\mathrm{S} 1+\mathrm{S} 2)$ was centrifuged at 9200x g for 15 minutes; the supernatant was discarded and the pellet was resuspended in $1.5 \mathrm{ml}$ of $\mathrm{CCV}$ buffer and centrifuged at 10200x g for 15 minutes. The supernatant was discarded and the pellet containing synaptosomes was resuspended in $700 \mu \mathrm{l}$ of $\mathrm{CCV}$ buffer and stored for further biochemical characterization. 


\subsubsection{Isolation of synaptic Clathrin-coated vesicles}

Clathrin-coated vesicles (CCVs) were isolated from synaptosomes prepared in section 2.3.2. The Clathrin coat of a CCV is not a sturdy coat and easily dissociates at physiological $\mathrm{pH}$. Therefore, a slightly acidic $\mathrm{pH}$ of 6.4 in $\mathrm{CCV}$ buffer (see section 2.2.1) aids in the isolation of CCV. The synaptosomes were homogenized with a ball homogenizer (Isobiotec, Heidelberg, Germany) with a clearance of 12 $\mu \mathrm{m}$ by 40 passages; the homogenized synaptosomes were transferred to Beckmann Eppendorf cups and centrifuged at 25000x g in the ultracentrifuge (Beckman Ultramax, Rotor type: TLA55) for 20 minutes. The supernatant was discarded and the pellet was resuspended in $550 \mu 1$ of $\mathrm{CCV}$ buffer and the protein concentration was determined by Bradford assay (see section 2.5.1. The optimal protein concentration should be in the range of $2-3 \mu \mathrm{g} / \mu \mathrm{l}$, for the isolation of Clathrin-coated vesicles (CCVs) on the sucrose gradient.

The synaptic CCVs were purified on 20-50\% continuous sucrose gradient. Fresh sucrose solution of 50\% and 20\% were prepared separately in CCV buffer and were chilled on ice prior to use. In SW60 Ti rotor tubes (4 ml), $1.75 \mathrm{ml}$ of ice-cold $50 \%$ sucrose solution was added followed by $1.75 \mathrm{ml}$ of ice-cold $20 \%$ sucrose solution. The 20-50\% continuous gradient was prepared by using Gradient Station IP, Biocomp, Canada. $500 \mu 1$ of synaptosomes extract was added on top of the gradient and centrifuged in swing bucket rotor (SW $60 \mathrm{Ti}$ ) at $33000 \mathrm{rpm}$ for 1.5 hours at $4^{\circ} \mathrm{C}$. The gradient of $4 \mathrm{ml}$ in total was fractionated into 10 fractions of $400 \mu 1$ each, and ccv distribution was determined by semi-quantitative western blot analysis using anti-CHC antibody.

\subsubsection{Immunoisolation of a sub-fraction of synaptic Clathrin Coated Vesicles}

CCVs were purified from synaptosomes on the sucrose gradient as described in section 2.3.2. A subpopulation of the total CCVs fractions was immunoisolated with the help of Hsc70 antibody. Hsc70 is a Clathrin basket disassembly protein, which is guided to the Clathrin disassembly site by its co-chaperones, Auxillin 1/2. At the basket disassembly site, Hsc70 undergoes ATP-ADP cycle and generates pressure from inside the basket thereby, disassembling the Clathrin coat (Sousa et $a l, 2016)$. However, Hsc70 has additional binding sites on the Clathrin coat, where 
it binds in a comparably more stable and promiscuously way, if not guided to its basket disassembly site (Sousa et al, 2016). So, if there would be a different association of Hsc70 to the Clathrin basket, then it would be possible to isolate those CCVs with anti-Hsc70 mouse monoclonal antibody (Synaptic Systems, Göttingen, Germany) and Protein G Sepharose 4 Fast Flow beads (GE Healthcare, Uppsala, Sweden). Protein G Sepharose beads bind to the Fc region of Hsc70 antibody and enable the isolation of antibody bound proteins.

\section{Pre-clearing of CCV fractions (optional)}

Protein G Sepharose beads are suspended in $20 \%$ ethanol for preservation which needs to be removed before the experiment. $50 \mu 1$ of Protein G slurry was washed three times with CCV buffer (see section 2.1.1) to remove ethanol from the beads slurry. The washed beads were added to the pooled CCV fractions 6-9, with peak fraction of either 7 or 8 (refer section 2.3.3 for CCV preparation) and incubated at $4^{\circ} \mathrm{C}$ for 1 hour on end over end wheel. The beads were spun down at $2000 \mathrm{rpm}$ for 30 seconds; the supernatant was used for immunoisolation of the sub-population of the CCV and beads were discarded.

The CCV fractions with/without preclearing (fraction 6-9 with peak fraction of either 7 or 8) were incubated with $5 \mu \mathrm{g}$ of anti-Hsc70 antibody on end-over-end wheel at $4^{\circ} \mathrm{C}$, overnight. $60 \mu \mathrm{l}$ of Protein G Sepharose beads were washed three times with CCV buffer and added to the antiHsc70 conjugated CCV fraction, incubated for 3 hours or overnight at $4^{\circ} \mathrm{C}$ on endover end-wheel. The beads were isolated by centrifugation at $2000 \mathrm{rpm}$ for 30 seconds and were washed five times with CCV buffer. $60 \mu 1$ of 3x SDS loading buffer (see section 2.2.2.4) was added to the beads, mixed and incubated at $90^{\circ} \mathrm{C}$ for 5 minutes; the beads were spun down at $2000 \mathrm{rpm} 30$ seconds and the supernatant was isolated as Elution 1; likewise, Elution 2 was isolated. Elution 1, Elution 2 and the beads were loaded on Poly-acrylamide gel and analyzed by semiquantitative western blot as described in section 2.5.2. 


\subsubsection{Isolation of proteins from adipose tissue}

The wild-type and knockout adipose tissue were isolated and flash froze in liquid Nitrogen $\left(-196^{\circ} \mathrm{C}\right)$ and stored at $-80^{\circ} \mathrm{C}$ until the experiment. The knockout and wild-type adipose tissue preparations were always done in parallel on the same day to take into account any differences based on sample preparation. On the day of the experiment, adipose tissue was thawed on ice and sliced with a scalpel in $1.5 \mathrm{ml}$ of PBS buffer with proteinase inhibitor cocktail. The sliced cortex was transferred to a glass porter and was homogenized with "Loose Piston" until no visible pieces of tissue sample were observed, followed by "tight Piston" until reduced resistance was felt. The homogenized adipose tissues were centrifuged at 1000x g for 10 minutes; the supernatant was transferred to a new Eppendorf with a $22 \mathrm{G}$ needle. It is important to take the supernatant carefully, by avoiding the fat layer accumulated at the top. Pass the supernatant with a 22G needle, 10-15 times; centrifuge at 3300x $\mathrm{g}$ for $10 \mathrm{~min}$. The supernatant was isolated and the pellet was discarded. The protein concentrations of the extracts were determined by Bradford Assay (see section 2.5.1) and were biochemically characterized by semi-quantitative western blot analysis (see section 2.5.2). 


\section{4. Mouse Embryonic Fibroblast Cells Culture}

Mouse embryonic fibroblasts (MEFs) cell lines derived from isogenic wildtype and $\sigma 1 \mathrm{~B}-/-, \mu 1 \mathrm{~A}-/-$ mice were used.

\begin{tabular}{|c|c|c|}
\hline MEF Cell lines & Description & References \\
\hline S1B111 D5 MEF & $\sigma 1 \mathrm{~B}+/+$ & (Glyvuk et al, 2010) \\
\hline S1B111 E8 MEF & $\sigma 1 \mathrm{~B}-/-$ & (Glyvuk et al, 2010) \\
\hline 24A MEF & $\mu 1 \mathrm{~A}-/-:: \mu 1 \mathrm{~A}$ cDNA & (Meyer et al, 2000) \\
\hline $24 \mathrm{MEF}$ & $\mu 1 \mathrm{~A}-/-$ & (Meyer et al, 2000) \\
\hline
\end{tabular}

\subsubsection{Thawing of the MEF cells:}

MEF cells were stored in liquid Nitrogen for long-term storage as described in section 2.4.4. The frozen cells were taken out of liquid nitrogen and the vials were thawed in $70 \%$ ethanol at $37^{\circ} \mathrm{C}$ to get rid of any contaminants on the vials. Thawed cells were cultured and maintained by passaging as described in section 2.4 .2 and 2.4.3.

\subsubsection{Culturing of the MEF cells:}

Frozen cells were thawed as described in section 2.4.1. The cells were preserved in freezing media for long-term storage, and in order to remove the freezing media, $10 \mathrm{ml}$ of pre-warmed DMEM growth media (see section 2.2.4.3) was added to the thawed cells and centrifuged at 300x g for 10 minutes. The supernatant was removed and the pellet containing the cells were resuspended in $5 \mathrm{ml}$ of fresh DMEM media and were seeded on the sterile tissue culture flask $\left(25 \mathrm{~cm}^{2}\right)$; additional $10 \mathrm{ml}$ of fresh media was added in the flask and incubated under water saturation atmosphere at $37^{\circ} \mathrm{C}$ and $5 \%(\mathrm{v} / \mathrm{v}) \mathrm{CO}_{2}$. The MEF cells are adherent cells and grow at the bottom of the flask. The growth and adherence of the cells were checked after two hours. The cells were allowed to grow until confluent (2-3 days). 


\subsubsection{Maintenance of the MEF cells culture}

The cells were grown until confluent as described in section 2.4.2 and were passaged after the culture flask becomes confluent. The cell culture media from the confluent plates were removed and the cells were washed with PBS three times. 0.5 $\mathrm{ml}$ of Trypsin-EDTA (see section 2.2.4.2) was added and incubated for 5 minutes at $37^{\circ} \mathrm{C}$, to detach the adherent cells growing on the bottom of the flask. $4.5 \mathrm{ml}$ of fresh pre-warmed DMEM media was added to resuspend the cells. $500 \mu 1$ of the resuspended cells were added to the new tissue culture flask with $4.5 \mathrm{ml}$ of DMEM media to have a split ratio of $1: 10$. The cells were incubated at $37^{\circ} \mathrm{C}$ and $5 \%(\mathrm{v} / \mathrm{v})$ $\mathrm{CO}_{2}$ until confluent.

\subsubsection{Long-term storage of MEF cells}

For long-term storage, the cells were stored in liquid Nitrogen $\left(-196^{\circ} \mathrm{C}\right)$. For this purpose, the cells were grown until confluent and detached from the bottom of the flask as described in section 2.4.3. The cells were centrifuged at 300x g for 5 minutes at room temperature; supernatant was removed and the pellet was resuspended in $1 \mathrm{ml}$ of freezing media (see section 2.2.4.4) containing dimethyl sulfoxide (DMSO). DMSO in the freezing media is used to avoid the formation of ice crystals when freezing the cells in liquid Nitrogen. Aliquots of $250 \mu 1$ were prepared in $1 \mathrm{ml}$ cryotubes, stored at $-20^{\circ} \mathrm{C}$ for three hours, and eventually moved to liquid Nitrogen.

\subsubsection{Protein extraction from MEF cells:}

MEF cells were grown until confluent as described in section 2.4.2. The confluent cells were washed with PBS three times. $1 \mathrm{ml}$ of PBS was added and the cells were scrapped with a cells scraper and were added to $2 \mathrm{ml}$ eppendorf tubes. The cells were centrifuged at 200x g for 10 minutes; supernatant was removed and the pellet was washed with lysing buffer (PBS pH 7.4, Proteinase Inhibitor Cocktail, Sigma, St. Louis, USA) and centrifuged at $200 \mathrm{x}$ g for 5 minutes at $4^{\circ} \mathrm{C}$. The supernatant was removed and the pellet was resuspended in $2 \mathrm{ml}$ of fresh lysing buffer and homogenized by passing the suspension through a $22 \mathrm{G}$ needle. The protein 
concentrations were determined by Bradford assay (section 2.5.1) and were further analyzed by semi-quantitative western blot (section 2.5.2). 


\subsection{Biochemical analysis of protein extracts:}

\subsubsection{Protein concentration determination by Bradford Assay:}

Bradford Assay was used to determine the total protein concentrations in the tissue and in the cell lysates. 200 $\mu 1$ of 5x Bradford reagent (Bio-Rad, Germany) was mixed with $800 \mu 1$ of water in an eppendorf tube, and $4 \mu 1$ of protein sample was added to the mixture. The reaction mixture was incubated for 5 minutes, transferred to UV spectroscopy cuvette and absorbance was measured at $595 \mathrm{~nm}$. Bradford reagent $(1 \mathrm{x})$ without protein sample served as blank. The protein concentration of the samples was calculated from the BSA standard reference curve generated by measuring the known concentrations of BSA (Bovine serum albumin). BSA standard curve was made by measuring BSA $(1 \mathrm{mg} / \mathrm{ml})$ in the range of $2-16 \mu \mathrm{g}$ at $595 \mathrm{~nm}$.

\subsubsection{Semi-quantitative western blot analysis:}

\subsubsection{SDS Poly-Acrylamide Gel Electrophoresis:}

Sodium Dodecyl Sulfate Polyacrylamide gel electrophoresis (SDS-PAGE) was performed according to the standard protocol established by (Laemmli, 1970). SDSPAGE is a commonly used biochemical method to separate proteins according to their molecular mass: by the differential rate of migration of proteins through the matrix (polyacrylamide gel). This method is based on the principle that a charged molecule moves towards its opposite charge electrode under a constant electric field. Sodium Dodecyl Sulfate (SDS) is an amphipathic surfactant molecule with an anionic head group and a 12carbon tail attached to the anionic head group. SDS denatures and linearizes the proteins by binding to the amino acid chain with its hydrocarbon tail. The SDS imparts an overall negative charge to the proteins so that the migration is based upon their size and not on their charge. The protein samples were also boiled in the presence of reducing agents as DTT (dithiothreitol) or BME

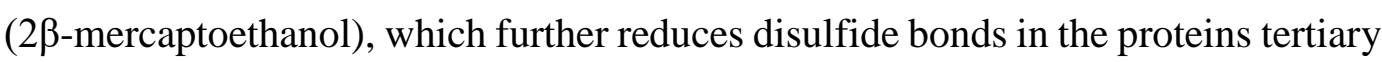


structure and linearize, the proteins (see section 2.2.2 for the composition of buffers and solutions used.)

The matrix for the separation of proteins was made of polyacrylamide (acrylamide/bisacrylamide) as it is inert in nature and could be easily made at different concentrations for variable pore size. The polymerization of acrylamide/bisacrylamide takes place by free radical mechanism initiated by Ammonium peroxodisulfate (APS) in the presence of $\mathrm{N}, \mathrm{N}, \mathrm{N}^{\prime}, \mathrm{N}^{\prime}-$ Tetramethylethylene-1,2-diamine (TEMED). Tris- $\mathrm{HCl}$ buffer was used for $\mathrm{pH}$ adjustment. The polyacrylamide gel was prepared in between two glass plates. The dimensions of the gel were $55 \mathrm{~mm}$ x $85 \mathrm{~mm}$. The gel was divided into two parts, upper "stacking gel" and the lower one "running gel". The stacking gel has a low concentration of acrylamide/bisacrylamide and low $\mathrm{pH}$ of 6.8 . The running gel has $\mathrm{pH}$ of 8.8 and acrylamide concentration ranging from $5 \%$ to $12.5 \%$ depending upon the size of the proteins to be separated (10\% is optimum for proteins ranging from $100 \mathrm{kDa}$ to $25 \mathrm{kDa}$ ). The running gel is prepared first and poured between the glass plates; covered with ethanol to avoid the contact with oxygen for the polymerization of the gel. Polymerization takes approximately 15-20 minutes. After the running gel has polymerized completely, ethanol was removed and stacking gel was poured and the comb was inserted. The polyacrylamide gel was run in glycine buffer with pH 8.3.

Protein samples $(40 \mu \mathrm{l})$ were mixed with $8 \mu \mathrm{l}$ of with $6 \mathrm{x}$ reducing buffer (see section 2.1.2) and fresh DTT $(50 \mathrm{mM})$ and boiled at $95^{\circ} \mathrm{C}$ for 5 minutes. After the protein samples reached room temperature, it was loaded in the gel pockets along with the standard protein ladder of known molecular weight for reference. A constant current of $15 \mathrm{~mA}$ was applied until the protein sample reached running gel part; subsequently, the current was increased to $30 \mathrm{~mA}$ and the gel was allowed to run till the samples reach the end of the running gel (around 50-60 minutes).

\subsubsection{Semi-dry western blot:}


The proteins were separated by SDS-PAGE as described in section 2.5.2. The separated proteins were transferred from the gel to a support membrane made of nitrocellulose (Amersham Protran 0.45 micron, GE Healthcare, Germany) for further analysis by Immunostaining. A transfer sandwich was prepared as shown in Fig. 2.1 to transfer the proteins from the gel to the membrane. Transfer sandwich consisted of three filter papers (Filter paper $330 \mathrm{~g} / \mathrm{m}^{2}$, Sartorius Stedim Biotech GmbH, Göttingen), nitrocellulose membrane and polyacrylamide gel without stacking part, soaked in anode buffer (see section 2.1.3) and three filter papers soaked in cathode buffer (see section 2.1.3). The transfer of the proteins was done at a constant electric field of $1 \mathrm{~mA} / \mathrm{mm}^{2}$ (dimensions of the gel $55 \mathrm{~mm} \times 85 \mathrm{~mm}$ ) for 30 minutes to 120 minutes depending upon the size of the proteins to be transferred. The proteins with molecular mass of 20-25 kDa required 30 minutes of transfer time while 200-250 kDa proteins required 120 minutes.

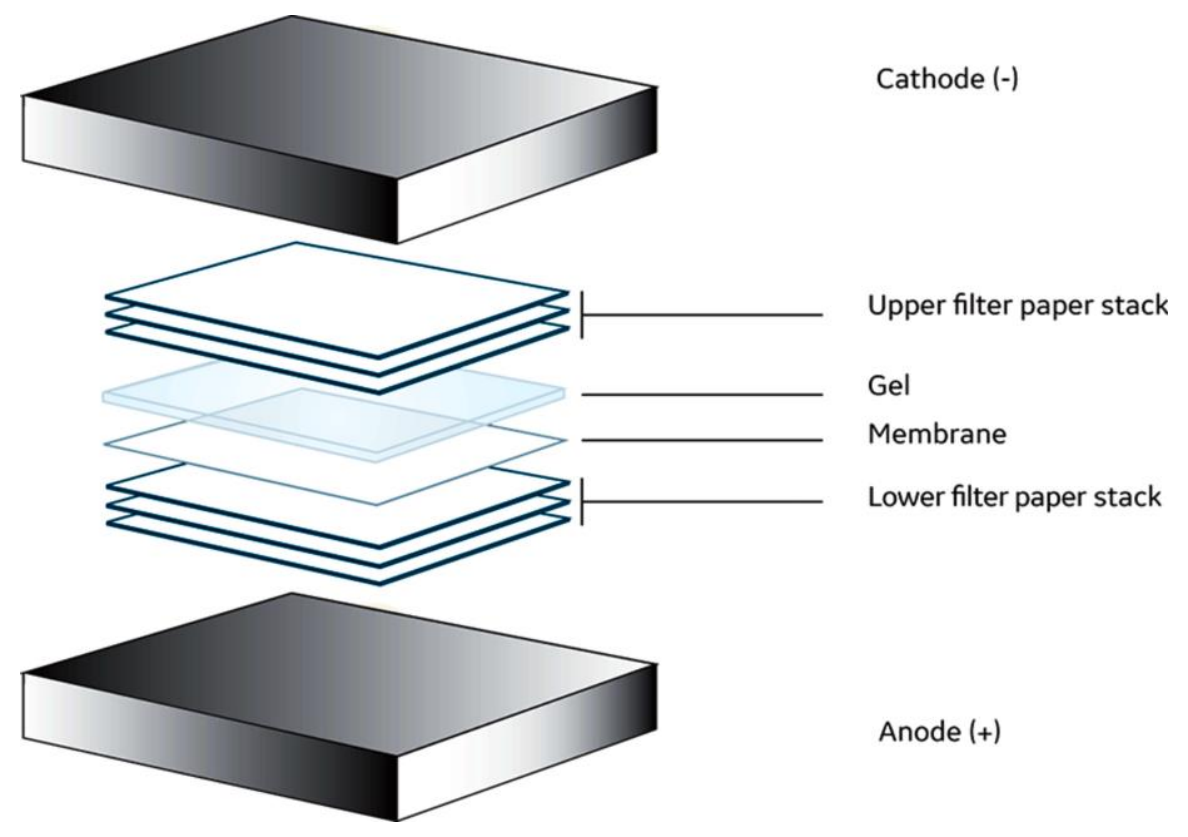

Figure 1.2 Semi-dry western blot transfer sandwich: The transfer sandwich was assembled as shown. The flow of proteins takes from cathode to anode as the proteins extracted are negatively charged imparted by SDS. (Figure adapted from GE healthcare website) 


\subsubsection{Immunostaining of proteins bound to the nitrocellulose membrane}

The proteins in the tissue/cell extracts were separated and transferred to the nitrocellulose membrane as described in section 2.5.2.1 and 2.5.2.2, respectively. The proteins on the membrane were detected by specific primary antibody followed by an appropriate secondary antibody. The membrane was incubated in blocking solution ( $5 \%$ skimmed milk in TBST) for 1 hour at room temperature with gentle shaking. Primary antibody was diluted to the desired concentration in blocking solution and the membrane was incubated overnight at $4^{\circ} \mathrm{C}$ with gentle shaking. Primary antibody was removed and can be reused for up to 6-8 times; the membrane was washed with blocking solution, three times 10-15 minutes each and incubated with appropriate HRP (Horse Radish Peroxide) coupled secondary antibody in blocking solution (1:10000) for 1 hour at room temperature with gentle shaking. The secondary antibody was removed; the membrane was washed with TBST (see section 2.1.3), three times for 10-15 minutes. The membrane was incubated in chemiluminescent substrate solution (see section 2.1.3) for 5 minutes and imaged by Intelligent Dark Box II camera (Fuji Film, Japan)

\subsubsection{Stripping of nitrocellulose membrane}

The proteins on the nitrocellulose membrane were detected by immunostaining as described in section 2.5.2.3. The membrane was reused for probing with different antibodies by removing the primary and secondary antibody under the mild condition to minimize any loss of proteins. The membrane was incubated in Glycine stripping buffer, pH 2 (glycine, SDS, tween 20, see section 2.2.3.7) for 10 minutes at room temperature with gentle shaking; washed with PBS (see section 2.1.3) twice for 10 minutes followed by washing with TBST twice for 10 minutes. The membrane was then ready for Immunostaining as described in section 2.5.2.3. 


\subsubsection{Primary antibodies}

\begin{tabular}{|l|l|l|l|l|}
\hline Antibody & Epitope & Species & Source & Dilution \\
\hline Amphiphysin & aa 2-15 & Rabbit & Synaptic System & $1: 1000$ \\
\hline Arf6 & $\begin{array}{l}\text { peptide aa 150 C- } \\
\text { ter }\end{array}$ & Rabbit & Abcam 77581 & $1: 1000$ \\
\hline Endophilin A1 & mouse aa 256-276 & Rabbit & SYSY 159 002 & $1: 1000$ \\
\hline Git 1 & $\begin{array}{l}\text { Rat aa 375-770 C- } \\
\text { ter }\end{array}$ & Mouse & $\begin{array}{l}\text { Acris AM60013 } \\
\text { PU-N }\end{array}$ & $1: 1000$ \\
\hline Hsc70 & aa 391-546 & Mouse & SYSY 149 011 & $1: 1000$ \\
\hline Hsp110 & Haster aa703-858 & Mouse & BD 610510 & $1: 1000$ \\
\hline Hsp90 $\alpha$ & Human peptide & Rabbit & Bioss bs-10100R & $1: 100$ \\
\hline Intersectin-1 & mouse aa 800-909 & Mouse & BD 611574 & $1: 500$ \\
\hline LRRK2 & $\begin{array}{l}\text { Human aa 2500- } \\
2527\end{array}$ & Rabbit & NB300-268 & $1: 1000$ \\
\hline $\begin{array}{l}\text { SGIP1 } \\
\text { human aa 1-30 }\end{array}$ & Rabbit & $\begin{array}{l}\text { Acris } \\
\text { AP53888PU-N }\end{array}$ & $1: 500$ \\
\hline $\begin{array}{l}\text { Synaptojanin-1 } \\
\text { splice variant }\end{array}$ & aa 1140-1155 & Rabbit & SySy 145 103 & $1: 1000$ \\
\hline Synaptojanin-1 & aa $38-255$ & Mouse & BD 610502 & $1: 2000$ \\
\hline
\end{tabular}




\section{Chapter 3: Results}

\subsection{Altered AP1 and AP2 mediated protein transport in $\sigma 1 \mathrm{~B}-/-$ synapses}

The AP1/ $/ 1 \mathrm{~B}-/-$ mice are hypoactive and have defects in motor coordination and have impaired spatial learning and memory (Glyvuk et al, 2010) (As described in section 1.3.2). Since the hippocampus is the site of learning and memory formation, the hippocampal synapses from wild-type and knockout mice were analyzed by electron microscopy to study the underlying neurological changes (Glyvuk et al, 2010). This analysis of hippocampal synapses has revealed that $\sigma 1 \mathrm{~B}$ knockout mice have a slower synaptic vesicle-recycling rate than the wild-type mice. Moreover, the synaptic vesicle recycling is incomplete and only $70 \%$ of the synaptic vesicles are reformed. Surprisingly, $\sigma 1 \mathrm{~B}-/-$ synapses have an accumulation of endosomes and clathrin-coated vesicles (CCVs) in the synapses, which was not as expected, given the slower rate of synaptic vesicle recycling and fewer synaptic vesicles in the $\sigma 1 \mathrm{~B}-/-$ synapses. Accordingly, one would expect also fewer CCVs mediating endocytosis (Glyvuk et al, 2010) (See section 1.3.2 for details). Subsequently, a protocol for the isolation of the accumulated endosomes was developed and they were biochemically characterized. The accumulated endosomes were PI3P positive early endosomes and not the 'bulk endosomes' generated by the endocytosis of the large plasma membrane domains. The early endosomes sort proteins into different endocytic routes, and of all the possible exit routes for proteins out of early endosomes, only the multivesicular body endosome (MVB), endolysosomal degradation pathway is up-regulated, possibly degrading almost about one-third of the synaptic vesicle proteins (Kratzke et al, 2014). In the brain, two isoforms of the AP1 complex are being expressed: one with the brain-specific $\sigma 1 \mathrm{~B}$ subunit

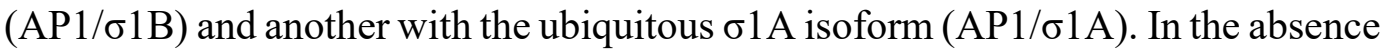

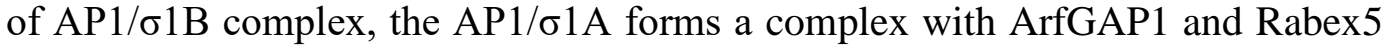
on these early endosomes and enhances their maturation into multivesicular late endosomes via the Rab5/Vps34 pathway (Candiello et al, 2016) (see section 1.3.4, for detailed molecular mechanism). 
In order to study the molecular details for the accumulation of CCVs, synaptic $\mathrm{CCVs}$ were isolated on a sucrose gradient and were biochemically characterized. The sample preparations from the brain were critical for the analysis, and few important steps were always taken care of. The synapses and CCVs fractions were prepared from wild-type and $\sigma 1 \mathrm{~B}-/-$ mice brains, always in parallel. It was important that the brains were isolated in the late afternoon only after the mice facility staffs leave, so that the nocturnal animals have some time to relax and thus should have comparable neuronal activities. The biochemical characterizations were done by semi-quantitative western-blot analysis, and the protein levels of knockout samples were compared to the wild-type (wild-type $=100 \%$ ) samples prepared on the same day in parallel. More than one protein was detected on one western-blot membrane in order to have internal controls for the loaded protein amounts. The data from at least three biologically independent samples were analyzed and plotted as a box-plot diagram to represent the complete set of data and a statistical analysis, as the box-plot also represents the median of the complete data set.

\subsubsection{AP2 CCV accumulation in the AP1/б1B-/- synapses}

The biochemical characterization of the accumulated CCV in the $\sigma 1 \mathrm{~B}-/-$ synapses revealed that they were not non-functional AP1 CCV, as one would expect due to the one missing subunit of an AP1 complex, but they were AP2 CCV. The amount of AP2 CCV in the synapse is almost doubled in the $\sigma 1 \mathrm{~B}-/-$ synapses compared to wild-type synapses. However, the amount of AP1 CCV is reduced in the $\sigma 1 \mathrm{~B}-/-$ synapses compared to wild-type (Kratzke et al, 2014). This increase in the AP2 $\mathrm{CCV}$ was not expected given the slower synaptic vesicle recycling rate and less synaptic vesicles in the $\sigma 1 \mathrm{~B}-/$ - synapses. During normal stimulation, AP2 CCVs are formed at the pre-synaptic plasma membrane, whereas, in the case of high stimulations, synaptic vesicle are endocytosed by fast endocytosis, in which plasma membrane is first internalized by actin-mediated endocytosis to form plasma membrane vacuoles, and then AP2 forms CCV from those vacuoles (Soykan et al, 2016), (Soykan et al, 2017), (González-Gaitán \& Jäckle, 1997). Thus, the reduced synaptic vesicle-recycling rate in the $\sigma 1 \mathrm{~B}$ knockout synapse does not explain the accumulation of AP2 CCV. The increase in AP2 CCV could be due either due to 
an increase in clathrin-mediated endocytosis of non-synaptic vesicle proteins like scaffolding proteins, ion channels or receptors, or due to the slow uncoating of the AP2 CCV coat and thus an extended lifetime, leading to the accumulation of AP2 $\mathrm{CCV}$. However, these two possibilities are not exclusive of each other and could operate in parallel. On the other hand, it is not clear whether this accumulation of AP2 CCV is specific for the synapse or whether it is a general phenotype of $\sigma 1 \mathrm{~B}$ deficiency.

\subsubsection{AP2 CCV accumulation is synapse specific in AP1/б1B-/- mice}

Besides the neuronal phenotype, adipose tissues in AP1/ $\sigma 1 \mathrm{~B}-/-$ mice also have a lipodystrophy (Baltes et al, 2014). The AP1/o1B-/- mice weigh less than the wildtype mice and have comparative lower adipose tissue volumes in the body. The biochemical characterization of the adipocytes revealed that they overexpress sortilin. In the 3T3L1 adipocyte model cell line, over-expression of sortilin is sufficient to suppress adipogenesis (Baltes et al, 2014). Sortilin is a neurotrophin binding-receptor and it is enriched in the glucose transporter GLUT4 storage vesicles in adipocytes (Lin et al, 1997; Morris et al, 1998). In the $\sigma 1 \mathrm{~B}-/$ - adipocyte cells, the GLUT4 expression, and serum glucose homeostasis was normal despite the over-expression of sortilin, which suggests the existence of adipocyte-specific, GLUT4 independent functions of sortilin in the adipocyte cells.

The $\sigma 1 \mathrm{~B}-/-$ binding of sortilin is mediated by a specific binding motif on sortilin, which is not bound by $\sigma 1 \mathrm{~A}$. The deficiency of $\sigma 1 \mathrm{~B}$ does not completely block the transport of sortilin out of an organelle, rather its transport to the lysosomes is reduced (Baltes et al, 2014). Sortilin binds DLK1 receptors, an inhibitor of latestage adipocyte differentiation. In the $\sigma 1 \mathrm{~B}$ deficient mice adipocyte cells, sortilin is over-expressed and this over-expression of sortilin prevents the down-regulation of DLK1, leading to the enhanced inhibition of adipocyte differentiation (Baltes et al, 2014). The brain is the tissue with the highest expression of $\sigma 1 \mathrm{~B}$ and sortilin. However, the sortilin is not overexpressed in the $\sigma 1 \mathrm{~B}-/-$ brain, suggesting that adipocyte-specific $\sigma 1 \mathrm{~B}$ dependent routes exist for the transport of sortilin (Baltes et $a l, 2014)$. 
In the brain of $\sigma 1 \mathrm{~B}-/-$ mice, we have observed an accumulation of AP2 CCV, despite the slow synaptic vesicle-recycling rate and fewer synaptic vesicles. In order to understand, whether this phenotype is specific to the brain, I have analyzed the adipocyte cells from wt and $\sigma 1 \mathrm{~B}-/-$ mice for the expression of AP1 and AP2 (Figure 3.1). The adipocytes from wild-type and $\sigma 1 \mathrm{~B}-/-$ mice were isolated and analyzed for AP1 and AP2 expression levels by semi-quantitative western-blot analysis. The AP1 expression levels in these adipocytes were slightly increased by $20 \%$ and the AP2 level was also increased by $10 \%$, but not doubled as in case of the synapses. In the synapse, we have an increase to $170 \%$ of wild-type levels in AP2 (Kratzke et al, 2014). However, I could not isolate CCVs from these adipocytes, as the adipocytes have comparatively less amount of proteins with respect to their volume, thus making it difficult to isolate enough CCVs on sucrose gradient from the adipocytes (data not shown). Thus, the accumulation of AP2 CCV in the synapse of the $\sigma 1 \mathrm{~B}-/-$ mice is a brain-specific transport route mediated by AP1 and AP2 CCVs and not a general phenotype pertaining to the deficiency of AP1/ $1 \mathrm{~B}$.

A

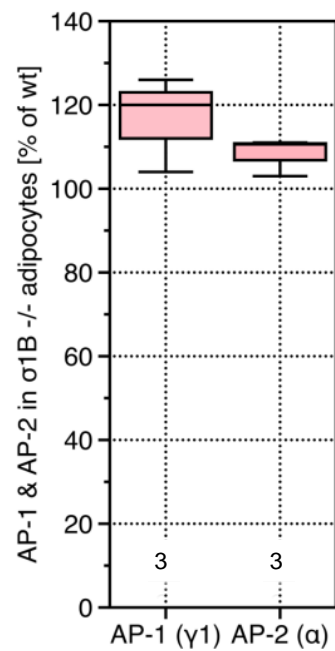

B

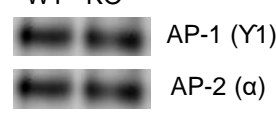

Figure 3.1 (A) Comparison of the levels of the all AP1 complexes by detecting AP $1 / \gamma 1$ and all AP2 complexes by detecting AP2 $/ \alpha$ in the adipocytes of wild-type ( $\mathrm{wt}=100 \%)$ and $\sigma 1 \mathrm{~B}-/-$ mice. The numbers in the box represent the number of biological independent samples analyzed. (B) Representative semi-quantitative western-blots of the analysis AP1 and AP2 comparison done in A.. This result is published, hence figure adapted and modified from (Zizioli et al, 2017)

\subsection{Existence of stabilized AP2 CCV in $\sigma 1 B-/-$ synapses}


AP2 CCV accumulates in the $\sigma 1 \mathrm{~B}-/-$ synapses as described in section 3.1.1. The accumulation could be either due to an increase in clathrin-mediated endocytosis (CME) of non-synaptic vesicle proteins like scaffolding proteins, ion channels or receptors, or it could be due to the slow uncoating of the AP2 CCV coat and thus an extended lifetime of the $\mathrm{CCV}$, leading to their accumulation. If the accumulated AP2 CCVs have a stable coat and thus have an extended lifetime, then the question was how to identify and isolate these stablilized AP2 CCV?

As described in section 1.1.2.3, during a $\mathrm{CCV}$ cycle, when a $\mathrm{CCV}$ is formed at the donor membrane, it detaches from the donor membrane and before its fusion with the target membrane to deliver its cargo proteins, the CCV has to shed off its clathrin coat. Hsc70 and its co-chaperones, Auxilin 1 and 2 mediate the disassembly of the clathrin basket (Braell, 1984; Schlossman, 1984; Scheele et al, 2003). Auxilin $1 / 2$ recruit $\mathrm{Hsc} 70$ to the basket disassembly site, where it starts the disassembly process (Scheele et al, 2003)(see section 1.1.2.3.2 for detailed molecular mechanism of clathrin uncoating process). However, Hsc70 has additional binding sites on the clathrin basket of a CCV, where it binds more stably and promiscuously, if not guided to the disassembly site (Xing et al, 2009; Park et al, 2015; Sousa \& Lafer, 2015). Based on this differential, but stable mode of binding of Hsc70 to the $\mathrm{CCV}$, we reasoned that, if there is a stable pool of AP2 CCV, then it could be immunoisolated by anti-Hsc70 monoclonal antibodies.

In our recent study (Candiello et al, 2017), we have immunoisolated a sub-pool of AP2 CCV from wild-type and $\sigma 1 \mathrm{~B}-/-$ synapses, by pull-down with anti-Hsc70 antibody. The biochemical characterization of this immunoisolated pool suggests that, o1B-/- synapses contain twice the amount of these AP2 CCV, than the comparable pool of wild-type synapses. This increase in AP2 is similar to the increased amounts of AP2 in the total accumulated CCV pool (Kratzke et al, 2014), thus representing a sub-population of the accumulated AP2 CCV pool. In addition, it was observed that $\sigma 1 \mathrm{~B}-/$ - synapses have normal amounts of Hsc70, but in the total accumulated CCV pool, there was also a $100 \%$ increase in the levels of Hsc70 associated with these CCV (Kratzke et al, 2014). This increased level of Hsc70 suggests, that the majority of AP2 CCV in the total accumulated CCV pool were undergoing rapid uncoating similar to the wild-type CCV. Thus the increase in AP2 $\mathrm{CCV}$ could be solely due to enhanced clathrin-mediated endocytosis, despite the 
reduction in synaptic vesicle number and synaptic vesicle recycling rate (Kratzke et al, 2014). In the Hsc70 immunoisolated AP2 CCV, we have observed an increase in the levels of Auxilin 1/2, but the levels of Hsc70 was not increased, suggesting that $\mathrm{Hsc70}$ is not guided to the clathrin basket disassembly site, where it starts the disassembly process of the clathrin basket (Candiello et al, 2017). Thus, the levels of Hsc70 and of Auxilin 1/2 demonstrate that these immunoisolated CCV have a stabilized CCV coat and thus have an extended lifetime. We have also observed an increase in Clathrin-heavy-chain (CHC), and the level of Clathrin-light-chain (CLC) is almost doubled (Candiello et al, 2017). CLC binds to the proximal legs of $\mathrm{CHC}$ and is required for the stability and lifetime of the clathrin basket (Brodsky, 2012), further supporting the enhanced stability of the immunoisolated AP2 CCV.

\subsubsection{Upregulated CME in the stabilized AP2 CCV of AP1/ б1B-/- synapses :}

The stabilized pool of AP2 CCV should either represent just an intermediate early stage of the $\mathrm{CCV}$ uncoating reaction or they should be the CCV of a specific Clathrin-mediated-endocytosis (CME) route. If the stabilized AP2 CCV represent a specific endocytic route in the synapse, then they should be enriched in specific cargo proteins. Stonin2 is a co-adaptor of AP2 and has a $\mu$-homology domain, which binds to cargo proteins like the $\mathrm{C}$-terminus of $\mathrm{AP} 2 / \mu 2$ adaptin.

We have analyzed the expression and distribution of Stonin 2 in $\sigma 1 \mathrm{~B}-/-$ synapses. In our previous studies, we have observed that $\sigma 1 \mathrm{~B}-/$ - cortices and synapses have $\sim 25 \%$ and $\sim 10 \%$ less Stonin2 compared to the wild-type respectively and the total synaptic CCV in $\sigma 1 \mathrm{~B}-/-$ synapses contains $~ 20 \%$ less Stonin2 compared to the wild-type (Kratzke et al, 2014). The stabilized AP2 CCV pool of AP1/。1B-/synapses contains $130 \%$ more of Stonin2 than wild-type (Figure 3.2A-D), implicating that stabilized AP2 CCV transport preferentially Stonin2 (cargo protein). Stonin 2 binds Git1 (GPCR kinase-interacting protein) and both localize at the active zone. Git1 is a scaffolding protein present at the outer rim of the presynaptic active zone, involved in the organization of cytomatrix and presynaptic active zone structural proteins. Git1 function is important for synaptic vesicle 
recycling, but the molecular mechanisms are not known (Podufall et al, 2014). Point mutations in Git1 are associated with Schizophrenia. We analyzed the levels of Git1 in the synapse, the total synaptic CCV pool, and in the stabilized AP2 CCV pool. The Git1 level is decreased in the total CCV by $30 \%$, but the stabilized AP2 CCV contains $120 \%$ more of Git1 than its comparable wild-type AP2 CCV (Figure 3.2A-D). Thus, the increase in Git1 in the stabilized pool suggests that Git1 is redistributed from the active zone in the stabilized AP2 CCV, mediated by Stonin2. The level of Git1 is also increased in the synapse of $\sigma 1 \mathrm{~B}-/-$ by $50 \%$, suggesting that it is not endocytosed to be degraded, but is maintained and may function in other pre-synaptic domains. Git 1 is a scaffolding protein with several protein interaction domains, with which it takes part in the organization of actin cytoskeleton and participates in cell migration and synapse formation. The deficiency in Git1 impairs the synaptic vesicle recycling (Podufall et al, 2014), thus the increased level of Git1 in the stabilized pool could support the synaptic vesicle recycling and could partially compensate for the reduction in synaptic vesicle numbers in the $\sigma 1 \mathrm{~B}-/-$ mice synapses.

Git1 has an ArfGAP activity and its substrate at the plasma membrane is Arf6. Arf6 regulates important vesicular transport routes, including CME and synaptic vesicle recycling pathways (Tagliatti et al, 2016; Kim et al, 2015). Thus, we analyzed and compared the expression levels of Arf6 in the synapses, in the total synaptic CCV and in the stabilized AP2 CCV pool. Arf6 levels are decreased in the synapse by $25 \%$, but in the total and the stabilized pool, Arf6 is increased by $30 \%$. The reduced amount of Arf6 in the synapse is not limiting for its recruitment in the total as well as in the stabilized AP2 CCV pool. However, Arf6 seems not to be in involved in the differential regulation of the two CME pathways.

This complete set of experiments was done along with my predecessor, Dr. Ermes Candiello. He analyzed the Stonin2 data and the stabilized pool data of Git1 and Arf6. I have analyzed the cortex, synapse and total CCV data of Git1 and synapse total CCV data of Arf6. The stabilized AP2 CCV represents a specific CME route was verified and confirmed by a quantitative mass-spectrometric analysis (iTRAQ), done by E. Candiello in collaboration with Dr. O Jahn (MPI Experimental Medicine, Göttingen) and Dr. B. Schmidt (mass-spectrometry department of our institute), published in (Candiello et al, 2017). 
A

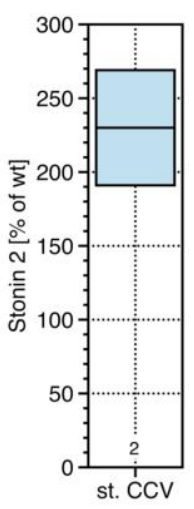

B

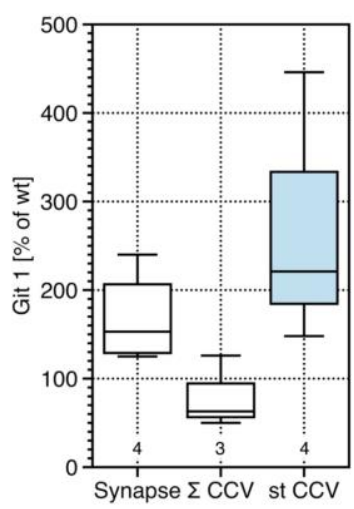

C

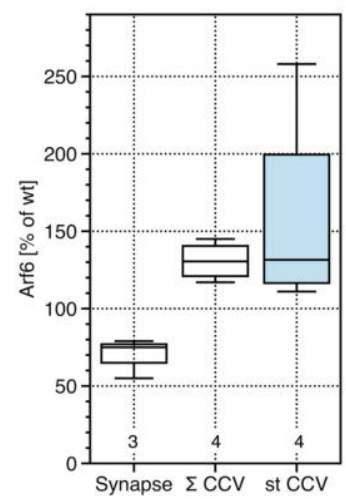

D

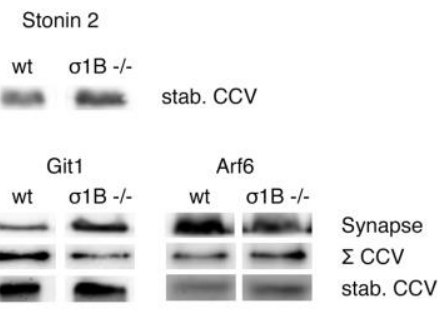

Figure 3.2. Comparison of the levels and distribution of (A) Stonin2 in the stable pool, isolated from wild-type (wt) and knockout (ko) mice brain. (B) Git 1 in synapse, total CCV ( $\left.\sum \mathrm{CCV}\right)$ and in the stabilized pool (st CCV) isolated from wild-type (wt) and knockout (ko) mice brain (C) Arf6 in synapse, total CCV $\left(\sum \mathrm{CCV}\right)$ and in the stabilized pool (st. CCV) isolated from wild-type (wt) and knockout (ko) mice brain. Wild-type level (wt) was set to $100 \%$ and the knock-out samples were compared with respect to the wt. The numbers in the box plot indicate the number of individual biological samples analyzed. (D) Representative western blot of the comparison and analysis done for Stonin2, Git1 and Arf6. These results are published, hence figure adapted from (Candiello et al, 2017). E. Candiello contributed stonin 2 data and the stabilized pool data of Git1 and Arf6 and R. Mishra contributed cortex, synapse and total CCV data of Git1 and the synapse, total CCV data of Arf6. 


\subsection{Molecular mechanisms for the formation of stabilized AP2 CCV:}

\subsubsection{Reduced recruitment of Hsp110 to the stabilized AP2 CCV:}

During the uncoating reaction of a $\mathrm{CCV}$, Hsc70 is recruited by its co-chaperones, Auxilin 1/2 and mediates the disassembly of the clathrin basket (see section 1.2.3.2 for the molecular mechanism of CCV uncoating). However, after the disassembly of the clathrin basket, Hsc70:ADP still remains associated with the clathrin triskelia and inhibits the polymerization of the clathrin, required for subsequent rounds of CCV formation (Schuermann et al, 2008). Therefore, Hsc70 has to be released from the Hsc70:ADP:clathrin complex. This is achieved by replacing ADP for ATP in the Hsc70:ADP:clathrin complex. Hsc70 nucleotide exchange factors (NEFs) are the class of proteins, which regulate the dissociation of $\mathrm{Hsc70}$ from their protein substrates, by stimulating the release of ADP from the Hsc70:ADP: substrate complex (Packschies et al, 1997). The exchange of ADP for ATP further stimulates the release of the substrate from the otherwise stable Hsc70 substrate complex. Hsp110 is a member of the Hsc70 family and is the most abundant Hsc70 NEF in the vertebrate brain (Morgan et al, 2013). Hsp110 also plays an important role in the regulation of synaptic vesicle endocytosis. The inhibition of Hsp110 at the giant reticulospinal synapses of sea lamprey shows a defect in synaptic vesicle endocytosis. Presumably, the inhibition of Hsp110 blocked its NEF activity, thereby inhibiting the release of Hsc70 from clathrin, thus limiting the availability of clathrin for subsequent rounds of endocytosis (Morgan et al, 2013).

I have analyzed the levels of Hsp110 in the whole brain cortex, synapses, the total synaptic CCV pool, and the immunoisolated stabilized AP2 CCV pool (Figure 3.3B,C). The amount of Hsp1 10 is increased in the $\sigma 1 \mathrm{~B}-/-$ whole brain cortex by $30 \%$, but in the synapses, it is decreased by $60 \%$ with respect to the wild-type. However, this decrease in the synapses is not limiting the recruitment of Hsp110 in the total CCV pool. In the total CCV pool, the amount of Hsp110 is not changed in the knockout synapse. However, in the immunoisolated stabilized AP2 CCV pool, HSP110 is reduced by $40 \%$ in the knockout synapses. The reduced levels of Hsp110 in the stabilized AP2 CCV suggest, that altered Hsp110 expression could be one of 
the factors inhibiting the recruitment of Hsc70 to the clathrin basket disassembly sites.
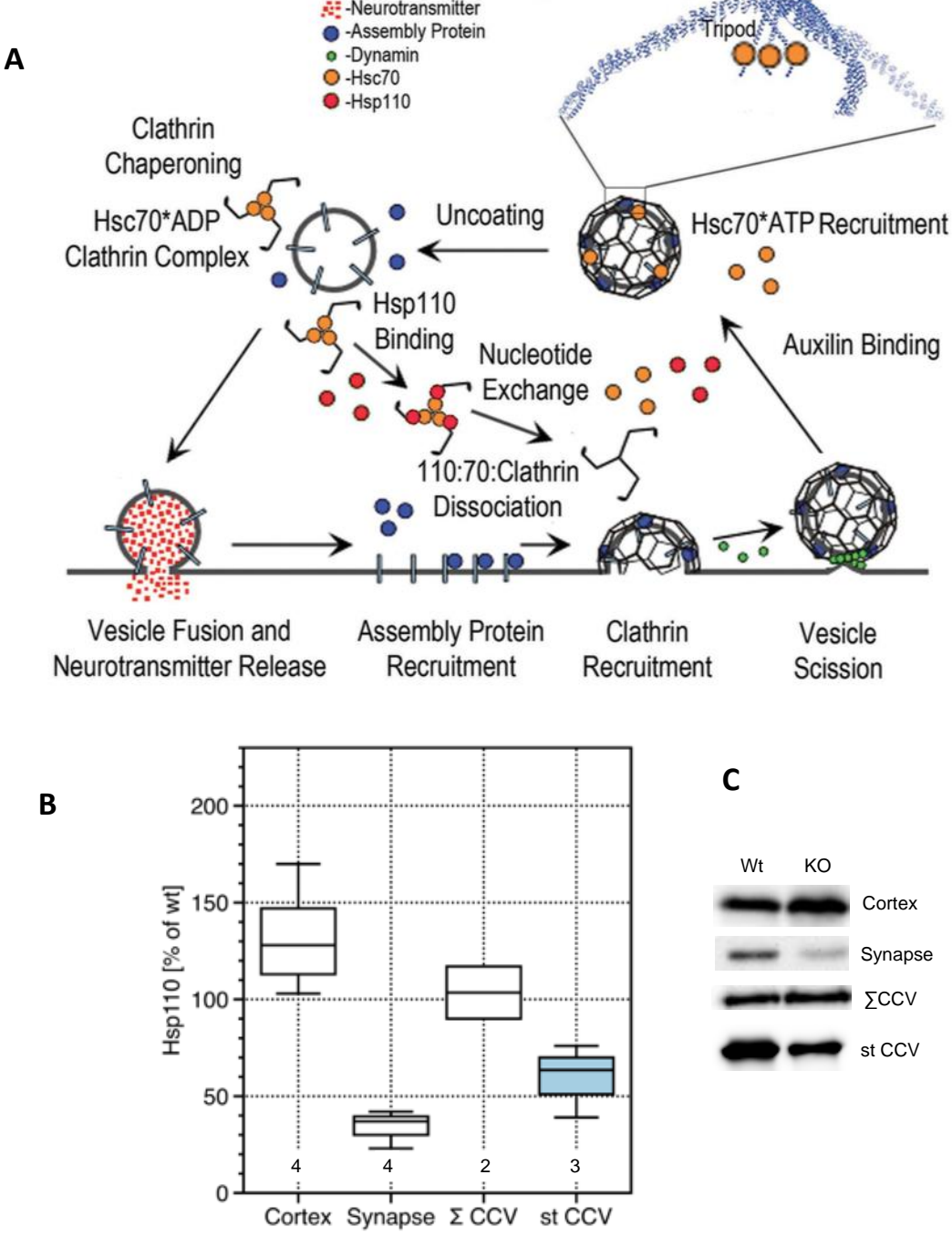

Figure 3.3. Hsp110 in the uncoating of CCV: (A) Molecular mechanism of HSP110 in CCV uncoating, during synaptic vesicle (SV) endocytosis: After the SV has fused with the pre-synaptic plasma membrane, it releases the neurotransmitters (exocytosis) and SV is endocytosed back for second round of exocytosis. During clathrin-mediated endocytosis, when a vesicle is formed, it has to shed off its clathrin coat before its fusion to the target membrane. Hsc70 and its cochaperones Auxilin1/2 mediate the uncoating process. After disassembly of clathrin basket, Hsc70 is still associated with Clathrin triskelia as Clathrin: Hsc70: ADP complex, and requires the nucleotide exchange factor (NEF) activity of HSP110 for its dissociating from clathrin triskelia. HSP110 is the most abundant NEFs in the brain and the inhibition of HSP110 leads to the defects in uncoating mechanisms, leading to the accumulation of CCV in the synapses (Morgan et al, 2013). Model adapted from (Sousa \& Lafer, 2015) (B) Comparison of the levels and distribution of HSP110 in cortex, synapse, in the total CCV $\left(\sum \mathrm{CCV}\right)$ and in the stabilized AP2 CCV (st CCV) isolated from wild-type (wt) and knockout (ko) mice brain (C) Representative western-blots of the HSP110 comparison done in B. 


\subsubsection{Stability of AP2 membrane binding}

The reduced recruitment of Hsp110 and of Hsc70, despite the increased amounts of its activators, Auxilin1/2 in the immunoisolated AP2 CCV, demonstrates that the clathrin baskets of these CCVs are not readily disassembled. The regulation of the binding of the AP2 to the membrane also plays an important role in the stability of a CCV. The binding of AP2 to the membrane lipid $\mathrm{PIP}_{2}$ and to cargo proteins is enhanced by its conformation change from a closed to an open conformation, in which the C-terminal domain of AP2/ 22 comes in close contact to the membrane and binds firmly to $\mathrm{PIP}_{2}$ and the cargo proteins. This conformational change is favored by the phosphorylation of $\mu 2-\mathrm{Thr}^{156}$ by AP2-associated kinase, AAK1 (Ricotta et al, 2002; Conner et al, 2003). AAK1 is not the only kinase, which phosphorylates $\mu 2$, but the others are not yet known. In our recent study, we have observed a dramatic increase in $\mu 2$ phosphorylation and in AAK1 kinase activity in the stabilized AP2 CCV pool (Candiello et al, 2017). This suggests that the phosphorylation of $\mu 2$ subunit further aids in the stability of these immunoisolated AP2 CCVs. AAK1 mediated $\mu 2$ phosphorylation has always been discussed exclusively for AP2 activation and the initiation of AP2 CCV formation. However, our data show that AAK1 function is used to differentially regulate the AP2 CCV life-time (Candiello et al, 2017).

The plasma membrane enriched phospholipid PI-4,5- $\mathrm{P}_{2}$ is not only bound by $\mu 2$, but also by the AP2 adaptins $\alpha$ and $\beta 2$. Thus, $\mathrm{PIP}_{2}$ contributes to the specific binding of AP2 to the plasma membrane and it has to be dephosphorylated to allow the dissociation of AP2 from the membrane.

\subsubsection{Reduced Synaptojanin-1 in stabilized AP2 CCV :}

$\mathrm{AP} 2$ requires $\mathrm{PIP}_{2}$ on the plasma membrane for its stable binding, and the activity of $\mathrm{PIP}_{2}$ phosphatases is essential for the release of AP2 from the membrane. Synaptojanins are the $\mathrm{PIP}_{2}$ phosphatases, which dephosphorylate $\mathrm{PIP}_{2}$ and thus help in the dissociation of AP2 from the membrane (McPherson et al, 1996) (Figure 3.5A) (see section 1.2.3.2, for the detailed molecular mechanism). There are two isoforms of Synaptojanin-1 expressed in the brain: ubiquitous Synaptojanin-1 and 
the brain-specific Synaptojanin-1 splice variant, has a C-terminal truncation (Perera et al, 2006).

We have tested the expression of both the Synaptojanins, in the cortex, synapse, the total synaptic CCV, and in the stabilized AP2 CCV in the wild-type and AP1/ $1 \mathrm{~B}-$ /- synapses. The cortices of $\sigma 1 \mathrm{~B}-/-$ mice contain less Synaptojanin-1, but the synapse has around 20\% more of Synaptojanin-1 than the wild-type, which is in line with the high AP2 CCV turnover (Figure 3.5B-C). However, the amount of brain-specific Synaptojanin isoform is not changed in the cortices and synapse of $\sigma 1 \mathrm{~B}-/-$ mice. In the total synaptic CCV, the amount of Synaptojanin-1 is not changed, but the brain-specific Synaptojanin-1 splice variant is reduced by $20 \%$ in the AP1/。1B-/- synapses. This could be because, brain-specific splice variant lacks AP2 binding site, and thus is recruited at the late stage of CCV formation by binding to Endophilin and/or Amphiphysin, suggesting an isoform-specific function of Synaptojanin-1 in the regulation of CCV uncoating (Perera et al, 2006). The immunoisolated pool of AP2 CCV from AP1/ 1 1B-/- synapses has $80 \%$ less of both Synaptojanin-1 (Figure 3.5B-C). The mechanisms responsible for the recruitment of synaptojanins are not isoform-specific and thus the isoforms do not contribute to the differential stability of the synaptic AP2 CCV. Therefore, reduced Synaptojanin-1 recruitment is contributing in the stabilization of AP2 CCV in the AP1/б1B-/- synapses. 
A
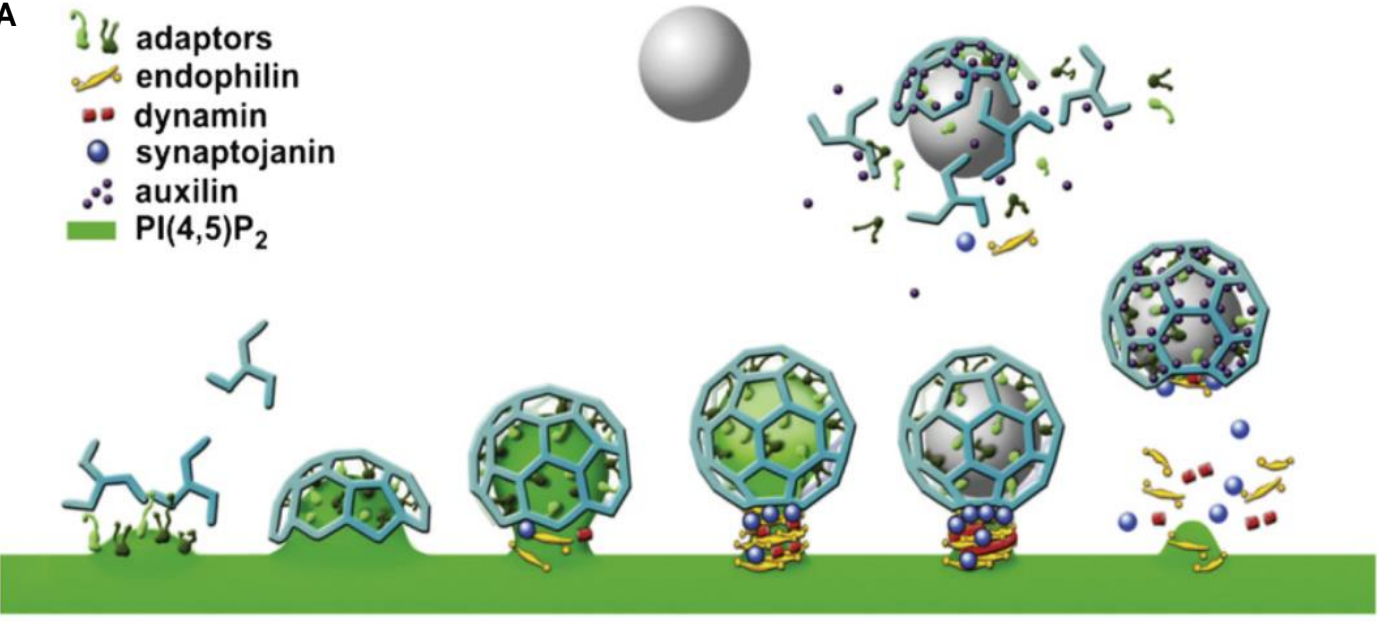

B

C
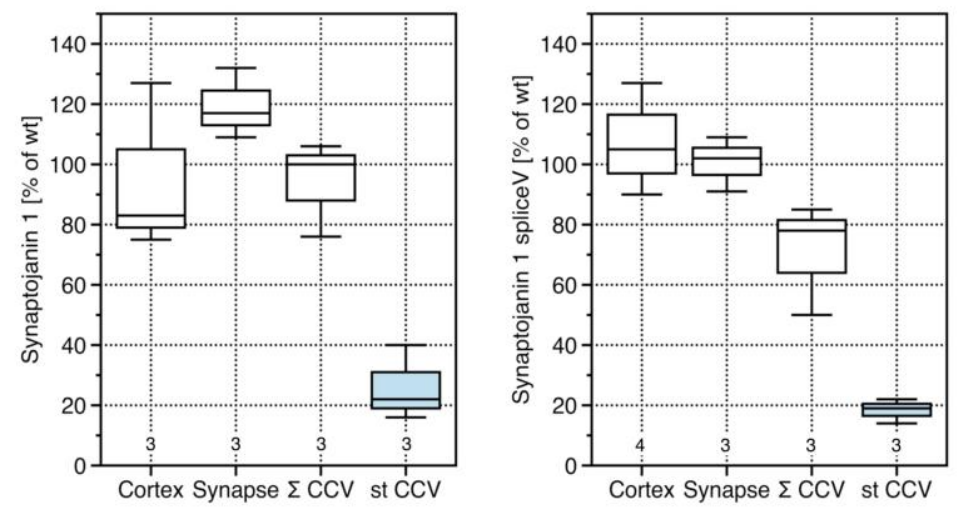

Synaptojanin $1 \underset{\substack{\text { Synaptojanin } 1 \\ \text { spliceV }}}{\text { Splo }}$

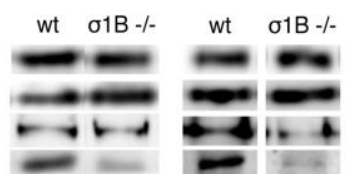

Cortex

Synapse

$\Sigma \mathrm{CCV}$

stab. CCV

Figure 3.5. (A) Scheme representing the fusion and uncoating of a clathrin-coated vesicle at the synapses, mediated by endophilin and synaptojanins(Milosevic et al, 2011). Endophilin is recruited at the late stage of a CCP from which CCV buds off. Endophilin recruits Synaptojanins. Synaptojanin-endophilin interaction is critically important for the fission of CCV. Synaptojanins are the $\mathrm{PIP}_{2}$ phosphatases, which dephosphorylate $\mathrm{PIP}_{2}$ and thus, help in the release of AP2 from the membrane. Figure adapted from (Milosevic et al, 2011) (B) Comparison of the levels and the distribution of Synaptojanin-1 ubiquitous and brain-specific splice variant in cortices, synapses, in the total synaptic $\mathrm{CCV}(\Sigma \mathrm{CCV})$ and in the stabilized $\mathrm{CCV}$ (st $\mathrm{CCV}$, blue boxes), from wt and $\sigma 1 \mathrm{~B}$ $-/-$ mice. Wild-type level is set to $100 \%$ and the numbers below the box-plot indicate the number of individual biological samples analyzed. (C) Representative western blots of the analysis of Synaptojanin 1 and Synaptojanin 1 splice variant, as shown in B. The results are published, hence figure is adapted from (Candiello et al, 2017). E. Candiello contributed the stable pool data and R. Mishra contributed cortex, synapse, and the total CCV data. 


\subsubsection{Synaptojanin-1 recruiting proteins EndophilinA1 and Amphiphysin}

In order to identify the mechanism responsible for the reduced recruitment of Synaptojanins, we analyzed first the expression levels of two recruiters of Synaptojanin-1, Endophilin A1 and Amphiphysin, which also bind to each other. Endophilin A1 recruits Synaptojanin-1 by direct interaction (Perera et al, 2006; Milosevic et al, 2011). We determined the level of Endophilin A1 in the cortices, synapses, the total synaptic CCV, and in the stabilized AP2 CCV of wild-type and AP1/ $1 \mathrm{~B}-/-$ synapses (Figure 3.6A and 3.6C). The level of Endophilin A1 is slightly increased by around $10 \%$ in cortices and synapses, but in the total synaptic CCV pool, it is reduced by $15 \%$ in $\sigma 1 \mathrm{~B}$ knockout compared to the wild-type mice. However, in the stabilized AP2 CCV of AP1/ $1 \mathrm{~B}-/-$ synapses, the amount of endophilin A1 is not changed compared to the wild-type CCV. Therefore, the amount of Endophilin A1 does not explain the reduced levels of Synaptojanin 1 in the stabilized AP2 CCV pool.

Another key protein that interacts directly with Synaptojanin-1 is Amphiphysin. Amphiphysin is recruited by AP2 (Olesen et al, 2008) and interacts with dynamin and the actin cytoskeleton during dynamin-mediated vesicle fission (Yamada et al, 2009). The level of Amphiphysin is slightly increased in cortices and synapses, but in total synaptic CCV, it is reduced by $35 \%$ and in the immunoisolated pool by $45 \%$. This reduction in the level of amphiphysin is not comparable with the reduction in the level of Synaptojanin-1, thus the reduced level of Synaptojanin-1 is not a consequence of just less amphiphysin. Therefore, these data suggest the involvement of other proteins and regulatory mechanisms, which regulate the recruitment of Synaptojanin-1 in the stabilized AP2 CCV.

This experiment was performed along with my predecessor in the lab, Dr. Ermes Candiello. He contributed the stable pool data and I have contributed the cortices, synapses, and total CCV pool data. 
A

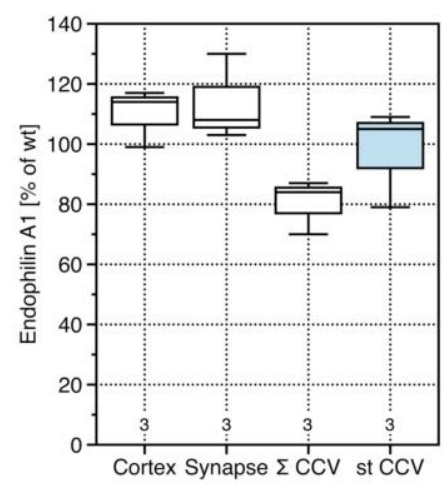

B

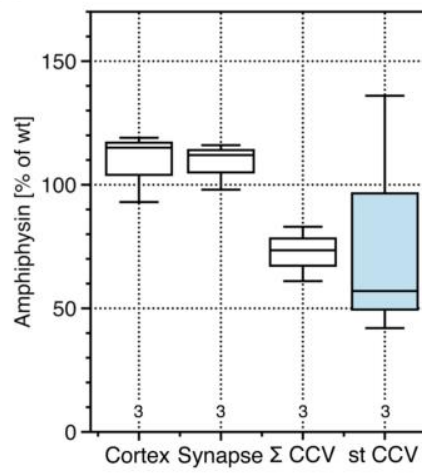

C

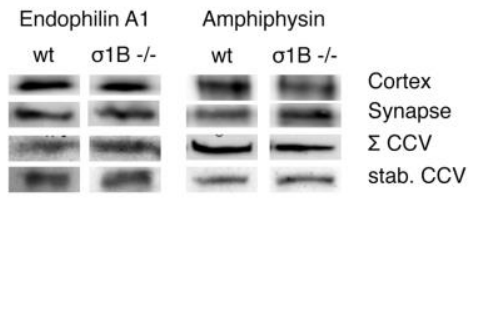

Figure 3.6 (A-B) Comparison of the levels and the distribution of Endophilin A1 (A) and Amphiphysin (B) in the cortices, synapses, in the total synaptic CCV ( $\Sigma \mathrm{CCV})$ and in the stabilized $\mathrm{CCV}$ (st CCV, blue boxes), from wt and $\sigma 1 \mathrm{~B}-/-$ mice. Wild-type level is set to $100 \%$ and the numbers below the box-plot, indicate the number of independent biological samples analyzed. (C) Representative western-blots of Endophilin A1 and Amphiphysin comparison shown in A and B. The results are published, hence figure is adapted from (Candiello et al, 2017). E. Candiello contributed the stable pool data and R. Mishra contributed cortex, synapse, and the total CCV data.

\subsubsection{Reduction of Intersectin-1 in stabilized AP2 CCV}

Besides Amphiphysin and Endophilin A1, Synaptojanins also bind the CCV protein Intersectin-1. Intersectin-1 (ITSN-1) is a multi-domain adaptor protein that interacts directly with dynamin, AP2, Stonin-2 and Synaptojanin-1, along with other CCV coat proteins, during the CCV cycle (Figure 3.7B) (Evergren et al, 2007; Pechstein et al, 2010). Intersectin-1 is highly expressed in neurons and plays a role in clathrin mediated synaptic vesicle recycling. Several studies in the past, have demonstrated the role of intersectin-1, in the endocytosis and vesicular trafficking of proteins (Hunter et al, 2013; Pechstein et al, 2010). The intersectin-1 knockout mice shows defects in vesicle trafficking in the brain (Hunter et al, 2013). Intersectin-1 interacts directly with clathrin/AP2 during clathrin mediated synaptic vesicle endocytosis and the perturbation of intersectin-1-AP2 interaction in lamprey synapses, inhibits the synaptic vesicle recycling (Pechstein et al, 2010).

Structurally, Intersectin-1 (Figure 3.7A) consists of two N-terminal Eps15 homology (EH) domains, a coiled-coil region (CC) and five Src homology3 (SH3) 
domains (Wong et al, 2012; O'Bryan, 2010). There are two isoforms of Intersectin expressed in mammals: One is the shorter isoform of Intersectin (ITSN-S) and another longer isoform of Intersectin (ITSN-L). ITSN-S posses two EH domain, one CC domain and five SH3 domains, whereas ITSN-L has additional C-terminal domain containing Dbl homology (DH) domain, a pleckstrin homology $(\mathrm{PH})$ domain, and a C2 domain (O'Bryan, 2010) (see Figure 3.7A). ITSN1 is expressed in brain. The DH-PH domain have GEF activity directly activating Cdc42 (O'Bryan, 2010). SH3 A-B linker domain of intersectin-1 bind with AP2 $\alpha$ - and $\beta$ appendage domains, and this binding inhibits the binding of synaptojanin-1 with intersectin-1 (Pechstein et al, 2010; 2015).

Therefore, in order to understand the differential regulation of the two-endocytic pathways, I investigated the expression and distribution of intersectin-1 in the cortices, synapses, the total synaptic CCV and in the stabilized AP2 CCV of wt and AP1/ $1 \mathrm{~B}-/-$ synapses. The level of intersectin- 1 is slightly reduced in the cortices and synapses of the $\sigma 1 \mathrm{~B}-/-$ mice (Figure 3.7C-D). However, the reduced level of intersectin-1 in the cortices and synapses does not limit its recruitment in the total synaptic CCV pool of AP1/ 1 1B-/- synapses. The level of Intersectin-1 is increased by $100 \%$ in the total CCV, again in line with the increase in the levels of AP2 in the total CCV. However, in the immunoisolated stabilized AP2 CCV, the level of intersectin- 1 is reduced by $\sim 30 \%$, despite the $100 \%$ increase in the amount of AP2 $\mathrm{CCV}$. This selective reduction of Intersectin-1 only in the stabilized AP2 CCV pool and not in the total CCV pool of AP1/б1B-/- synapses, suggests that Intersectin-1 is involved in the differential regulation of the CCV stability. 


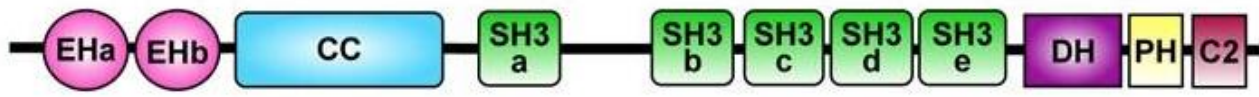

B

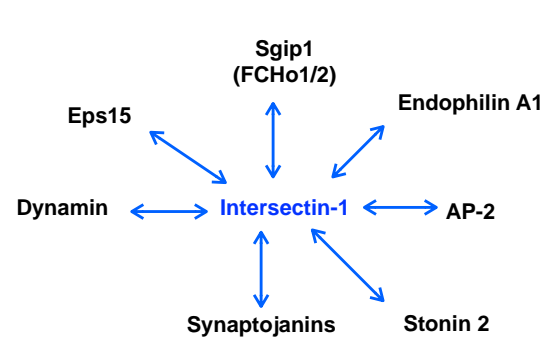

C

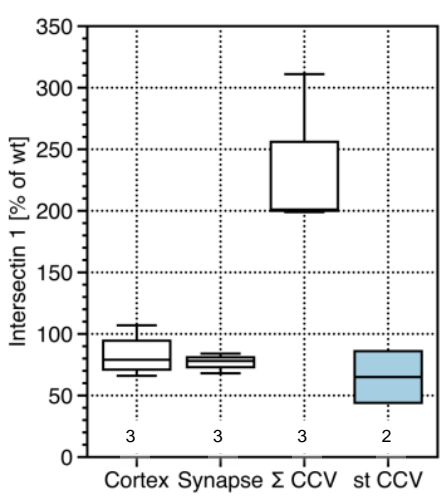

D

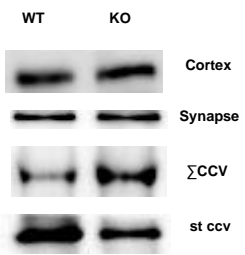

Figure 3.7 (A) Cartoon representation of the structure of Intersectin-1 long isoform, figure adapted from (Wong et al, 2012). (B) Scheme showing molecular interaction of Intersectin 1 with proteins involved in the formation of a CCV (C) Comparison of the levels and the distribution of Intersectin1 in cortices, synapses, in the total synaptic CCV $(\Sigma \mathrm{CCV})$ and in the stabilized CCV (st CCV, blue boxes), from wild-type (wt) and $\sigma 1 \mathrm{~B}-/-$ mice. Wild-type level is set to $100 \%$ and the numbers below the box-plot, indicate the number of independent biological samples analyzed. (D) Representative western-blots of the analysis of the distribution of Intersectin-1, done in C.

\subsubsection{Increased level of SGIP1 in the stabilized AP2 CCV}

The selective reduction in the level of Intersectin-1 in the stabilized AP2 CCV pool suggests its involvement in the differential regulation of the stable pool formation. SGIP1 (Src homology 3-domain growth factor receptor-bound 2-like (endophilin) interacting protein 1) is a BAR domain protein, which senses low curvature membrane and binds at the early stages of the budding reactions. SGIP1 interacts directly with endophilin and membrane phospholipids, during endocytosis at the plasma membrane. It was shown that SGIP1 binds to phosphatidylserine and phosphoinositides on the plasma membrane and deforms the membrane into narrow tubules, suggesting its functions in vesicle formation during endocytosis (Uezu et $a l, 2007)$. Furthermore, it was also demonstrated that SGIP1 interacts with Eps15, a co-adaptor protein of CCV and AP2 (Uezu et al, 2007). SGIP1 also interacts with Intersectin-1 during Clathrin-Coated Pit formation. Thus, the determination of SGIP1 levels was essential to understand the molecular mechanism for less 
recruitment of intersectin-1 to stabilized AP2 CCV.

I have analyzed and compared the expression of SGIP1 in the wild-type and $\sigma 1 \mathrm{~B}-$ /- mice (Figure 3.5). The amount of SGIP1 is not changed much $(\sim 10 \%)$ in the cortices and synapses of the AP1/ $1 \mathrm{~B}-/-$ synapses. In the total CCV, as well as in the stabilized AP2 CCV, the amount of SGIP1 is increased by $\sim 120 \%$, in line with the increase in AP2. Since SGIP1 is recruited at early stages of vesicle formation and speeds up the budding process, both CME pathways appears to form CCV with the same speed.

The selective reduction of Synaptojanin-1 appears not to be simply due to stoichiometric alterations in CCV coat proteins and thus, points towards regulatory mechanism involving specific kinases and phosphatases, which regulate the formation of the stabilized AP2 CCV in AP1/ $1 \mathrm{~B}-/-$ synapses.

A

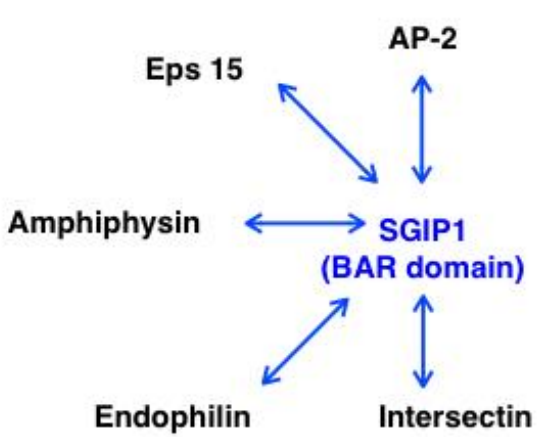

B

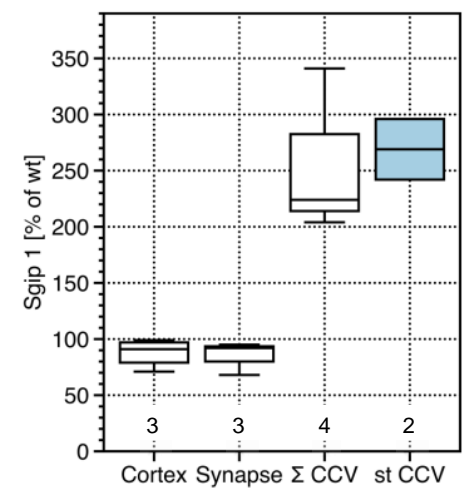

C

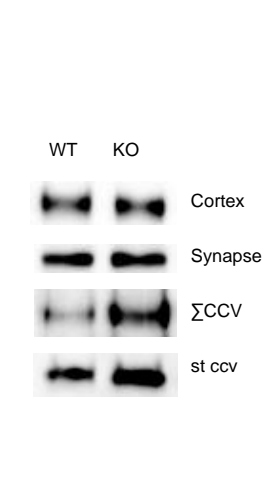

Figure 3.8 (A) Scheme showing molecular interaction of SGIP1 with other CCV coat proteins involved in the formation of clathrin-coated vesicles (B) Comparison of the expression and the distribution of SGIP 1 in cortices, synapses, total synaptic CCV $(\Sigma \mathrm{CCV})$ and immunoisolated stable $\mathrm{CCV}$ (st CCV, blue boxes), from wild-type (wt) and $\sigma 1 \mathrm{~B}-/-$ mice, (wt $=100 \%$ ). The numbers below the box-plot indicate the number of biological samples analyzed (C) Representative western-blots of the expression and distribution of SGIP, done in B. 


\subsection{Regulation of stabilized AP2 CCV formation in AP1/б1B-/-synapses:}

\subsubsection{Increased LRRK2 in the stabilized AP2 CCV of AP1/б1B-/- synapses}

LRRK2 (leucine-rich repeat kinase 2) is one of the highly expressed kinases in the brain and has been shown to be associated with CCV (Arranz et al, 2015), (PaisánRuíz et al, 2004; Pan et al, 2017). LRRK2 plays an essential role in brain function due to its involvement in synaptic vesicle endocytosis (Arranz et al, 2015). Mutations in the LRRK2 kinase are associated with Parkinson's disease, more likely due to the phosphorylation of numerous Rab proteins (Paisán-Ruíz et al, 2004). A study done in Drosophila melanogaster suggests, that LRRK2 kinase activity is a part of endoA1 (endophilin A1, also known as SH3GL2) phosphorylation cycle, which facilitates the efficient formation of synaptic vesicles (Matta et al, 2012) at the neuromuscular junction (NMJ). In the mammalian synapse, the knockout or the pharmacological inhibition of LRRK2, also exhibit defects in synaptic vesicle endocytosis and impairs neurotransmission (Arranz et $a l, 2015)$. This study also shows that the mammalian BAR domain of endophilin A1 is phosphorylated by LRRK2 at residues Thr73 and Ser75 and this phosphorylation in the BAR domain inhibits membrane tubulation in-vitro (Arranz et al, 2015). LRRK2 also interacts directly with Synaptojanins and it was shown invitro, that LRRK2 phosphorylates Synaptojanin-1, leading to the disruption of Synaptojani1-Endophilin A1 interaction during synaptic vesicle endocytosis (Pan et al, 2017). Thus, the LRRK2 kinase activity has an important role in the regulation of synaptic vesicle endocytosis and could explain the regulatory mechanism for the reduced recruitment of synaptojanin- 1 and the formation of the stabilized AP2 CCV pool.

The LRRK2 level was increased by $60 \%$ in the cortices, whereas it is reduced by $40 \%$ in the synapses of AP1/ $\sigma 1 \mathrm{~B}-/-$, compared to wild-type mice (Figure 3.9B,C). However, in the total synaptic CCV pool and in the stabilized AP2 CCV, the level of LRRK2 is increased by $\sim 20 \%$. The increase in LRRK2 level in both total and the stabilized AP2 CCV suggest that LRRK2 may not be involved in the differential regulation of the two CME pathways. However, LRRK2 is a large protein of 2527 
amino acids (Figure 3.9A), with multiple protein interaction domains apart from its kinase activity domain, thus it interacts and regulates the levels of several different proteins and participates in a number of signaling pathways. The predicted LRRK2 domain structure (Figure 3.9A), suggests that LRRK2 is composed of 13 LRRs domains, which play roles in protein-protein interaction, followed by the Roc, a GTPase domain which regulates the activity of kinase domain, COR domain which is LRRK2 dimerization domain and MAPKKK domain, a kinase domain functioning in mitogen-activated protein kinase signaling pathways, as well as seven WD40 at the C-terminus responsible for protein-protein interaction (Gandhi et al, 2009).

Therefore, despite the comparably increased levels of LRRK2 in stabilized and total $\mathrm{CCV}$ does not exclude different type of interactions of LRRK2 in the two CCV pools. These data further provides insight into the complex regulatory mechanism for the formation of the stabilized AP2 CCV. In the future, we would like to specifically check the activation of the kinase domain of LRRK2, in the stable and total $\mathrm{CCV}$ and this would provide a better understanding of these regulatory mechanisms. 


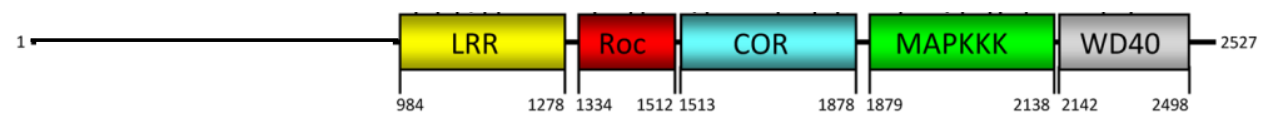

B

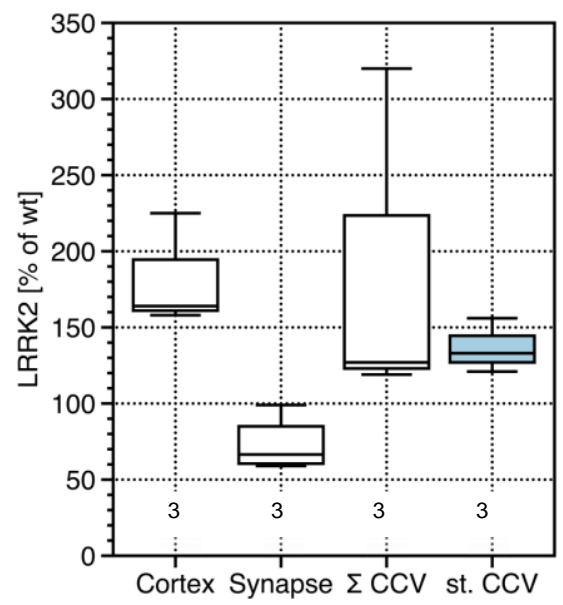

C

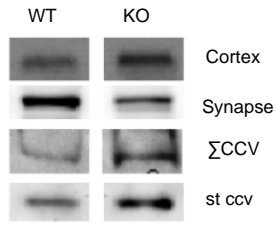

Figure 3.9 (A) Cartoon representing the predicted domain structure of LRRK2; LRRK2 is composed of 13 LRRs protein-protein interaction domains, followed by the Roc, a GTPase domain, COR domain, a LRRK2 dimerization domain and MAPKKK domain, a kinase domain followed by seven WD40 at the C-terminus, which plays a role in protein-protein interaction. Figure adapted from (Gandhi et al, 2009) (B) Comparison of the levels and the distribution of LRRK2 in cortices, synapses, in the total synaptic CCV ( $\Sigma \mathrm{CCV}$ ) and in the stabilized CCV (st CCV, blue boxes), from wild-type (wt) and $\sigma 1 \mathrm{~B}-/-$ mice. Wild-type level is set to $100 \%$ and the numbers below the boxplot, indicate the number of independent biological samples analyzed. (C) Representative westernblots of the LRRK 2 comparison, shown in B. E. Candiello contributed the $\Sigma$ CCV data and R. Mishra contributed the data from cortex, synapse and the stabilized CCV. 


\section{Chapter 4: Discussion}

In our lab, we have generated three AP1 adaptin 'knockout' mice models. The knockouts of $\gamma 1$ and $\mu 1 \mathrm{~A}$ were embryonically lethal and died at the age of 3.5 day and 13.5 day in-utero respectively (Meyer et al., 2000), (Zizioli et al, 1999). Only $\sigma 1 \mathrm{~B}-/-$ mice were viable and fertile, but are hypoactive and have impaired motor coordination and also have defects in learning and memory formation (Glyvuk et al., 2010). $\gamma 1$ and $\mu 1 \mathrm{~A}$ adaptins are ubiquitously expressed, whereas $\sigma 1 \mathrm{~B}$ adaptin is an isoform of the ubiquitously expressed $\sigma 1 \mathrm{~A}$ adaptin. Similarly, a mouse knockout of $\mu 1 \mathrm{~A}$ adaptin isoform, $\mu 1 \mathrm{~B}$, expressed in the polarized epithelial cells (Ohno et al, 1999), is also viable (Hase et al, 2013). The viability and the defects in the $\sigma 1 \mathrm{~B}-/-$ mice, demonstrate that $\sigma 1 \mathrm{~B}$ adaptin is not required for the ubiquitous housekeeping functions of AP1, but rather suggests tissuespecific functions. The brain is the tissue with the highest expression of

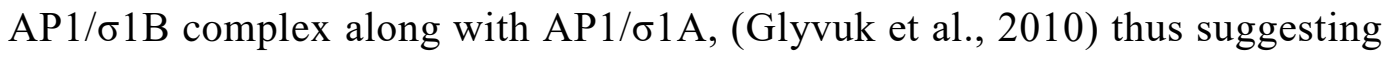
brain-specific functions of AP1/ $11 \mathrm{~B}$ adaptin.

The AP1/ $\sigma 1 \mathrm{~B}$ deficient mice are a model for a human severe $\mathrm{X}$-linked mental retardation disease (XLMR), in which patients have a premature STOP codon in the $\sigma 1 \mathrm{~B}$ gene (Glyvuk et al, 2010; Tarpey et al, 2006).The patients of XLMR have severe impaired learning and memory and show a lack of motor coordination (Tarpey et al, 2006).

Since the hippocampus is the site of learning and memory formation, the

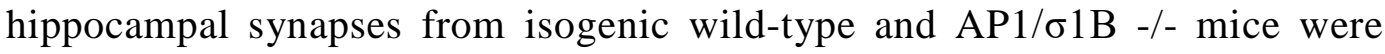
analyzed in our lab, to study the molecular mechanism of the underlying defects in brain functions caused by $\sigma 1 \mathrm{~B}$ deficiency. The studies have demonstrated that the AP1/o1B -/- synapse has slower synaptic vesicle recycling and has fewer synaptic vesicles than the wild-type (Glyvuk et al, 2010). The delayed synaptic vesicle recycling was accompanied by an accumulation of endosome like compartments, and of clathrin-coated vesicles (CCV) (Glyvuk et al, 2010). The biochemical characterization of these endosome like compartments demonstrated that they are PI3P positive, early endosomes accumulating in the 
o1B-/- synapses (Kratzke et al, 2014). Out of all the possible exit routes of proteins from the early endosomes, only the multivesicular body (MVB) endolysosomal degradative pathway was upregulated (Kratzke et al, 2014). In

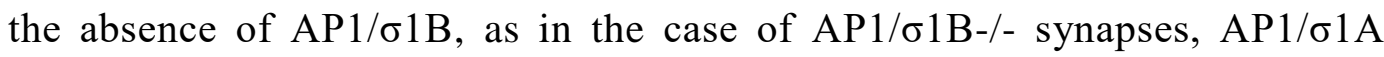
forms a complex with ArfGAP1-Rabex5 on these early endosomes and upregulates the maturation of early endosomes into MVB via the Rab5/Vps34pathway (Candiello et al, 2016).

The accumulated synaptic CCV were isolated on the sucrose gradient and were biochemically characterized to understand the molecular mechanism for their accumulation.

\subsection{Brain-specific AP2 CCV accumulation in the AP1/б1B-/- synapses}

We have isolated the accumulated synaptic CCV on the sucrose density gradient and there was no difference in the migration behavior of the CCVs isolated from wt, and AP1/ $/ \mathrm{B}-/-$ synapses, indicating that the size and the physical properties of the CCVs were not significantly altered (Kratzke et al, 2014). The coat compositions of the accumulated CCVs were biochemically characterized to understand the molecular mechanism for their accumulation. The accumulated CCVs were not crippled AP1/ $1 \mathrm{~A} \mathrm{CCV}$, as one would expect due

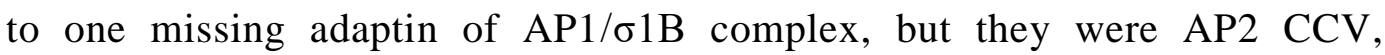
demonstrating that $\mathrm{AP} 1 / \sigma 1 \mathrm{~B}$ dependent synaptic vesicle recycling is coupled to the AP2 mediated endocytosis (Kratzke et al, 2014).

In this study, I have studied the AP2 CCV in more detail to understand the mechanism leading to their accumulation in the AP1/ $1 \mathrm{~B}-/-$ synapses, but first, I analyzed whether this altered AP1 and AP2 mediated protein transport is synapse specific, or whether it is a general consequence of AP $1 / \sigma 1 \mathrm{~B}$ deficiency.

The AP1/б1B-/- mice also have lipodystrophy with the reduction of adipose tissue mass on average by $20 \%$ and of epididymal adipose tissue by $50 \%$, compared to the wild-type mice (Baltes et al, 2014). This defect is caused by the overexpression of Sortilin preventing the degradation of DLK1, an 
adipogenesis inhibiting factor (Baltes et al, 2014). Sortilin is neurotrophinbinding receptor also known to form hetero-dimeric receptor complexes. The б1B-/- binding of sortilin is mediated by a specific binding motif on Sortilin, which is not bound by $\sigma 1 \mathrm{~A}$, but the deficiency of $\sigma 1 \mathrm{~B}$ does not completely block the transport of Sortilin out of an organelle, rather its transport to the lysosomes is reduced (Baltes et al, 2014). The brain is the tissue with the highest expression of $\sigma 1 \mathrm{~B}$ as well as Sortilin, but Sortilin and DLK1 level are not upregulated in the brain, demonstrating the tissue-specific Golgi network-endosome sorting function of AP1/ $1 \mathrm{~B}$ in the adipocytes (Baltes et al, 2014).

The AP1/ $/ \mathrm{B}$ deficient adipose tissue is the only tissue besides brain, for which a $\sigma 1 \mathrm{~B}$ dependent function had been demonstrated (Baltes et al, 2014). Therefore,

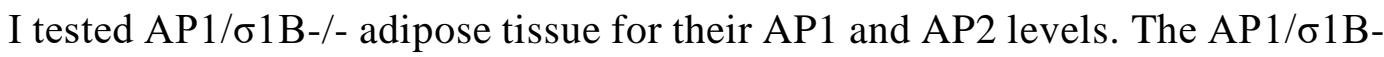
/- adipocytes do not show an increase in AP2 levels, as in the case of AP1/ $1 \mathrm{~B}$ /- hippocampal synapse (Zizioli et al, 2017). Thus, the alterations in the AP1 and AP2 dependent protein transport routes are a brain specific phenotype and not

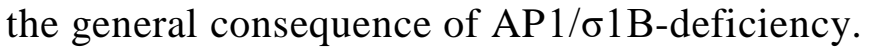




\subsection{Existence of a sub-pool of stabilized AP2 CCV:}

Since, the accumulation of AP2 CCV was a synapse specific phenotype, the main goal of this project was to characterize these accumulated AP2 CCV to understand the molecular mechanism for their accumulation and their function in the AP1/o1B -/- synapse and thus AP2 functions in wild-type synapses as well.

The iTRAQ and semi-quantitative western-blot analyses revealed that the accumulated AP2 $\mathrm{CCV}$ have altered coat composition, which indicated that there could be a sub-population of AP2 CCV accumulating in these synapses. We have immunoisolated a sub-pool of AP2 CCV from both wild-type and AP1/б1B-/- synapses, based upon the differential, but stable mode of binding of Hsc70 during the uncoating of a CCV. Hsc70 has binding sites on the CCV proteins, where it binds more stably and promiscuously, if not guided to the disassembly site (Xing et al, 2009; Park et al, 2015; Sousa \& Lafer, 2015). Thus, we reasoned that if there were a stable pool, it would have a different stable mode of binding of Hsc70 and thus, could be immunoisolated with an antiHsc70 monoclonal antibody.

The iTRAQ mass-spectrometry and semi-quantitative western-blot analysis of

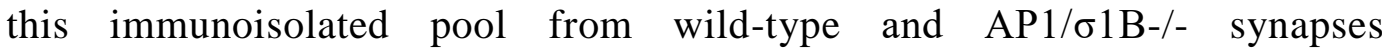
demonstrates, that the pool of stabilized AP2 $\mathrm{CCV}$ is upregulated in the AP1/ 1 1B -/- synapse. The coat composition of these immunoisolated AP2 CCV revealed that the levels of $\mathrm{Hsc} 70$ bound to them is not increased in the AP1/ $1 \mathrm{~B}$ -/- synapse, despite the increase in its J-domain protein recruiters, Auxilin1 and 2 (Candiello et al, 2017). Thus, Auxilin 1 and 2 are not able to recruit Hsc70 to the disassembly site of the clathrin basket in these CCVs. However, in our previous analysis, we have observed a $100 \%$ increase in the Hsc70 levels in the total $\mathrm{CCV}$ pool of $\mathrm{AP} 1 / \sigma 1 \mathrm{~B}-/-$ synapses compared to the wild-type,

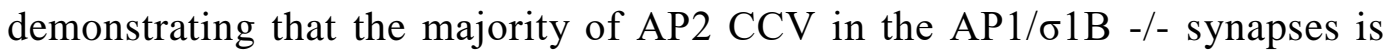
undergoing rapid uncoating similar to the wild-type (Kratzke et al, 2014). The

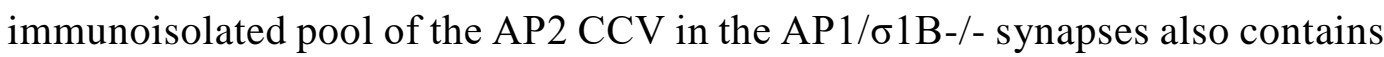


an increased amount of clathrin light chain (CLC), which further stabilizes the clathrin basket. Thus, the immunoisolated pool of AP2 CCV represents AP2 CCV with a stabilized clathrin coat and could represent a specialized endocytic route in the AP1//1B-/- synapses.

\subsubsection{Altered active zone dynamics in AP1/o1B-/- synapses}

The stabilized pool of AP2 CCV indeed, represents a novel and specific endocytic route in the synapses, as these AP2 CCV are enriched in specific

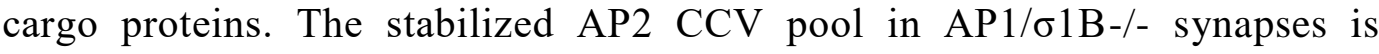
enriched in Stonin2, a co-adaptor of AP2 (Candiello et al, 2017). Stonin2 is associated with Git1, a scaffolding protein, at the outer rim of the synaptic active zone, and they bind to each other. We have observed that Git1 is enriched only in the stabilized AP2 CCV pool of the AP1/o1B-/- synapses, like Stonin2, indicating that Stonin2 is transporting Git1 from the active zone in these stabilized CCV (Candiello et al, 2017). The stabilized AP2 CCV pooltransporting Git1 from the active zone appears to prevent its degradation in the AP1/б1B-/- synapses, as the Git1 level is increased in those synapses. Deficiency in Git1 impairs synaptic vesicle recycling (Podufall et al, 2014) and thus, the increased level of Git1 in these synapses could support the synaptic vesicle recycling and could partially compensate for the reduction in synaptic vesicle numbers in the AP1/ $11 \mathrm{~B}-/-$ synapses.

However, the redistribution of Git 1 could also mean that Git 1 is not transported away from the active zone in the stabilized AP2 $\mathrm{CCV}$, rather it might be retained near the active zone until the uncoating of the vesicles. After the uncoating of the vesicles, they can fuse back directly with the plasma membrane at the active zone and Git1 and Stonin2 could be repositioned at the active zone; or they could also lead to the formation of a new active zone.

The natural in-vitro instability of the CCVs and the immunoisolation procedures does not allow the precise determination of the ratio of rapid uncoating and stabilized AP2 CCV, however, the pool size of the stabilized AP2 CCV can be estimated. The increases of AP2 in the total and stabilized 
pool are almost identical $(\sim 200 \%)$ and thus, the pool size of stabilized AP2 could be estimated by their $\mu 2-\mathrm{Pi}$ ratio (see section 4.2 .2 for $\mu 2-\mathrm{Pi}$, in the molecular mechanism for stabilized AP2 CCV formation). The stabilized AP2 $\mathrm{CCV}$ have $215 \%$ more of $\mu 2-\mathrm{Pi}$ (Candiello et al, 2017), whereas the total synaptic CCV pool has only $30 \%$ more $\mu 2-\mathrm{Pi}$ (Kratzke et al, 2014). We can assume that the $30 \%$ increase in the $\mu 2-\mathrm{Pi}$ in the total synaptic CCV pool is mainly due to the stabilized AP2 CCV pool, because total CCV contains less of the $\mu 2$ phosphorylating AAK1 (Ricotta et al, 2002; Conner et al, 2003), whereas the stabilized CCV contain more AAK1. With the given ratio of $\mu 2$-Pi between total/stabilized pools, $215 / 30$, stabilized $\mathrm{CCV}$ represent $\sim 15 \%$, of the total synaptic CCV pool. Such a small size of stabilized CCV specializes in the transport of small subsets of specialized active zone proteins, like Stonin2 and Git1. AAK1 mediated $\mu 2$ phosphorylation has always been discussed exclusively for AP2 activation and the initiation of AP2 CCV formation (Ricotta et al, 2002; Conner et al, 2003). However, our data shows that AAK1 function is used to differentially regulate the AP2 CCV lifetime.

\subsubsection{Molecular mechanisms for the formation of stabilized AP2 CCV}

There are two pools of AP2 CCV accumulated in the AP1/ $\sigma 1 \mathrm{~B}-/-$ synapses, one is the normal AP2 CCV formed by the canonical Clathrin-mediated-endocytosis (CME) pathway and the other formed by specialized molecular pathway leading to stabilized and thus longer lived AP2 CCV. We have identified four different molecular mechanisms for the formation of the stabilized AP2 CCV.

The first molecular mechanism for the formation of the stabilized AP2 CCV is the altered association of the heat shock protein Hsc70, which mediates the disassembly of the clathrin basket. Hsc70 is not efficiently recruited to the site of clathrin basket disassembly, because the stabilized pool of AP2 CCV has only wild-type levels of Hsc70, despite the increased amount of its J-domain protein recruiters, Auxilin 1 and 2 (Candiello et al, 2017). It is possible that the Hsc70 recruitment to the disassembly site is inhibited by the reduced amount 
of Hsp110. Hsp110 is a Hsc70 nucleotide exchange factor (NEF), which is highly expressed in brain and helps in the dissociation of Hsc70 from the clathrin:Hsc70: ADP complex, formed after the disassembly of the clathrin basket by Hsc70 (Morgan et al, 2013). The clathrin:Hsc70: ADP complex limits the further recruitment of Hsc70 and has to be dissociated by Hsp110. We have observed a reduction in the levels of HSP110 in the stabilized AP2 CCV pool

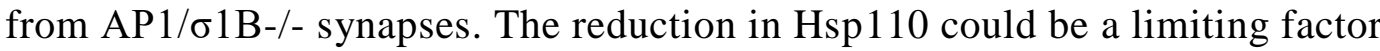
for the recruitment of Hsc70. Thus, the reduced amounts of Hsc70 and Hsp110, despite the increase in Auxilin1/2 is the first molecular mechanism for the stabilization of the stabilized AP2 CCV pool in the AP1/ $1 \mathrm{~B}-/-$ synapses.

The second molecular mechanism demonstrates that the binding of AP2 to the

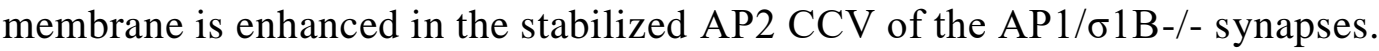
High-affinity membrane binding of AP2 requires its conformational change from a closed into an open conformation, in which the $\mu 2$ adaptin cargo binding domain comes in close contact of the membrane, enabling its binding to $\mathrm{PIP}_{2}$ and cargo proteins. This conformational change is mediated by the activity of the AAK1 kinase (Ricotta et al, 2002) (Conner et al, 2003). We have observed a hyper-phosphorylation of the $\mu 2$ in the stabilized AP2 CCV of the AP1//61B-/synapses, and also the level of AAK1 kinase is increased in this pool (Candiello et al, 2017). Thus, in the stabilized AP2 CCV, AP2 is in the open configuration and therefore, bound more stable to the membrane in the stabilized AP2 CCV than in the AP2 $\mathrm{CCV}$ formed by canonical CME route. This demonstrates the second molecular mechanism for the stabilization of those AP2 CCV in AP1/。1B-/- synapses.

The third molecular mechanism is the reduced recruitment of the two isoforms of Synaptojanin-1: Synaptojanin-1 ubiquitous and Synaptojanin-1 brain-specific splice variant. Synaptojanins are the $\mathrm{PIP}_{2}$ phosphatases and their activities are required for the release of AP2 from the membrane (McPherson et $a l, 1996)$. We have observed a dramatic reduction in the levels of both the Synaptojanins by $80 \%$ in the stabilized AP2 CCV of AP1/ 1 1B-/- compared to the wild-type CCV. This demonstrates that the AP2 is stable bound to the

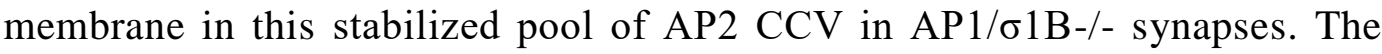


reduced level of synaptojanins could either be a consequence of the lower amounts of its recruiting proteins, or it could also point towards complex regulatory mechanism and the involvements of additional kinases and also phosphatases, which could regulate the recruitment of Synaptojanins. Therefore, I also investigated the levels of those CCV proteins, known to bind Synaptojanin-1.

\subsubsection{Analysis of Synaptojanin-1 recruiting proteins}

In order to understand the drastic reduction of Synaptojanins in the stabilized AP2 CCV of AP1/ $1 \mathrm{~B}-/-$ synapses, we looked for the expression of the proteins, which interact directly with Synaptojanin-1, like the BAR domain proteins Endophilin A1 and Amphiphysin which are associated with the CCV (Perera et al, 2006; Milosevic et al, 2011). The level of Endophilin A1 is not significantly altered in the stabilized AP2 CCV of AP1/ $11 \mathrm{~B}-/-$ synapses (Candiello et al, 2017), and thus could not explain the reduced recruitment of Synaptojanin-1 to this pool. The amphiphysin level is reduced in the stabilized AP2 CCV of AP1/б1B-/- synapses compared to the wild-type, however, the reduction is not comparable to the reduction in the levels of synaptojanin-1. Thus, the altered levels of curvature sensing BAR domain protein and of the two synaptojanins suggest that the two different clathrin-mediated-endocytosis (CME) routes, mediated by normal and stabilized pool of AP2 CCV, also differ in their budding kinetics.

The fourth molecular mechanism for the formation of stabilized AP2 CCV is mediated by Intersectin-1. Besides Endophilin A1 and Amphiphysin, Synaptojanins also interacts directly with the CCV protein, Intersectin-1. Intersectin 1 (ITSN-1) directly interacts with AP2, Stonin-2 and Dynamin and Synaptojanin-1 (Evergren et al, 2007; Pechstein et al, 2010). The levels of AP2, Stonin2 and Dynamin is increased in the stabilized AP2 CCV and thus, one would expect the level of Intersectin-1 to be increased as well. We did observe

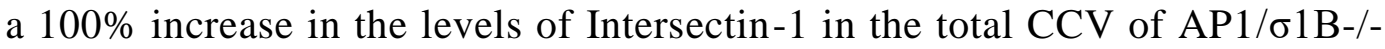
synapses compared to the wild-type CCV, in line with the $100 \%$ increase in the 
AP2 levels. However, the levels of Intersectin-1 in the stabilized AP2 CCV of AP1/б1B-/- synapses is reduced, which clearly suggest that Intersectin-1 is involved in the differential regulation of synaptic AP2 CCV stability. Thus, the reduced level of Intersectin could be one of the reasons for less recruitment of Synaptojanins. However, the involvement of kinases become more evident at this point, which could explain in detail the reduced levels of Synaptojanins. This is the fourth molecular mechanism leading to the formation of the stabilized pool of AP2 CCV in the AP1/б1B-/- synapses.

Intersectin-1 and also Amphiphysin and Endophilin A1 interact with the AP2 $\mathrm{CCV}$ protein, SGIP1 and thus, I also analyzed the levels of this protein in the synaptic AP2 CCV. SGIP1 is a F-BAR domain containing protein, homologous to FCHo1/2, which senses low curvature membrane and is involved in the early stages of CCV budding kinetics (Henne et al, 2010). I have observed an increased level of SGIP1 in the total CCV as well as in the stabilized AP2 CCV in the AP1/o1B-/- synapses. SGIP1 binds to phosphatidylserine and phosphoinositides on the plasma membrane and deforms the membrane and also speeds up the budding process (Uezu et al, 2007). Thus, SGIP1 is involved in the both synaptic $\mathrm{CME}$ routes and the CCVs of both the $\mathrm{CME}$ routes are formed at the same speed. However, SGIP1 appears not to be involved in the differential regulation of the two CME pathways. 


\subsection{Regulation of stabilized AP2 CCV formation in AP1/o1B-/- synapses:}

Alterations in the levels of CCV coat proteins alone do not explain the reduced amounts of some of them in the stabilized AP2 CCV pool of AP1//1B-/synapses. Thus, the alterations appear not to be simply due to the stoichiometric alterations, rather it points towards altered regulatory mechanisms and the involvement of kinases and phosphatases.

One kinase known to be associated with CCV is LRRK2 kinase. Mutations in the LRRK2 kinase are associated with Parkinson's disease (Paisán-Ruíz et al, 2004). LRRK2 is a large, multi-domain protein, which interacts with many different proteins and is involved in numerous protein trafficking pathways including synaptic vesicle endocytosis (Arranz et al, 2015; Paisán-Ruíz et al, 2004; Pan et al, 2017; Matta et al, 2012).

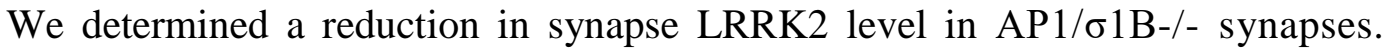
However, its reduced level does not limit its recruitment in the total as well as in the stabilized AP2 CCV pools. The comparable increase in the levels of LRRK2 in both, the total and stabilized AP2 CCV pool in the AP1/。1B-/- synapses does not necessarily mean that LRRK2 is not involved in the differential regulation of the two CME pathways. LRRK2 is a multi-domain protein with a number of protein interaction domains, and it is possible that in the total CCV and in the stabilized CCV, LRRK2 undergoes different kind of protein interactions, leading to different effects on CCV stability. Proteins, which directly activate the kinase domain of LRRK2, are candidates to investigate in

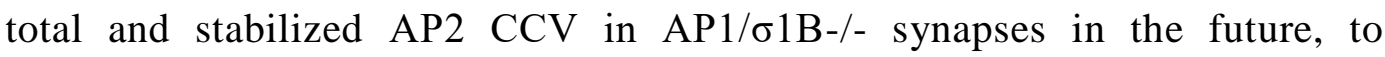
understand the differential regulation of stabilized AP2 CCV formation. 
wt

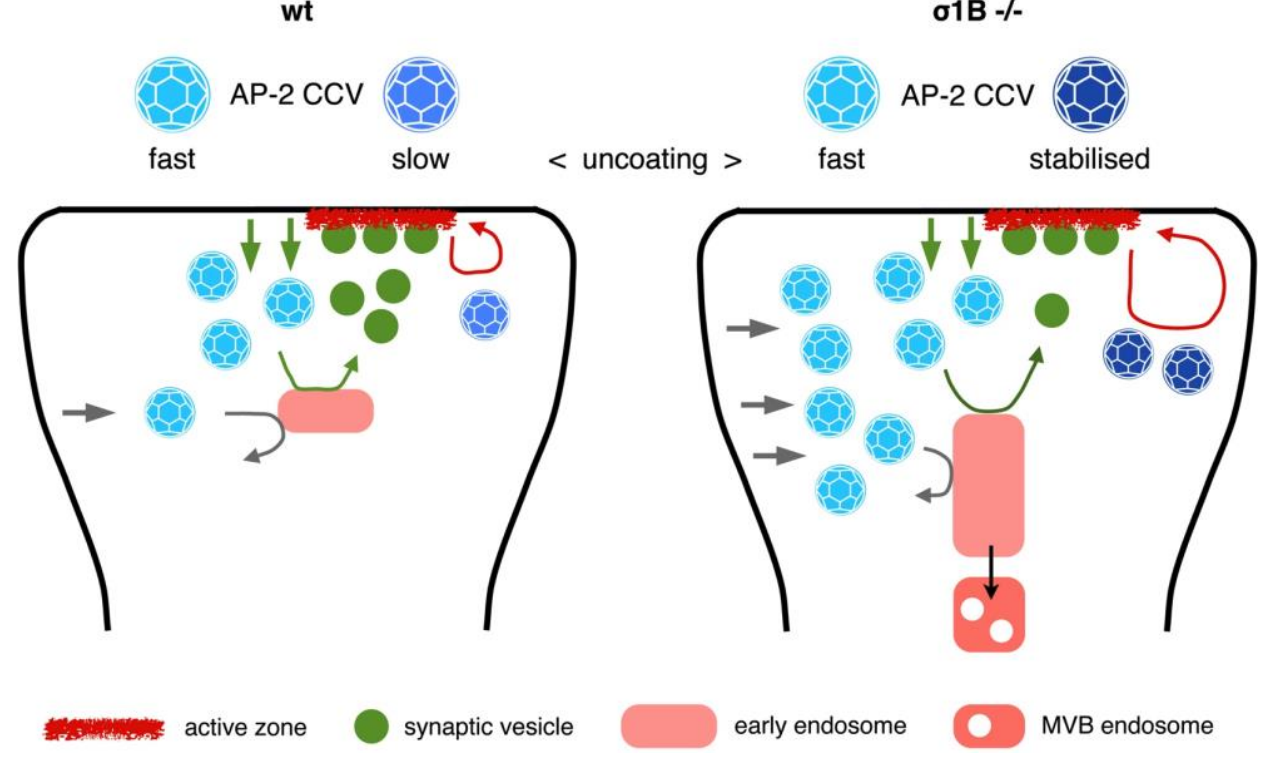

Figure 4.1 Cartoon summarizing the differences between wild-type (left) and $\sigma 1 \mathrm{~B}-/$ - (right) synapses. The function of different type of CCVs formed and the alterations in the active zone dynamics in the $\sigma 1 \mathrm{~B}-/-$ synapses has been depicted. These data are published, hence the figure is adapted from (Candiello et al, 2017). 


\section{Summary}

The knockout mouse model of AP1/ $/ 1 \mathrm{~B}$ adaptin generated in our lab shows hypoactivity and severe neurological defects. Figure 4.1, summarizes the differences between wild-type and AP1/ $1 \mathrm{~B}-/-$ synapses. The analysis of hippocampal synapses had revealed that AP1/\%1B-/- have slower synaptic vesicle recycling and fewer synaptic vesicles, but an accumulation of early endosomes and of AP2 CCV (Glyvuk et al, 2010; Kratzke et al, 2014). In addition, AP1/ $1 \mathrm{~B}-/-$ have an upregulated multi-vesicular body (MVB) endolysosomal degradative pathway, possibly degrading about one-third of synaptic vesicle proteins (Kratzke et al, 2014; Candiello et al, 2016).

In this work, we have analyzed synaptic AP2 CCV in more detail to understand the molecular mechanisms leading to the formation of stabilized, and thus long-lived $\mathrm{AP} 2 \mathrm{CCV}$, as well as the functions of these $\mathrm{CCV}$ in synaptic plasticity. The biochemical characterization of the wild-type and AP1/ $1 \mathrm{~B}-/-$ synapses demonstrates, that there are two different pools of AP2 CCV accumulated in the AP1/o1B-/- synapses: one is the normal AP2 CCV pool formed by canonical clathrin-mediated endocytosis (CME) pathway and another one of stabilized AP2 CCV formed by a specific CME pathway. The stabilized AP2 CCV mediate the sorting and transport of Stonin2 and Git1, two synaptic active zone proteins, leading

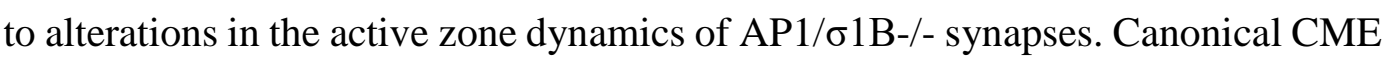
is upregulated in these synapses, for yet unknown reasons.

We have identified four different molecular mechanisms, which lead to the formation of the stabilized AP2 CCV in the AP1/ $11 \mathrm{~B}-/-$ synapses:

- Reduced recruitment of CCV uncoating proteins, Hsc70 and its nucleotide exchange factor (NEF), Hsp110

- Enhanced stability of AP2 membrane binding by $\mu 2$ hyperphosphorylation and thus AP2 hyper-activation by increased AAK1 kinase levels and by the-

- Reduced recruitment of $\mathrm{PIP}_{2}$ phosphatase, Synaptojanin-1.

- Reduced recruitment of Intersectin-1. 
This study raises several questions, which need to be addressed in the future. What are the regulatory mechanisms leading to altered coat protein recruitment in the stabilized AP2 CCV pool in AP1/ $1 \mathrm{~B}-/$ - synapses? How does the Git1 and Stonin 2 sorting affects the molecular architecture and function of the active

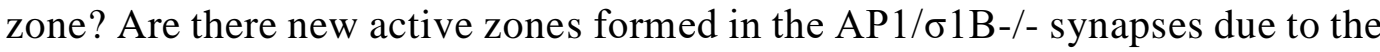
increased CME of active zone scaffolding proteins? How are the altered active zone dynamics observed in the AP1//1B-/- synapses linked to the synaptic signaling? These are some of the important questions, our lab will be focusing on in the future. 


\section{References}

Antonny B, Burd C, De Camilli P, Chen E, Daumke O, Faelber K, Ford M, Frolov VA, Frost A, Hinshaw JE, Kirchhausen T, Kozlov MM, Lenz M, Low HH, McMahon H, Merrifield C, Pollard TD, Robinson PJ, Roux A \& Schmid S (2016) Membrane fission by dynamin: what we know and what we need to know. The EMBO Journal 35: 2270-2284

Arranz AM, Delbroek L, Van Kolen K, Guimaraes MR, Mandemakers W, Daneels G, Matta S, Calafate S, Shaban H, Baatsen P, De Bock PJ, Gevaert K, Vanden Berghe P, Verstreken P, De Strooper B \& Moechars D (2015) LRRK2 functions in synaptic vesicle endocytosis through a kinase-dependent mechanism. Journal of Cell Science 128: 541-552

Backer JM (2008) The regulation and function of Class III PI3Ks: novel roles for Vps34. Biochemical Journal 410: 1-17

Baltes J, Larsen JV, Radhakrishnan K, Geumann C, Kratzke M, Petersen CM \& Schu P (2014) $\sigma 1 \mathrm{~B}$ adaptin regulates adipogenesis by mediating the sorting of sortilin in adipose tissue. Journal of Cell Science 127: 3477-3487

Behnia R, Barr FA, Flanagan JJ, Barlowe C \& Munro S (2007) The yeast orthologue of GRASP65 forms a complex with a coiled-coil protein that contributes to ER to Golgi traffic. J. Cell Biol. 176: 255-261

Ben-Tekaya H, Miura K, Pepperkok R \& Hauri H-P (2005) Live imaging of bidirectional traffic from the ERGIC. Journal of Cell Science 118: 357-367

Bennett EM, Chen C-Y, Engqvist-Goldstein ÅEY, Drubin DG \& Brodsky FM (2001) Clathrin Hub Expression Dissociates the Actin-Binding Protein Hip1R from Coated Pits and Disrupts Their Alignment with the Actin Cytoskeleton. Traffic 2: $851-858$

Bielli A, Haney CJ, Gabreski G, Watkins SC, Bannykh SI \& Aridor M (2005) Regulation of Sar1 NH2 terminus by GTP binding and hydrolysis promotes membrane deformation to control COPII vesicle fission. J. Cell Biol. 171: 919924

Boehm M \& Bonifacino JS (2001) Adaptins: the final recount. Mol. Biol. Cell 12: $2907-2920$

Braell WA (1984) Dissociation of clathrin coats coupled to the hydrolysis of ATP: role of an uncoating ATPase. J. Cell Biol. 99: 734-741

Brodsky FM (2012) Diversity of Clathrin Function: New Tricks for an Old Protein. Annu. Rev. Cell Dev. Biol. 28: 309-336 
Burgess J, Jauregui M, Tan J, Rollins J, Lallet S, Leventis PA, Boulianne GL, Chang HC, Le Borgne R, Krämer H \& Brill JA (2011) AP-1 and clathrin are essential for secretory granule biogenesis in Drosophila. Mol. Biol. Cell 22: 2094-2105

Cacciagli P, Desvignes J-P, Girard N, Delepine M, Zelenika D, Lathrop M, Lévy N, Ledbetter DH, Dobyns WB \& Villard L (2014) AP1S2 is mutated in Xlinked Dandy-Walker malformation with intellectual disability, basal ganglia disease and seizures (Pettigrew syndrome). Eur. J. Hum. Genet. 22: 363-368

Candiello E, Kratzke M, Wenzel D, Cassel D \& Schu P (2016) AP-1/ 1 1A and AP$1 / \sigma 1 \mathrm{~B}$ adaptor-proteins differentially regulate neuronal early endosome maturation via the Rab5/Vps34-pathway. Sci Rep: 6(1), 29950

Candiello E, Mishra R, Schmidt B, Jahn O \& Schu P (2017) Differential regulation of synaptic AP-2/clathrin vesicle uncoating in synaptic plasticity. Sci Rep: 111

Cao X (1998) Initial docking of ER-derived vesicles requires Uso1p and Ypt1p but is independent of SNARE proteins. The EMBO Journal 17: 2156-2165

Cao X \& Barlowe C (2000) Asymmetric Requirements for a Rab Gtpase and Snare Proteins in Fusion of Copii Vesicles with Acceptor Membranes. J. Cell Biol. 149: $55-66$

Choudhury R, Diao A, Zhang F, Eisenberg E, Saint-Pol A, Williams C, Konstantakopoulos A, Lucocq J, Johannes L, Rabouille C, Greene LE \& Lowe M (2005) Lowe Syndrome Protein OCRL1 Interacts with Clathrin and Regulates Protein Trafficking between Endosomes and the Trans-Golgi Network. Mol. Biol. Cell 16: 3467-3479

Collins BM, McCoy AJ, Kent HM, Evans PR \& Owen DJ (2002) Molecular Architecture and Functional Model of the Endocytic AP2 Complex. Cell 109: $523-535$

Conner SD, Schröter T \& Schmid SL (2003) AAK1-Mediated $\mu 2$ Phosphorylation is Stimulated by Assembled Clathrin. Traffic 4: 885-890

Cremona O, Di Paolo G, Wenk MR, Lüthi A, Kim WT, Takei K, Daniell L, Nemoto Y, Shears SB, Flavell RA, McCormick DA \& De Camilli P (1999) Essential Role of Phosphoinositide Metabolism in Synaptic Vesicle Recycling. Cell 99: 179-188

Damke H, Baba T, Warnock DE \& Schmid SL (1994) Induction of mutant dynamin specifically blocks endocytic coated vesicle formation. J. Cell Biol. 127: 915934

Erdmann KS, Mao Y, McCrea HJ, Zoncu R, Lee S, Paradise S, Modregger J, Biemesderfer D, Toomre D \& De Camilli P (2007) A Role of the Lowe Syndrome Protein OCRL in Early Steps of the Endocytic Pathway. Developmental Cell 13: 377-390 
Eugster A, Frigerio G, Dale M \& Duden R (2000) COP I domains required for coatomer integrity, and novel interactions with ARF and ARF-GAP. The EMBO Journal 19: 3905-3917

Evergren E, Gad H, Walther K, Sundborger A, Tomilin N \& Shupliakov O (2007) Intersectin is a negative regulator of dynamin recruitment to the synaptic endocytic zone in the central synapse. J. Neurosci. 27: 379-390

Faso C, Boulaflous A \& Brandizzi F (2009) The plant Golgi apparatus: Last 10 years of answered and open questions. FEBS Letters 583: 3752-3757

Ferguson SM, Ferguson S, Raimondi A, Paradise S, Shen H, Mesaki K, Ferguson A, Destaing O, Ko G, Takasaki J, Cremona O, O' Toole E \& De Camilli P (2009) Coordinated actions of actin and BAR proteins upstream of dynamin at endocytic clathrin-coated pits. Developmental Cell 17: 811-822

Ferreira F, Foley M, Cooke A, Cunningham M, Smith G, Woolley R, Henderson G, Kelly E, Mundell S \& Smythe E (2012) Endocytosis of G protein-coupled receptors is regulated by clathrin light chain phosphorylation. Curr. Biol. 22: $1361-1370$

Fotin A, Cheng Y, Sliz P, Grigorieff N, Harrison SC, Kirchhausen T \& Walz T (2004) Molecular model for a complete clathrin lattice from electron cryomicroscopy. Nature 432: 573-579

Galli T \& Haucke V (2004) Cycling of Synaptic Vesicles: How Far? How Fast! Science Signaling 2004: re19-re19

Gandhi PN, Chen SG \& Wilson-Delfosse AL (2009) Leucine-rich repeat kinase 2 (LRRK2): A key player in the pathogenesis of Parkinson's disease. J. Neurosci. Res. 87: 1283-1295

Gariano G, Guarienti M, Bresciani R, Borsani G, Carola G, Monti E, Giuliani R, Rezzani R, Bonomini F, Preti A, Schu P \& Zizioli D (2013) Analysis of three $\mu 1-A P 1$ subunits during zebrafish development. Dev. Dyn. 243: 299-314

Glyvuk N, Tsytsyura Y, Geumann C, D'Hooge R, Hüve J, Kratzke M, Baltes J, Boening D, Böning D, Klingauf J \& Schu P (2010) AP-1/sigma1B-adaptin mediates endosomal synaptic vesicle recycling, learning and memory. The EMBO Journal 29: 1318-1330

González-Gaitán M \& Jäckle H (1997) Role of Drosophila $\alpha$-Adaptin in Presynaptic Vesicle Recycling. Cell 88: 767-776

Grabner CP, Price SD, Lysakowski A, Cahill AL \& Fox AP (2006) Regulation of large dense-core vesicle volume and neurotransmitter content mediated by adaptor protein 3. Proc Natl Acad Sci USA 103: 10035-10040

Hammond AT \& Glick BS (2000) Dynamics of Transitional Endoplasmic Reticulum Sites in Vertebrate Cells. Mol. Biol. Cell 11: 3013-3030 
Hase K, Nakatsu F, Ohmae M, Sugihara K, Shioda N, Takahashi D, Obata Y, Furusawa Y, Fujimura Y, Yamashita T, Fukuda S, Okamoto H, Asano M, Yonemura S \& Ohno H (2013) AP-1B-mediated protein sorting regulates polarity and proliferation of intestinal epithelial cells in mice. Gastroenterology 145: 625-635

Haucke V \& De Camilli P (1999) AP-2 recruitment to synaptotagmin stimulated by tyrosine-based endocytic motifs. Science 285: 1268-1271

Haucke V, Neher E \& Sigrist SJ (2011) Protein scaffolds in the coupling of synaptic exocytosis and endocytosis. Nat Rev Neurosci 12: 127-138

Henne WM, Boucrot E, Meinecke M, Evergren E, Vallis Y, Mittal R \& McMahon HT (2010) FCHo proteins are nucleators of clathrin-mediated endocytosis. Science 328: 1281-1284

Hinrichsen L, Meyerholz A, Groos S \& Ungewickell EJ (2006) Bending a membrane: how clathrin affects budding. Proc Natl Acad Sci USA 103: 87158720

Hoffman GR, Rahl PB, Collins RN \& Cerione RA (2003) Conserved Structural Motifs in Intracellular Trafficking Pathways. Molecular Cell 12: 615-625

Hui E, Johnson CP, Yao J, Dunning FM \& Chapman ER (2009) SynaptotagminMediated Bending of the Target Membrane Is a Critical Step in Ca2+Regulated Fusion. Cell 138: 709-721

Hunter M, Russo A \& O'Bryan J (2013) Emerging Roles for Intersectin (ITSN) in Regulating Signaling and Disease Pathways. IJMS 14: 7829-7852

Ishihara K, Yasuda K \& Hatayama T (2000) Phosphorylation of the 105-kDa Heat Shock Proteins, HSP $105 \alpha$ and HSP105 $\beta$, by Casein Kinase II. Biochemical and Biophysical Research Communications 270: 927-931

Jackson LP (2014) Structure and mechanism of COPI vesicle biogenesis. Current Opinion in Cell Biology 29: 67-73

Kaksonen M \& Roux A (2018) Mechanisms of clathrin-mediated endocytosis. Nat. Rev. Mol. Cell 19: 313-326

Kelly BT, McCoy AJ, Späte K, Miller SE, Evans PR, Höning S \& Owen DJ (2008) A structural explanation for the binding of endocytic dileucine motifs by the AP2 complex. Nature 456: 976-979

Kim SH \& Ryan TA (2010) CDK5 Serves as a Major Control Point in Neurotransmitter Release. Neuron 67: 797-809

Kim Y, Lee S-E, Park J, Kim M, Lee B, Hwang D \& Chang S (2015) ADPribosylation Factor 6 (ARF6) Bidirectionally Regulates Dendritic Spine Formation Depending on Neuronal Maturation and Activity. J. Biol. Chem. 290: 7323-7335 
Kirchhausen T, Nathanson KL, Matsui W, Vaisberg A, Chow EP, Burne C, Keen JH \& Davis AE (1989) Structural and functional division into two domains of the large (100- to $115-\mathrm{kDa}$ ) chains of the clathrin-associated protein complex AP-2. Proc Natl Acad Sci USA 86: 2612-2616

Kirchhausen T, Scarmato P, Harrison SC, Monroe JJ, Chow EP, Mattaliano RJ, Ramachandran KL, Smart JE, Ahn AH \& Brosius J (1987) Clathrin light chains LCA and LCB are similar, polymorphic, and share repeated heptad motifs. Science 236: 320-324

Kononenko NL, Puchkov D, Classen GA, Walter AM, Pechstein A, Sawade L, Kaempf N, Trimbuch T, Lorenz D, Rosenmund C, Maritzen T \& Haucke V (2014) Clathrin/AP-2 Mediate Synaptic Vesicle Reformation from Endosomelike Vacuoles but Are Not Essential for Membrane Retrieval at Central Synapses. Neuron 82: 981-988

Kosaka T \& Ikeda K (1983) Reversible blockage of membrane retrieval and endocytosis in the garland cell of the temperature-sensitive mutant of Drosophila melanogaster, shibirets1. J. Cell Biol. 97: 499-507

Kratzke M, Candiello E, Schmidt B, Jahn O \& Schu P (2014) AP-1/б1B-Dependent SV Protein Recycling Is Regulated in Early Endosomes and Is Coupled to AP2 Endocytosis. Mol Neurobiol 52: 142-161

Laemmli UK (1970) Cleavage of structural proteins during the assembly of the head of bacteriophage T4. Nature 227: 680-685

Lee C \& Goldberg J (2010) Structure of Coatomer Cage Proteins and the Relationship among COPI, COPII, and Clathrin Vesicle Coats. Cell 142: 123132

Lee SY, Yang J-S, Hong W, Premont RT \& Hsu VW (2005) ARFGAP1 plays a central role in coupling COPI cargo sorting with vesicle formation. J. Cell Biol. 168: $281-290$

Lin B-Z, Pilch PF \& Kandror KV (1997) Sortilin Is a Major Protein Component of Glut4-containing Vesicles. J. Biol. Chem. 272: 24145-24147

Macia E, Ehrlich M, Massol R, Boucrot E, Brunner C \& Kirchhausen T (2006) Dynasore, a cell-permeable inhibitor of dynamin. Developmental Cell 10: 839850

Matsuoka K, Orci L, Amherdt M, Bednarek SY, Hamamoto S, Schekman R \& Yeung T (1998) COPII-Coated Vesicle Formation Reconstituted with Purified Coat Proteins and Chemically Defined Liposomes. Cell 93: 263-275 
Matta S, Van Kolen K, da Cunha R, van den Bogaart G, Mandemakers W, Miskiewicz K, De Bock P-J, Morais VA, Vilain S, Haddad D, Delbroek L, Swerts J, Chávez-Gutiérrez L, Esposito G, Daneels G, Karran E, Holt M, Gevaert K, Moechars DW, De Strooper B, et al (2012) LRRK2 Controls an EndoA Phosphorylation Cycle in Synaptic Endocytosis. Neuron 75: 1008 1021

McPherson PS, Garcia EP, Slepnev VI, David C, Zhang X, Grabs D, Sossin WS, Bauerfeind R, Nemoto Y \& De Camilli P (1996) A presynaptic inositol-5phosphatase. Nature 379: 353-357

Mettlen M, Chen P-H, Srinivasan S, Danuser G \& Schmid SL (2018) Regulation of Clathrin-Mediated Endocytosis. Annu. Rev. Biochem. 87: 871-896

Meyer C, Zizioli D, Lausmann S, Eskelinen EL, Hamann J, Saftig P, Figura von K \& Schu P (2000) $\mu 1 \mathrm{~A}$-adaptin-deficient mice: lethality, loss of AP-1 binding and rerouting of mannose 6-phosphate receptors. The EMBO Journal 19: 21932203

Milosevic I, Giovedi S, Lou X, Raimondi A, Collesi C, Shen H, Paradise S, O'Toole E, Ferguson S, Cremona O \& Pietro De Camilli (2011) Recruitment of Endophilin to Clathrin-Coated Pit Necks Is Required for Efficient Vesicle Uncoating after Fission. Neuron 72: 587-601

Montpetit A, Côté S, Brustein E, Drouin CA, Lapointe L, Boudreau M, Meloche C, Drouin R, Hudson TJ, Drapeau P \& Cossette P (2008) Disruption of AP1S1, causing a novel neurocutaneous syndrome, perturbs development of the skin and spinal cord. PLoS Genet. 4: e1000296

Morgan JR, Jiang J, Oliphint PA, Jin S, Gimenez LE, Busch DJ, Foldes AE, Zhuo Y, Sousa R \& Lafer EM (2013) A role for an Hsp70 nucleotide exchange factor in the regulation of synaptic vesicle endocytosis. J. Neurosci. 33: 8009-8021

Morris NJ, Ross SA, Lane WS, Moestrup SK, Petersen CM, Keller SR \& Lienhard GE (1998) Sortilin Is the Major 110-kDa Protein in GLUT4 Vesicles from Adipocytes. J. Biol. Chem. 273: 3582-3587

Mundigl O \& De Camilli P (1994) Formation of synaptic vesicles. Current Opinion in Cell Biology 6: 561-567

Nakayama Y, Goebl M, O'brine Greco B, Lemmon S, Pingchang Chow E \& Kirchhausen $\mathrm{T}$ (1991) The medium chains of the mammalian clathrinassociated proteins have a homolog in yeast. European Journal of Biochemistry 202: $569-574$

Neher E (2010) What is rate-limiting during sustained synaptic activity: vesicle supply or the availability of release sites. Front. Synaptic Neurosci. 2: 144 
Newmyer SL \& Schmid SL (2001) Dominant-Interfering Hsc70 Mutants Disrupt Multiple Stages of the Clathrin-Coated Vesicle Cycle in Vivo. J. Cell Biol. 152: $607-620$

Newmyer SL, Christensen A \& Sever S (2003) Auxilin-dynamin interactions link the uncoating ATPase chaperone machinery with vesicle formation. Developmental Cell 4: 929-940

O'Bryan JP (2010) Intersecting Pathways in Cell Biology. Science Signaling 3: 152

Ohno H, Tomemori T, Nakatsu F, Okazaki Y, Aguilar RC, Foelsch H, Mellman I, Saito T, Shirasawa T \& Bonifacino JS (1999) $\mu 1 \mathrm{~B}$, a novel adaptor medium chain expressed in polarized epithelial cells 1. FEBS Letters 449: 215-220

Olesen LE, Ford MGJ, Schmid EM, Vallis Y, Babu MM, Li PH, Mills IG, McMahon HT \& Praefcke GJK (2008) Solitary and Repetitive Binding Motifs for the AP2 Complex $\alpha$-Appendage in Amphiphysin and Other Accessory Proteins. J. Biol. Chem. 283: 5099-5109

Owen DJ (2000) The structure and function of the $\beta 2$-adaptin appendage domain. The EMBO Journal 19: 4216-4227

Owen DJ, Collins BM \& Evans PR (2004) ADAPTORS FOR CLATHRIN COATS: Structure and Function. Annu. Rev. Cell Dev. Biol. 20: 153-191

Owen DJ, Vallis Y, Noble MEM, Hunter JB, Dafforn TR, Evans PR \& McMahon HT (1999) A Structural Explanation for the Binding of Multiple Ligands by the a-Adaptin Appendage Domain. Cell 97: 805-815

Packschies L, Theyssen H, Buchberger A, Bukau B, Goody RS \& Reinstein J (1997) GrpE Accelerates Nucleotide Exchange of the Molecular Chaperone DnaK with an Associative Displacement Mechanism. Biochemistry 36: 3417 3422

Paisán-Ruíz C, Jain S, Evans EW, Gilks WP, Simón J, van der Brug M, de Munain AL, Aparicio S, Gil AM, Khan N, Johnson J, Martinez JR, Nicholl D, Carrera IM, Peňa AS, de Silva R, Lees A, Martí-Massó JF, Pérez-Tur J, Wood NW, et al (2004) Cloning of the Gene Containing Mutations that Cause PARK8Linked Parkinson's Disease. Neuron 44: 595-600

Pan P-Y, Li X, Wang J, Powell J, Wang Q, Zhang Y, Chen Z, Wicinski B, Hof P, Ryan TA \& Yue Z (2017) Parkinson's Disease-Associated LRRK2 Hyperactive Kinase Mutant Disrupts Synaptic Vesicle Trafficking in Ventral Midbrain Neurons. J. Neurosci. 37: 11366-11376

Paolo GD, Moskowitz HS, Gipson K, Wenk MR, Voronov S, Obayashi M, Flavell R, Fitzsimonds RM, Ryan TA \& Camilli PD (2004) Impaired PtdIns(4,5) $P_{2}$ synthesis in nerve terminals produces defects in synaptic vesicle trafficking. Nature 431: 415-422 
Park BC, Yim YI, Zhao X, Olszewski MB, Eisenberg E \& Greene LE (2015) The clathrin-binding and J-domains of GAK support the uncoating and chaperoning of clathrin by Hsc70 in the brain. Journal of Cell Science 128: 3811-3821

Park SY \& Guo X (2014) Adaptor protein complexes and intracellular transport. Biosci. Rep. 34: 381-390

Pechstein A, Bacetic J, Vahedi-Faridi A, Gromova K, Sundborger A, Tomlin N, Krainer G, Vorontsova O, Schafer JG, Owe SG, Cousin MA, Saenger W, Shupliakov O \& Haucke V (2010) Regulation of synaptic vesicle recycling by complex formation between intersectin 1 and the clathrin adaptor complex AP2. Proc Natl Acad Sci USA 107: 4206-4211

Pechstein A, Gerth F, Milosevic I, Japel M, Eichhorn-Grunig M, Vorontsova O, Bacetic J, Maritzen T, Shupliakov O, Freund C \& Haucke V (2015) Vesicle uncoating regulated by $\mathrm{SH} 3-\mathrm{SH} 3$ domain-mediated complex formation between endophilin and intersectin at synapses. EMBO reports 16: 232-239

Perera RM, Zoncu R, Lucast L, De Camilli P \& Toomre D (2006) Two synaptojanin 1 isoforms are recruited to clathrin-coated pits at different stages. Proc Natl Acad Sci USA 103: 19332-19337

Podufall J, Tian R, Knoche E, Puchkov D, Walter AM, Rosa S, Quentin C, Vukoja A, Jung N, Lampe A, Wichmann C, Böhme M, Depner H, Zhang YQ, Schmoranzer J, Sigrist SJ \& Haucke V (2014) A presynaptic role for the cytomatrix protein GIT in synaptic vesicle recycling. Cell Reports 7: 14171425

Poirier S, Mayer G, Murphy SR, Garver WS, Chang TY, Schu P \& Seidah NG (2013) The cytosolic adaptor AP-1A is essential for the trafficking and function of Niemann-Pick type C proteins. Traffic 14: 458-469

Poupon V, Girard M, Legendre-Guillemin V, Thomas S, Bourbonniere L, Philie J, Bright NA \& McPherson PS (2008) Clathrin light chains function in mannose phosphate receptor trafficking via regulation of actin assembly. Proc. Natl. Acad. Sci. U.S.A. 105: $168-173$

Pucadyil TJ \& Schmid SL (2008) Real-Time Visualization of Dynamin-Catalyzed Membrane Fission and Vesicle Release. Cell 135: 1263-1275

Reider A, Barker SL, Mishra SK, Im YJ, Maldonado-Báez L, Hurley JH, Traub LM \& Wendland B (2009) Syp1 is a conserved endocytic adaptor that contains domains involved in cargo selection and membrane tubulation. The EMBO Journal 28: $3103-3116$

Ricotta D, Conner SD, Schmid SL, Figura von K \& Höning S (2002) Phosphorylation of the AP $2 \mu$ subunit by AAK 1 mediates high affinity binding to membrane protein sorting signals. J. Cell Biol. 156: 791-795

Rizzoli SO (2014) Synaptic vesicle recycling: steps and principles. The EMBO Journal 33: 788-822 
Robinson MS (1990) Cloning and expression of gamma-adaptin, a component of clathrin-coated vesicles associated with the Golgi apparatus. J. Cell Biol. 111: 2319-2326

Saheki Y \& De Camilli P (2012) Synaptic vesicle endocytosis. Cold Spring Harbor Perspectives in Biology 4: a005645-a005645

Scheele U, Alves J, Frank R, Duwel M, Kalthoff C \& Ungewickell E (2003) Molecular and functional characterization of clathrin- and AP-2-binding determinants within a disordered domain of auxilin. J. Biol. Chem. 278: 2535725368

Schlossman DM (1984) An enzyme that removes clathrin coats: purification of an uncoating ATPase. J. Cell Biol. 99: 723-733

Schuermann JP, Jiang J, Cuéllar J, Llorca O, Wang L, Gimenez LE, Jin S, Taylor AB, Demeler B, Morano KA, Hart PJ, Valpuesta JM, Lafer EM \& Sousa R (2008) Structure of the Hsp110:Hsc70 Nucleotide Exchange Machine. Molecular Cell 31: 232-243

Setta-Kaffetzi N, Simpson MA, Navarini AA, Patel VM, Lu H-C, Allen MH, Duckworth M, Bachelez H, Burden AD, Choon S-E, Griffiths CEM, Kirby B, Kolios A, Seyger MMB, Prins C, Smahi A, Trembath RC, Fraternali F, Smith $\mathrm{CH}$, Barker JN, et al (2014) AP1S3 Mutations Are Associated with Pustular Psoriasis and Impaired Toll-like Receptor 3 Trafficking. The American Journal of Human Genetics 94: 790-797

Smith CJ, Grigorieff N \& Pearse BM (1998) Clathrin coats at 21 A resolution: a cellular assembly designed to recycle multiple membrane receptors. The EMBO Journal 17: 4943-4953

Sousa R \& Lafer EM (2015) The role of molecular chaperones in clathrin mediated vesicular trafficking. Front. Mol. Biosci. 2: 19-6

Sousa R, Liao H-S, Cuéllar J, Jin S, Valpuesta JM, Jin AJ \& Lafer EM (2016) Clathrin-coat disassembly illuminates the mechanisms of Hsp70 force generation. Nat Struct Mol Biol 23: 821-829

Soykan T, Kaempf N, Sakaba T, Vollweiter D, Goerdeler F, Puchkov D, Kononenko NL \& Haucke V (2017) Synaptic Vesicle Endocytosis Occurs on Multiple Timescales and Is Mediated by Formin-Dependent Actin Assembly. Neuron 93: 854-866.e4

Soykan T, Maritzen T \& Haucke V (2016) ScienceDirect Modes and mechanisms of synaptic vesicle recycling. Current Opinion in Neurobiology 39: 17-23

Stack JH, Herman PK, Schu PV \& Emr SD (1993) A membrane-associated complex containing the Vps15 protein kinase and the Vps34 PI 3-kinase is essential for protein sorting to the yeast lysosome-like vacuole. The EMBO Journal 12: 2195-2204 
Stephens DJ (2003) De novo formation, fusion and fission of mammalian COPIIcoated endoplasmic reticulum exit sites. EMBO reports 4: 210-217

Stimpson HEM, Toret CP, Cheng AT, Pauly BS \& Drubin DG (2009) Earlyarriving Syp1p and Ede1p function in endocytic site placement and formation in budding yeast. Mol. Biol. Cell 20: 4640-4651

Stowell MH, Marks B, Wigge P \& McMahon HT (1999) Nucleotide-dependent conformational changes in dynamin: evidence for a mechanochemical molecular spring. Nature Cell Biology 1: 27-32

Sundborger A, Soderblom C, Vorontsova O, Evergren E, Hinshaw JE \& Shupliakov O (2011) An endophilin-dynamin complex promotes budding of clathrincoated vesicles during synaptic vesicle recycling. Journal of Cell Science 124: 133-143

Südhof TC (2004) The Synaptic Vesicle Cycle. Annu. Rev. Neurosci. 27: 509-547

Südhof TC \& Rothman JE (2009) Membrane fusion: grappling with SNARE and SM proteins. Science 323: 474-477

Sweitzer SM \& Hinshaw JE (1998) Dynamin undergoes a GTP-dependent conformational change causing vesiculation. Cell 93: 1021-1029

Szul T \& Sztul E (2011) COPII and COPI Traffic at the ER-Golgi Interface. Physiology 26: 348-364

Tagliatti E, Fadda M, Falace A, Benfenati F \& Fassio A (2016) Arf6 regulates the cycling and the readily releasable pool of synaptic vesicles at hippocampal synapse. eLife 5: 1094

Takamori S, Holt M, Stenius K, Lemke EA, Grønborg M, Riedel D, Urlaub H, Schenck S, Brügger B, Ringler P, Müller SA, Rammner B, Gräter F, Hub JS, De Groot BL, Mieskes G, Moriyama Y, Klingauf J, Grubmüller H, Heuser J, et al (2006) Molecular Anatomy of a Trafficking Organelle. Cell 127: 831-846

Tarpey PS, Stevens C, Teague J, Edkins S, O'Meara S, Avis T, Barthorpe S, Buck G, Butler A, Cole J, Dicks E, Gray K, Halliday K, Harrison R, Hills K, Hinton J, Jones D, Menzies A, Mironenko T, Perry J, et al (2006) Mutations in the gene encoding the Sigma 2 subunit of the adaptor protein 1 complex, AP1S2, cause $\mathrm{X}$-linked mental retardation. Am. J. Hum. Genet. 79: 1119-1124

Theos AC, Tenza D, Martina JA, Hurbain I, Peden AA, Sviderskaya EV, Stewart A, Robinson MS, Bennett DC, Cutler DF, Bonifacino JS, Marks MS \& Raposo G (2005) Functions of Adaptor Protein (AP)-3 and AP-1 in Tyrosinase Sorting from Endosomes to Melanosomes. Mol. Biol. Cell 16: 5356-5372

Thurieau C, Brosius J, Burne C, Jolles P, Keen Jh, Mattaliano Rj, Chow Ep, Ramachandran Kl \& Kirchhausen T (1988) Molecular Cloning and Complete Amino Acid Sequence of AP50, an Assembly Protein Associated with Clathrin- 
Coated Vesicles. DNA 7: 663-669

Truckenbrodt S \& Rizzoli SO (2014) Synaptic Vesicle Pools: Classical and Emerging Roles. Presynaptic Terminals 329-359.

Uezu A, Horiuchi A, Kanda K, Kikuchi N, Umeda K, Tsujita K, Suetsugu S, Araki N, Yamamoto H, Takenawa T \& Nakanishi H (2007) SGIP1 $\alpha$ Is an Endocytic Protein That Directly Interacts with Phospholipids and Eps15. J. Biol. Chem. 282: 26481-26489

Ungewickell A, Ward ME, Ungewickell E \& Majerus PW (2004) The inositol polyphosphate 5-phosphatase Ocrl associates with endosomes that are partially coated with clathrin. Proc Natl Acad Sci USA 101: 13501-13506

Van der Bliek AM, Redelmeier TE, Damke H, Tisdale EJ, Meyerowitz EM \& Schmid SL (1993) Mutations in human dynamin block an intermediate stage in coated vesicle formation. J. Cell Biol. 122: 553-563

Velasco A, Hendricks L, Moremen KW, Tulsiani DR, Touster O \& Farquhar MG (1993) Cell type-dependent variations in the subcellular distribution of alphamannosidase I and II. J. Cell Biol. 122: 39-51

Watanabe S, Rost BR, Camacho-Pérez M, Davis MW, Söhl-Kielczynski B, Rosenmund C \& Jorgensen EM (2013) Ultrafast endocytosis at mouse hippocampal synapses. Nature 504: 242-247

Weissman JT, Plutner H \& Balch WE (2001) The Mammalian Guanine Nucleotide Exchange Factor mSec12 is Essential for Activation of the Sar1 GTPase Directing Endoplasmic Reticulum Export. Traffic 2: 465-475

Wigge P, Köhler K, Vallis Y, Doyle CA, Owen D, Hunt SP \& McMahon HT (1997) Amphiphysin heterodimers: potential role in clathrin-mediated endocytosis. Mol. Biol. Cell 8: 2003-2015

Wilbur JD, Chen C-Y, Manalo V, Hwang PK, Fletterick RJ \& Brodsky FM (2008) Actin Binding by Hip1 (Huntingtin-interacting Protein 1) and Hip1R (Hip1related Protein) Is Regulated by Clathrin Light Chain. J. Biol. Chem. 283: 32870-32879

Wong KA, Wilson J, Russo A, Wang L, Okur MN, Wang X, Martin NP, Scappini E, Carnegie GK \& O'Bryan JP (2012) Intersectin (ITSN) family of scaffolds function as molecular hubs in protein interaction networks. PLoS ONE 7: e36023

Xing Y, cking TBO, Wolf M, Grigorieff N, Kirchhausen T \& Harrison SC (2009) Structure of clathrin coat with bound Hsc70 and auxilin: mechanism of Hsc70facilitated disassembly. The EMBO Journal 29: 655-665

Xue M, Reim K, Chen X, Chao H-T, Deng H, Rizo J, Brose N \& Rosenmund C (2007) Distinct domains of complexin I differentially regulate neurotransmitter 
release. Nat Struct Mol Biol 14: 949-958

Yamada H, Padilla-Parra S, Park S-J, Itoh T, Chaineau M, Monaldi I, Cremona O, Benfenati F, De Camilli P, Coppey-Moisan M, Tramier M, Galli T \& Takei K (2009) Dynamic Interaction of Amphiphysin with N-WASP Regulates Actin Assembly. J. Biol. Chem. 284: 34244-34256

Yáñez-Mó M, Siljander PRM, Andreu Z, Bedina Zavec A, Borràs FE, Buzas EI, Buzas K, Casal E, Cappello F, Carvalho J, Colás E, Cordeiro-da Silva A, Fais S, Falcon-Perez JM, Ghobrial IM, Giebel B, Gimona M, Graner M, Gursel I, Gursel M, et al (2015) Biological properties of extracellular vesicles and their physiological functions. Journal of Extracellular Vesicles 4: 27066-60

Zizioli D, Geumann C, Kratzke M, Mishra R, Borsani G, Finazzi D, Candiello E \& Schu P (2017) $\gamma 2$ and $\gamma 1 \mathrm{AP}-1$ complexes: Different essential functions and regulatory mechanisms in clathrin-dependent protein sorting. European Journal of Cell Biology 96: 356-368

Zizioli D, Meyer C, Guhde G, Saftig P, Figura von K \& Schu P (1999) Early embryonic death of mice deficient in gamma-adaptin. J. Biol. Chem. 274: $5385-5390$

Zoncu R, Perera RM, Sebastian R, Nakatsu F, Chen H, Balla T, Ayala G, Toomre D \& De Camilli PV (2007) Loss of endocytic clathrin-coated pits upon acute depletion of phosphatidylinositol 4,5-bisphosphate. Proc Natl Acad Sci USA 104: 3793-3798 


\section{Acknowledgements}

This project would not have been complete without the help of many people. I would like to thank them for their help and support throughout my Ph.D. journey. First, I would like to thank my supervisor, Prof. Dr. Peter Schu for providing me an opportunity to do my Ph.D. in his lab. Thank you, Peter, for your guidance and support during my entire journey of Ph.D. and for always being there to help and guide me during my lab troubles and figuring things related to the experimental approaches and also for proofreading my thesis and making all the minute to detail changes. Without your constant support and guidance, this project would be not possible to complete.

I would like to thank my thesis committee members Dr. Hans Dieter Schmidt and Prof. Dr. Thomas Bayer for their support, guidance and their valuable suggestions during the thesis committee meetings. I would like to thank our collaborators, Dr. Olaf Jahn and Dr. Bernhard Schmidt for their mass spectroscopy analysis and my predecessor, Dr. Ermes Candiello for providing me the initial results for starting this project. I would also like to thank Göksemin Fatma Sengul, my successor for helping me during the completion of this thesis and wish her success in taking this project forward.

I would like to thank GGNB and the Molecular Biology of cells program for their commitment to higher education and Petra Engelmann and Eva Ausmeier for their administrative support. I would like to thank the entire group of Prof. Dr. Peter Rehling for providing a friendly and helpful environment in the lab. I am also very thankful for the Department of Cellular Biochemistry, University of Göttingen and DFG for funding my research project.

Last, but not the least, I would like to thank my lovely fiancée, Prachi Richa for her love and constant support during my entire journey of $\mathrm{Ph} . \mathrm{D}$. Thank you, Prachi for constantly discussing my project and helping me during the preparation of my presentations and in the completion of my thesis. Thank you, Prachi, for always being there in my life, your support means a lot to me. I would like to thank all my family members, especially my late grand father, Mr. Amar Nath Jha for his constant support and believing in me through my entire educational career. 